\title{
Modeling and simulation of selected distributed generation sources and their assessment
}

Ju-chirl Park

West Virginia University

Follow this and additional works at: https://researchrepository.wvu.edu/etd

\section{Recommended Citation}

Park, Ju-chirl, "Modeling and simulation of selected distributed generation sources and their assessment" (1999). Graduate Theses, Dissertations, and Problem Reports. 989.

https://researchrepository.wvu.edu/etd/989

This Thesis is protected by copyright and/or related rights. It has been brought to you by the The Research Repository @ WVU with permission from the rights-holder(s). You are free to use this Thesis in any way that is permitted by the copyright and related rights legislation that applies to your use. For other uses you must obtain permission from the rights-holder(s) directly, unless additional rights are indicated by a Creative Commons license in the record and/ or on the work itself. This Thesis has been accepted for inclusion in WVU Graduate Theses, Dissertations, and Problem Reports collection by an authorized administrator of The Research Repository @ WVU. For more information, please contact researchrepository@mail.wvu.edu. 


\title{
MODELING AND SIMULATION OF SELECTED DISTRIBUTED \\ GENERATION SOURCES AND THEIR ASSESSMENT
}

\author{
Ju-chirl Park \\ Thesis submitted to the \\ College of Engineering and Mineral Resources \\ at West Virginia University \\ Master of Science \\ In \\ Electrical Engineering
}

Dr. Muhammad A. Choudhry (chair)

Dr. Parviz Famouri

Dr. Ronald L. Klein

Department of Computer Science and Electrical Engineering

Morgantown, WV

1999

Keywords: Distributed Generation, Combustion Turbine Copyright 1999 Juchirl Park 


\begin{abstract}

\section{MODELING AND SIMULATION OF \\ SELECTED DISTRIBUTED GENERATION SOURCES AND THEIR ASSESSMENT}

\author{
By Ju-chirl Park
}

Consumers want an economical and uninterrupted electric power. It is crucial to the industrial consumers and wholesalers who have to pay the penalty for a blackout, if power is disconnected for any reason. Recently, distributed generation (DG) has become an attractive method of providing electricity to consumers and retailers. In addition, from the viewpoint of economic feasibility, the costs of installing the generators and producing the electricity can be comparatively inexpensive using the DG method. Furthermore, electrical or thermal efficiency can also be improved if the utilities use co-generation or a combined heat cycle.

In this thesis, the models of small turbine generators (i.e. a combustion turbine, a diesel engine, etc), that are used for distributed generation will be obtained as dynamic. Also, the detailed synchronous machine and the excitation system model are obtained for the standard simulation. The simulation will be performed with an infinite bus system model. The synchronous machine is connected with a local load in order to develop the terminal voltage, avoiding the differentiation.

In order to use fuel cells and solar cells, which are new forms of technology, have the potential to reduce costs, and can be used for the DG in the near future, the inverter (DC-AC) model is necessary. In this thesis, the power delivered to voltage sources is examined with the DC current. 


\section{ACKNOWLEDGEMTNS}

I would like to take this opportunity to express my appreciation to my research advisor and academic advisory committee chairperson, Dr. Muhammad A. Choudhry for his support, guidance, and encouragement throughout this research. I would also like to extend credit to the other committee members, Dr. Parvitz Famouri and Dr. Ronald L. Klein for their valuable suggestions to improve this work.

My parents, Myongsoo Park and Poksoo Lee, also deserve more thanks than I can give. They have made it possible that I have been here and studying. Mom and dad, I couldn't have found any word to express how much you love, trust in, and support.

Warm thanks to my colleagues, Dulpichet Rerkpreedapong and Hoowang Shim, for their trusting, friendships, and support. They have always encouraged me throughout my research. 


\section{TABLE OF CONTENTS}

Page

ABSTRACT ii

ACKNOWLEDGEMENTS

CHAPTER 1: INTRODUCTION 1

1.1 The Distributed Generation 1

1.2 Dynamic Model 6

1.3 The Objectives 7

1.4 The Structure of the Thesis 8

CHAPTER 2: POWER SURVEY 10

$\begin{array}{ll}2.1 \text { Questionnaire } & 10\end{array}$

2.2 The Electrical Load Profiles $\quad 14$

$\begin{array}{ll}2.3 \text { A Load Classification } & 19\end{array}$

CHAPTER 3: DYNAMIC MODELING 20

3.1 A Gas Turbine Model 20

3.2 An Excitation Model 28

3.3 A Diesel Engine Model 34

3.4 A Synchronous Machine Model 36

$\begin{array}{lll}3.5 & \text { An Inverter Model } & 47\end{array}$

CHAPTER 4: SIMULATION SCHEME 56

4.1 The Simulation of Synchronous Machine with an Infinite Bus 56

4.2 Find Steady State Values $\quad 60$ 
4.3 An Inverter 63

4.4 A Local Generator Simulation 64

CHAPTER 5: SIMULATION RESULTS 65

5.1 Simulation Results for a Gas Turbine 65

5.2 Simulation Results for a Diesel Engine 68

5.3 A Local Load Simulation with a fault 71

$\begin{array}{lll}5.4 & \text { An Inverter } & 74\end{array}$

CHAPTER 6: CONCLUSIONS 85

6.1 Dynamic Model 85

6.2 Simulation Results 86

6.3 Potential of the Distributed Generation 87

$\begin{array}{lll}6.4 & \text { Future work } & 87\end{array}$

$\begin{array}{lr}\text { REFERENCE } & 88\end{array}$

APPENDIX - SIMULINK Block Diagram 92 


\section{Chapter one}

\section{INTRODUCTION}

\subsection{The Distributed Generation}

Recently, the technologies for small generators (combustion turbines, diesel engines) and new generation systems (fuel cells, solar cells) have been improved in terms of their facilities and their costs have been reduced [1,31]. On the other hand, even though the construction and operation of huge nuclear power and coal-fired generators was cheap by the latter part of the $20^{\text {th }}$ century, they soon became difficult and inefficient to construct and operate because of environment pollution and the construction of the transmission line. Smaller generators became more efficient and reasonable at providing good power quality and energy supply. Also, the consumers could choose and install their own small generators due to the lower costs. Furthermore, the power industry [31] has been restructured to allow consumers to competitively select either energy from distributors or from their own small generators.

Some of the research $[1,2,31,32]$ shows that the cost of relatively small generators will possibly decrease if we consider installing the new power generators. In case of a new coal-fired or fossil fuel steam station, if the plant consists of a three-650MW unit, it could be built for $\$ 886 / \mathrm{kW}$, in 1997 dollars for 7 construction years. Based on economic tests done in 1997 [31], this plant would be built at a price of more than $\$ 36.45 / \mathrm{MWh}$ or $\$ 64.66 / \mathrm{MWh}$ in 2010 . On the contrary, in a combined cycle facility, the building cost would be $\$ 470 / \mathrm{kW}$ in 1997 dollars with a 2-year construction period. After construction of a combined cycle, its operating costs and contribution to its capital costs would be covered for any price over $\$ 17.13 / \mathrm{MWh}$ in 1997 or $\$ 30.18 / \mathrm{MWh}$ in 2010 . Another case is that of a gas-fired combustion turbine. With an 18-month construction period, this turbine would have the lowest cost, at $\$ 323 / \mathrm{kW}$ in 1997 dollars. Based on economic test [31], however, this plant would be constructed at a price of more than $\$ 117.2 / \mathrm{MWh}$ in 1997 or $\$ 250.80 / \mathrm{MWh}$ in 2010 because of its lower capacity utilization rate. After construction of this combustion turbine, its operating costs and contribution to its capital 
costs would be covered at any price above $\$ 34.87 / \mathrm{MWh}$ in 1997 or $\$ 61.78 / \mathrm{MWh}$ in 2010. From the viewpoint of this research, the small combustion turbine and gas-fired turbine might be more attractive than the coal-fired steam station. The constructed combustion turbine, however, would compete with an existing coal-fired steam turbine.

In Fig.1-1, for the near future the expected power market structures are shown. The huge generators such as fossil fuel or coal-fired power generators supply the electric power to the consumers using transmission lines. The ISO (Independent System Operator) can control the transmission lines more efficiently and supply the power to desired customers or power retailers. An ISO deals with power distribution independently.
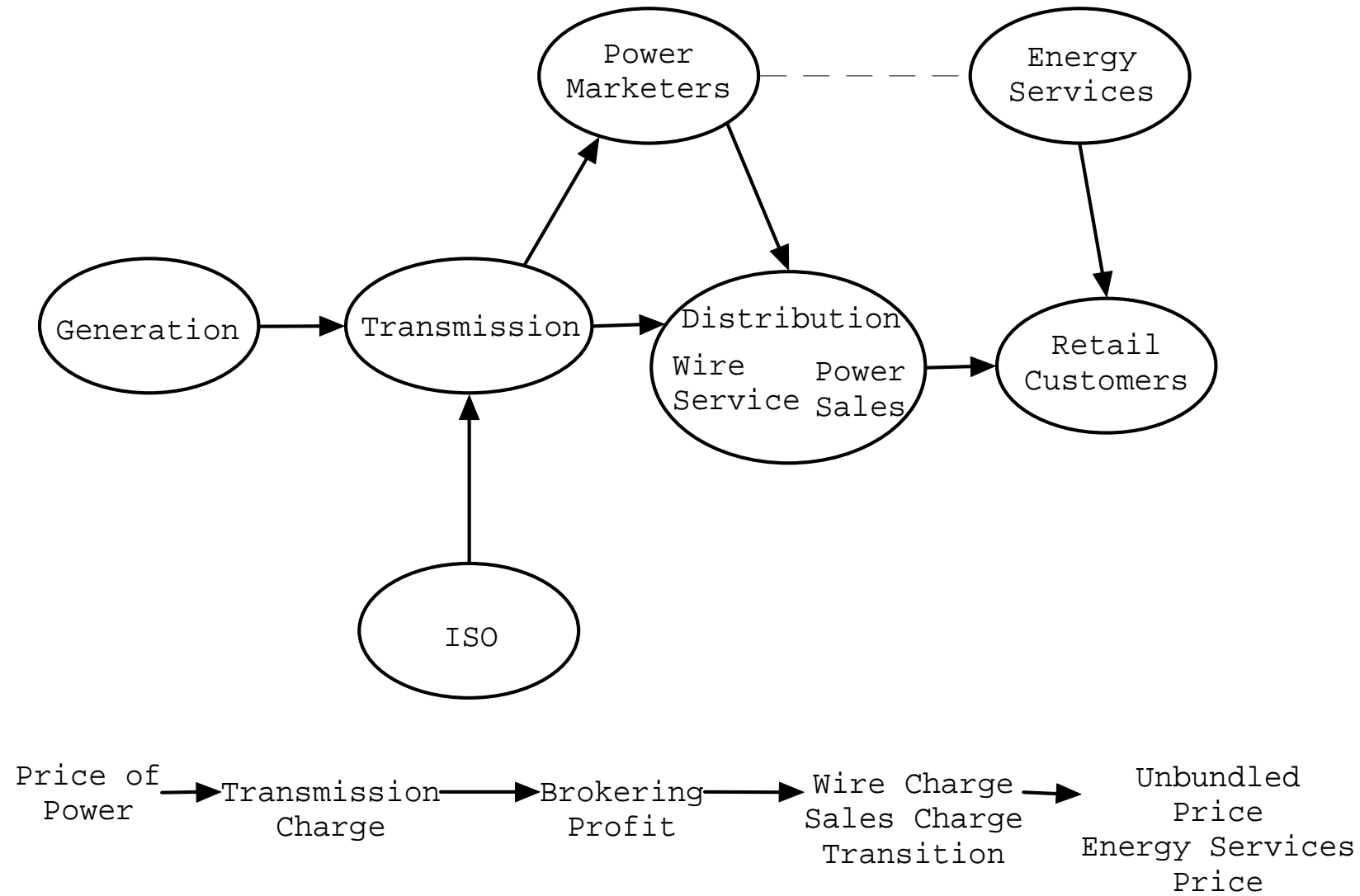

Fig. 1-1 US electric industry-expected future structure. 
A typical example of the distributed generation schematic is shown in Fig. 1-2 [1]. The bulk power grid can be either large fossil fuel or coal-fired steam generation, or alternatively, an ISO operator. The utilities can feed or supply the power to their own facilities or to other utilities. Usually, DG (distributed generation) uses technological facilities such as combustion turbines, diesel engines, micro-turbines, fuel cells, or solar cells. The combustion turbines typically range from $25 \mathrm{~kW}$ to $50 \mathrm{MW}$ generations. If the utilities use a gas turbine as a combined cycle with a steam turbine, the efficiency can be improved significantly [31]. The diesel engine and micro-turbine are usually used as the standby or emergency generators because of their maintenance costs.

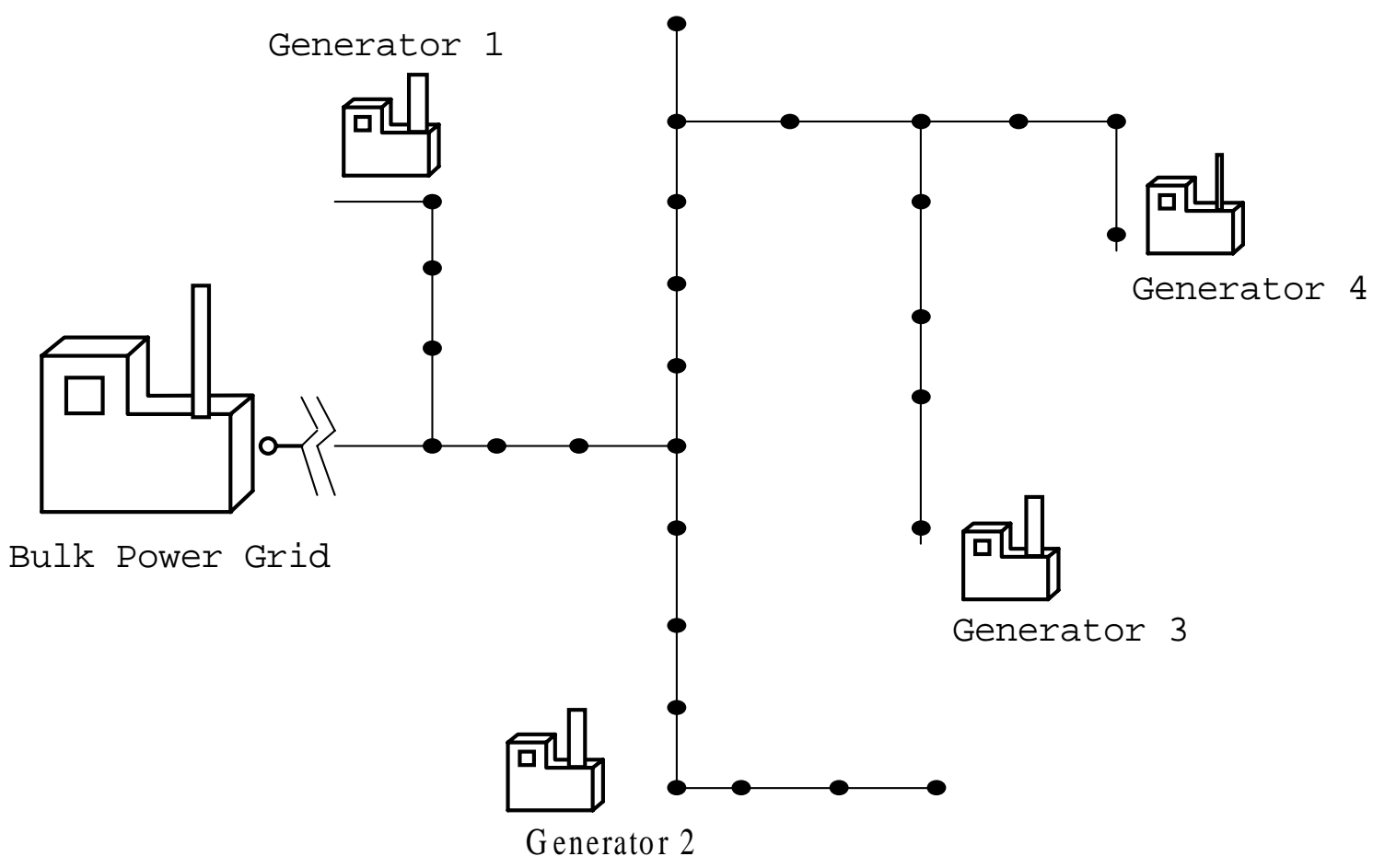

Fig. 1-2 An example of distributed generation system. 
Table 1-1 Average Operating Expenses for Major U.S. Investor-Owned Electric Utilities, 1993 through 1997 (Mills per Kilowatt-hour)

\begin{tabular}{|c|c|c|c|c|c|}
\hline Plant type & 1993 & 1994 & 1995 & 1996 & $1997^{1}$ \\
\hline \multicolumn{6}{|l|}{ Operation } \\
\hline Nuclear & 10.20 & 9.79 & 9.43 & 9.47 & 11.50 \\
\hline Fossil System & 2.37 & 2.32 & 2.38 & 2.25 & 2.28 \\
\hline Hydroelectric $^{2}$ & 3.82 & 4.53 & 3.69 & 3.87 & 2.36 \\
\hline Gas Turbine and Small Scale & 6.47 & 4.58 & 3.57 & 5.08 & 4.58 \\
\hline \multicolumn{6}{|l|}{ Maintenance } \\
\hline Nuclear & 5.73 & 5.20 & 5.21 & 5.68 & 7.40 \\
\hline Fossil System & 2.96 & 2.82 & 2.65 & 2.49 & 2.40 \\
\hline Hydroelectric & 2.65 & 2.90 & 2.19 & 2.08 & 2.47 \\
\hline Gas Turbine and Small Scale & 7.52 & 5.39 & 4.28 & 4.98 & 3.45 \\
\hline \multicolumn{6}{|l|}{ Fuel } \\
\hline Nuclear & 5.88 & 5.87 & 5.75 & 5.50 & 5.89 \\
\hline Fossil System & 17.65 & 16.67 & 16.07 & 16.51 & 16.67 \\
\hline \multicolumn{6}{|l|}{ Hydroelectric } \\
\hline Gas Turbine and Small Scale & 26.39 & 22.19 & 20.83 & 30.58 & 24.91 \\
\hline \multicolumn{6}{|l|}{ Total $^{4}$} \\
\hline Nuclear & 21.80 & 20.86 & 20.39 & 20.65 & 24.80 \\
\hline Fossil System & 22.97 & 21.80 & 21.11 & 2.25 & 21.34 \\
\hline Hydroelectric & 6.47 & 7.43 & 5.89 & 5.95 & 5.73 \\
\hline Gas Turbine and Small Scale & 40.38 & 32.16 & 28.67 & 40.64 & 32.94 \\
\hline
\end{tabular}

1.Geysers is reported in the gas turbine and small category.

2. Includes Pumped Storage.

3. Includes gas turbine, internal combustion, photovoltaic, and wind plants.

4. Totals may not equal sum of components because of independent rounding

Notes: Data are final. Expenses are average expenses weighted by net generation. A mill is a monetary cost and billing unit equal to $1 / 1000$ of the U.S. dollar.

Source: Federal Energy Regulatory Commission, FERC Form 1, "Annual Report of Major Electric Utilities, Licensees and Others." The 1997 data are as accepted from the FERC World Wide Web site. 
Table 1-2 Costs to Generate Electricity Using Fuel Cells

\begin{tabular}{|l|l|l|l|}
\hline & Natural Gas & Propane & Methanol \\
\hline Capital Cost & $\$ 3,167$ & $\$ 3,167$ & $\$ 3,167$ \\
\hline Year Annual Cost & $\$ 651.32$ & $\$ 651.32$ & $\$ 651.32$ \\
\hline Life (in years) & 7.3 & 7.3 & 7.3 \\
\hline Salvage Value & $\$ 166.67$ & $\$ 166.67$ & $\$ 166.67$ \\
\hline Unit Size kW & 3.3 & 3.3 & 3.3 \\
\hline kWh Capacity (annual) & 29,200 & 29,200 & 29,200 \\
\hline Load Factor & $73 \%$ & $73 \%$ & $73 \%$ \\
\hline Annual kWh & 21,413 & 21,413 & 21,413 \\
\hline Annual O\&M & $\$ 366.67$ & $\$ 366.67$ & $\$ 366.67$ \\
\hline $\begin{array}{l}\text { Efficiency } \\
\text { (Fuel in, electricity out) }\end{array}$ & $48 \%$ & $50 \%$ & $50 \%$ \\
\hline Fuel Cost & $\$ 3.25$ & $\$ 0.83$ & $\$ 0.40$ \\
\hline Fuel Cost Units & $\$ / \mathrm{MCF}$ & $\$ /$ Gallon & $\$ / \mathrm{Gallon}$ \\
\hline Fuel Cost per kWh & $\$ 0.0229$ & $\$ 0.0622$ & $\$ 0.0570$ \\
\hline Capital cost per kWh & $\$ 0.0304$ & $\$ 0.0304$ & $\$ 0.0304$ \\
\hline O\&M cost per kWh & $\$ 0.0171$ & $\$ 0.0171$ & $\$ 0.0171$ \\
\hline $\begin{array}{l}\text { Average cost } \\
\text { Per kWh }\end{array}$ & $\$ 0.070$ & $\$ 0.110$ & $\$ 0.105$ \\
\hline
\end{tabular}

Source: Doug Patterson at SFCCG (Small-Scale Fuel Cell Commercialization Group, Inc). These table or research topics are also available at World Wide Web, http://www.oge.com/sfccg/outputs.htm.

In table (1-1), the costs from 1993 through 1997 are shown. The costs of small scale or gas turbine generators have been decreasing. The development of fuel cells is now focused on reducing costs (see table 1-2). This table is achieved by using a Monte Carlo simulation based on the delivery of a 100,000-unit [34]. Furthermore, using fuel cells as a combined cycle generation, the efficiency of generating electricity would be higher and the cost would be lower. In table 1-3, the economic comparison of 
Distributed Generation Technologies [1] such as the diesel engine, the combustion is shown.

There are several advantages both on the consumer's side and on the utility's side. If the utilities embrace the distributed generation structure, they don't have to construct new transmission and distribution (T\&D), so the line losses and costs of $T \& D$ can be eliminated.

When gas turbines and fuel cells are used in co-generation (combined heat and power) application, the efficiencies of energy can be improved. On the customer's side, the consumers have better power quality and reliability (voltage support, source of reactive power, and power factor correction, etc). Another main advantage is that the consumers have a potential source of high-reliability, as well as standby power. It is cruel when consumers have to face the big penalty of a power blackout. With respect to the economic point of view, installing a small scale or combustion turbine is more advantageous than installing a nuclear or fossil fuel generator. From the reference paper [35], one can see the advantages.

\subsection{Dynamic Model}

With MATLAB SIMULINK GUI (graphic user interface), one can simulate the systems if they have the transfer function blocks with the numerical values. In the entire simulation, MATLAB SIMULINK or POWER SYSTEM BLOCKSET $[28,29]$ is used. The speed governors have usually second-order or first-order transfer function for a combustion turbine or a diesel engine $[6,8,10,13,14,17,18]$. To achieve the models of a diesel engine and a combustion turbine, the assumption that the systems have reached a steady state is considered. In the excitation system, a simple DC machine is modeled. Detailed synchronous machine equations are used for the dynamic models. The per unit system for all the models is considered. For the inverter models, the ideal diodes and switches are used. 
Table 1-3 Economic comparison of distributed generation technologies

\begin{tabular}{|c|c|c|c|c|c|c|}
\hline $\begin{array}{c}\text { Technology } \\
\text { Comparison }\end{array}$ & $\begin{array}{c}\text { Diesel } \\
\text { Engine }\end{array}$ & Gas Engine & $\begin{array}{c}\text { Simple } \\
\text { Cycle Gas } \\
\text { Turbine }\end{array}$ & $\begin{array}{c}\text { Micro- } \\
\text { turbine }\end{array}$ & Fuel Cell & $\begin{array}{c}\text { Photo- } \\
\text { voltaics }\end{array}$ \\
\hline $\begin{array}{c}\text { Product } \\
\text { Rollout }\end{array}$ & Commercial & $\begin{array}{c}\text { Commercia } \\
1\end{array}$ & Commercial & $1999-2000$ & $1996-2010$ & Commercial \\
\hline $\begin{array}{c}\text { Size Range } \\
(\mathrm{kW})\end{array}$ & $20-10,000+$ & $50-5,000+$ & $1,000+$ & $30-200$ & $50-1000+$ & $1+$ \\
\hline $\begin{array}{c}\text { Efficiency(H } \\
\text { HV })\end{array}$ & $36-43 \%$ & $28-42 \%$ & $21-40 \%$ & $25-30 \%$ & $35-54 \%$ & N/A. \\
\hline $\begin{array}{c}\text { Genset } \\
\text { Package } \\
\text { Cost } \$ / \mathrm{kW})\end{array}$ & $125-300$ & $250-600$ & $300-600$ & $350-750$ & $1500-3000$ & N/A \\
\hline $\begin{array}{c}\text { O\&M Cost } \\
(\$ / \mathrm{kW})\end{array}$ & $0.005-0.010$ & $0.007-0.015$ & $0.003-0.008$ & $0.005-0.010$ & $0.005-0.010$ & $0.001-0.004$ \\
\hline
\end{tabular}

Source: Onsite Sycom Energy Corporation 1999 Gas Research Institute

\subsection{Objectives}

In the previous sections, the DG (distributed generation) and the advantages of the DG were examined. It is clear that there are advantages and attraction in using the DG by understanding the benefits of using DG as an aspect of the economic test. Also, one needs to look at what the advantages for using DG are with respect to electrical power. The power quality of the DG using small turbines such as, a combustion turbine, a diesel engine, a fuel cell, and a photovoltaic would be examined. First, one needs to achieve the models of the system to simulate. For the power sources and the synchronous machine simulation, the mechanical power output, the speed of the machine, the voltage of the exciter, and voltages and currents of the machine are investigated when small disturbance is applied. The disturbance will be $\pm 1 \%$ of the reference signals for the speed and $\pm 10 \%$ of reference signals for the regulator voltage. Another simulation of synchronous machine is performed with a three-phase fault at transmission line. Furthermore, for the inverter simulation, the disturbances would be voltage source magnitude changes that are 5\% more for Phase A and 5\% less for Phase C. Phase B would be kept constant. Next, the reference current magnitude will be adjusted to deliver the nominal power on the voltage sources. 


\subsection{The Structure of Thesis}

Some papers have examined the economic and technical demands for distributed generation. To examine the power quality and harmonic distortion of the DG, detailed models of the synchronous machine, the turbines, and the electronic facilities are necessary. The information we have surveyed about the load profile in West Virginia Industry would be used to assess the potential of distributed generation. In addition, the survey forms are included in chapter two.

In Chapter Three, detailed models for a gas turbine, a diesel engine, an excitation system, a speed governor, a synchronous machine, and an inverter are examined. The turbine systems can be tested with a simple synchronous machine model. The parameters are given by some of the papers, as well as by the IEEE standard. Most of the models are built using MATLAB SIMULINK and POWER SYSTEM BLOCKSET (PSB). The MATLAB SIMULINK provides useful tools for solving the differential equations and algebraic equations. Also, the POWER SYSTEM BLOCKSET contributes electric circuits and some power system machines such as a synchronous machine, an induction machine, and excitation system etc. If one uses the PSB, the load flow solutions can be achieved to get initial conditions for a steady state.

In Chapter Four, simulation of a synchronous machine with a turbine model connected to an infinite bus system is discussed. A fictitious local resistance is introduced to develop the terminal voltage of the synchronous machine without differentiation to avoid the noise and error. Park's transformation to the voltage equation for a transmission line is applied to transform the voltage equations to the rotor reference frame. Next, the steady state values need to be found for a synchronous machine model. The simulation results and the system model simulations are investigated with disturbance for sources of mechanical energy (generators, turbines, and governor). The disturbance will be $\pm 1 \%$ for speed governor or $\pm 10 \%$ for exciter from the original reference signals. For the inverter, the currents, voltages and power for a source are investigated in terms of both balanced and unbalanced sources. 
The simulation results are provided in Chapter Five for a synchronous machine, a local load and an inverter. For each of the cases (i.e. a combustion turbine and a diesel engine), the mechanical power from turbines, the speed of a synchronous machine, and the voltage from the exciter will be displayed. For an inverter simulation, the powers delivered on each phase, with both balanced and unbalanced voltage magnitudes are demonstrated. Furthermore, the powers, which are delivered with adjusted current reference, for an unbalanced voltage magnitude are shown.

In Chapter Six, the conclusions, discussions, and future work are provided. 


\section{Chapter two POWER SURVEY}

\subsection{Questionnaire}

To assess the potential of the distributed generation, a questionnaire was mailed to companies related to metal, chemical/polymer, aluminum, glass, metal casting, wood product, and others. The following is the format of the questionnaire.

\section{Questionnaire on}

\section{Potential for Distributed Generation/ Co-Generation}

(The company names and the name of individual responding to the survey will be kept strictly confidential)

1. Name, phone, e-mail, and fax number of person completing this survey.

Name:

Phone Number:

E-mail:

Fax Number:

2. Name and street address of your plant.

3. Which of the following areas describe your company?

\begin{tabular}{|l|l|l|l|l|l|l|l|}
\hline Steel & Aluminum & Glass & $\begin{array}{l}\text { Chemical/ } \\
\text { Polymer }\end{array}$ & $\begin{array}{l}\text { Metal } \\
\text { Casting }\end{array}$ & $\begin{array}{l}\text { Wood } \\
\text { Product }\end{array}$ & Mining & $\begin{array}{l}\text { Other(Please } \\
\text { specify) }\end{array}$ \\
\hline & & & & & & & \\
\hline
\end{tabular}

4. What is the approximate number of employees at your facility?

5. What is the peak electrical power demand during the summer? $\mathrm{kW}$ MW

6. What is the peak electrical power demand during the winter?

7. What is the daily load factor (average daily electrical power demand/peak electrical power demand) at your facility?

8. What is the monthly load factor (average monthly electrical power demand/peak electrical power demand) at your facility? 
Please show typical electrical load at your facility for a 24-hour period during weekdays and weekend. Please circle $\mathrm{kW}$ or MW as appropriate.

Weekdays
\begin{tabular}{|c|c|c|c|}
\hline Time & kW or MW & Time & kW or MW \\
\hline 12 a.m. & & 12 a.m. & \\
\hline 1 a.m. & & 1 a.m. & \\
\hline 2 a.m. & & 2 a.m. & \\
\hline$\ldots$ & & $\ldots$ & \\
\hline 12 a.m. & & 12 a.m. & \\
\hline
\end{tabular}

9. Is there a penalty if your electrical load is more than a certain value? Yes No If yes, what is that maximum load?

10. Is there a penalty if the electrical power factor at the plant is below a certain value? If yes, what is that power factor?

11. Do you generate any electrical power at your facility?

If yes, what is the rating of the generating unit?

12. Do you have any waste material that can be used to produce electrical power at your facility?

If so, please describe type and quantity.

\begin{tabular}{|c|c|}
\hline Type & Quantity \\
\hline & \\
\hline
\end{tabular}

13. Do you use any steam at your facility?

Please go to question 15 if your answer is no.

14. Please show typical steam usage at your facility during weekdays and weekend.

Pressure of steam: psi Temperature of steam: F

Weekdays Weekend

\begin{tabular}{|c|c|c|c|}
\hline Time & lb/min & Time & lb/min \\
\hline 12 a.m. & & 12 a.m. & \\
\hline 1 a.m. & & 1 a.m. & \\
\hline
\end{tabular}




\begin{tabular}{|c|c|c|c|}
\hline 2 a.m. & & 2 a.m. & \\
\hline$\cdots$ & & $\cdots$ & \\
\hline 12 a.m. & & 12 a.m. & \\
\hline
\end{tabular}

15. How many electric power interruptions did you have at your facility during the last year?

16. What are the costs of electric power interruption for 10 minutes, 20 minutes, 1 hour, and 24 hours?

\begin{tabular}{|c|c|}
\hline Interruption & Cost of Interruption \\
\hline 10 minutes & \\
\hline 20 minutes & \\
\hline 1 hour & \\
\hline 24 hours & \\
\hline
\end{tabular}

17. What are the primary and secondary voltages of distribution transformers at your facility?

$\mathrm{kV}$ (line-to-line)/V(line-to-line) $\mathrm{V}$

What is the distribution voltage levels within your facility?

18. What percentage of your load can be classified as motor load, lighting load, air conditioning load, computer load, heating load, and other load?

\begin{tabular}{|c|l|}
\hline Type of Load & Percentage \\
\hline Motor & \\
\hline Lighting & \\
\hline Air Conditioning & \\
\hline Computer & \\
\hline Electric Heating & \\
\hline Other & \\
\hline
\end{tabular}

19. Do you use adjustable speed drives and programmable logic controllers at your facility?

If yes, what are the power ratings of these drives? 
Power: $\mathrm{kW} / \mathrm{MW}$

Voltage: $\mathrm{V} / \mathrm{kV}$

20. Would you be able to modify your electrical loads to benefit from real time pricing of electricity if it is offered in West Virginia?

21. Have you considered building a distributed generation / co-generation power facility? If yes, what factors influenced your decision?

22. Would you anticipate any difficulty obtaining large quantities of natural gas for a power generation facility?

If yes, please explain

23. Do you have a need for getting help with power quality problems and/or information technology (such as web page development, e-commerce, and local area networks) if it were available to you at no cost?

Power quality: Yes

No

Information technology: Yes No

24. Do you have any further comments or questions regarding distributed/ co-generation? 


\subsection{Electrical Load Profiles}

From the survey questionnaire the following data are obtained and plotted. Each company's electrical load profiles are reported to assess the potential of distributed generation. In Fig. 2-1 and Fig. 2-2 chemical/polymer company's electrical load profiles are shown. The y-axis represents how much power they need (electrical load, MW). The 24-hour period is represented in an x-axis. The weekdays electrical load profile is shown in Fig. 2-1 and weekend electrical load profile is shown in Fig. 2-2. Other following two figures show the electrical load profiles for a steel company. The weekdays and weekend electrical load profiles are shown in Fig. 2-3 and Fig. 2-4 respectively. On the other hand, Fig. 2-5 and Fig. 2-6 show electrical load profiles for an aluminum company. For glass company's weekdays and weekend electrical usage profiles are shown in Fig. 2-7 and Fig. 2-8. Finally, for a glass company the electrical and gas usage is shown in Fig. 29 for 1-year period.

\section{2-1 Chemical/Polymer Company}

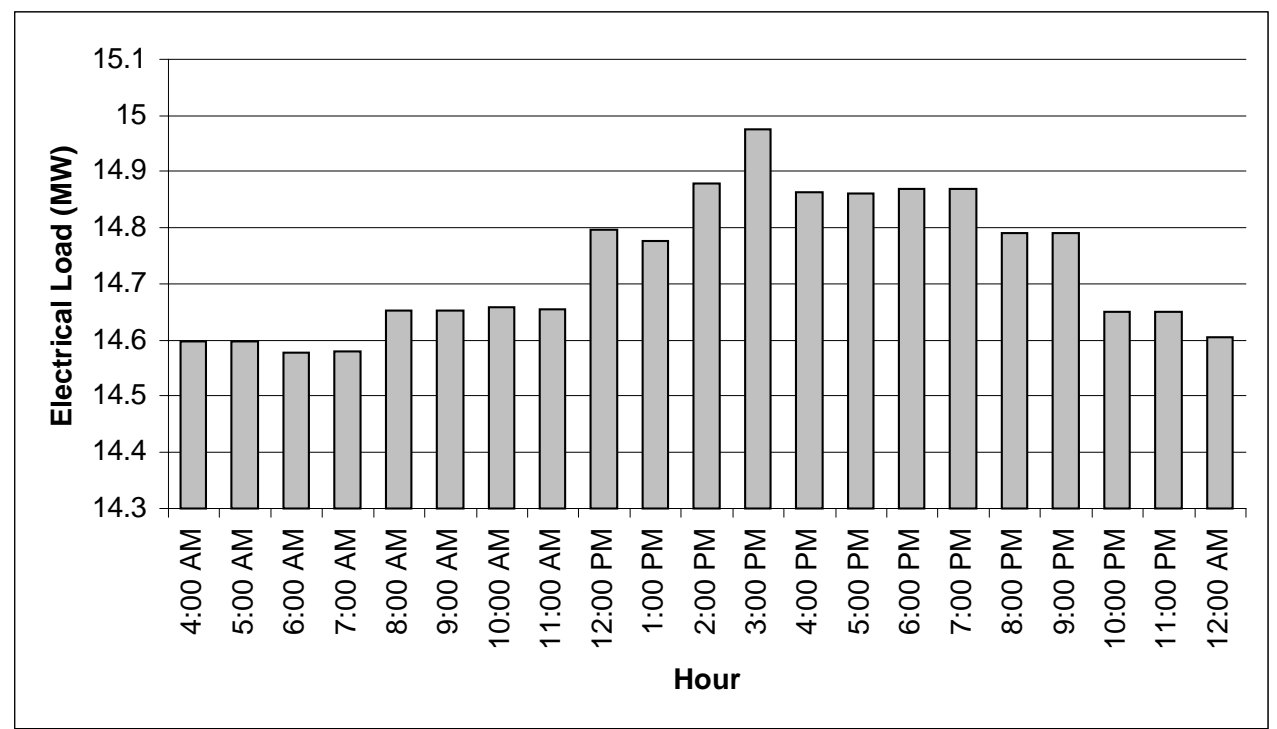

Fig. 2-1 Electrical load profile of weekdays in chemical/polymer company. 


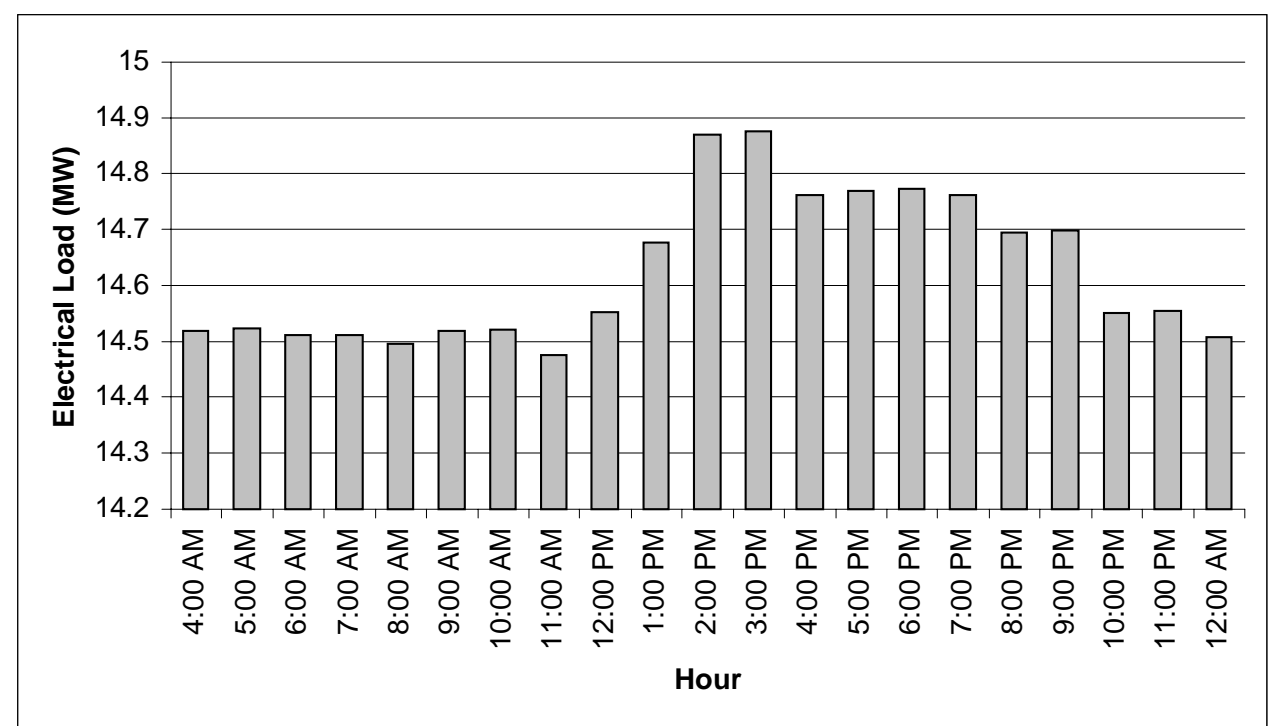

Fig. 2-2 Electrical load profile of weekend in chemical/polymer company.

\section{2-2 Steel Company}

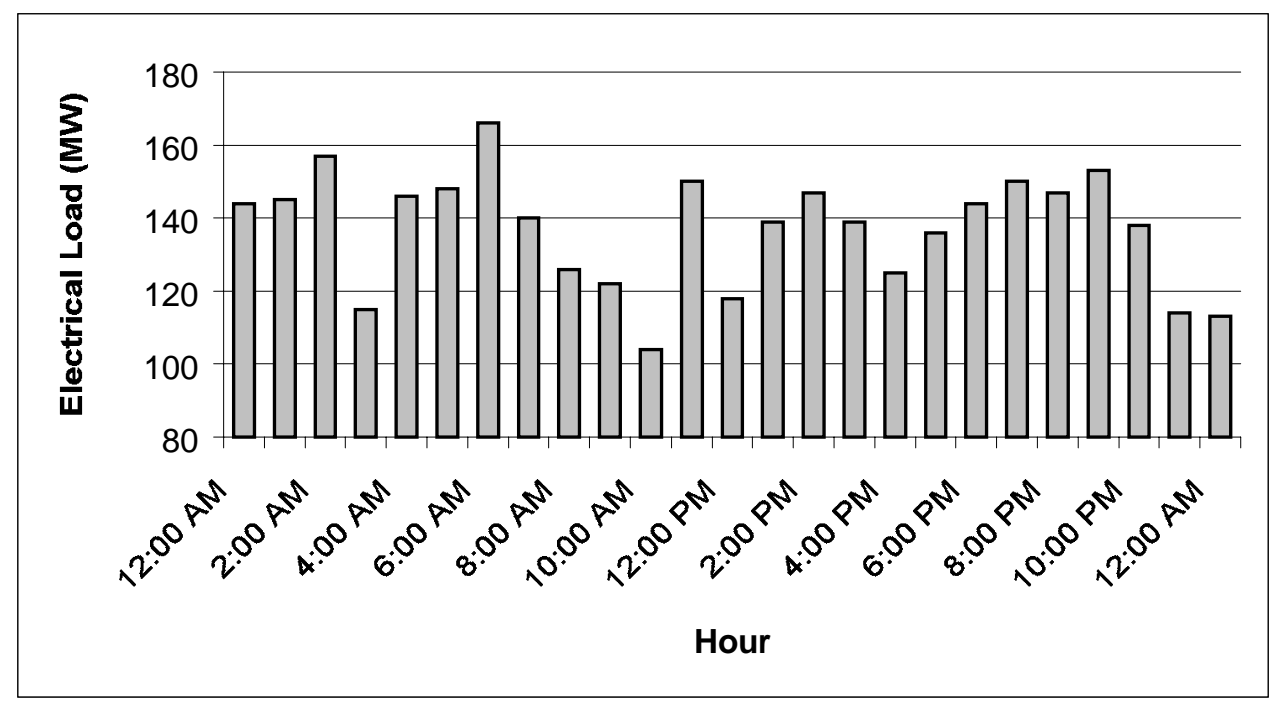

Fig. 2-3 Electrical load profile of weekdays in steel company. 


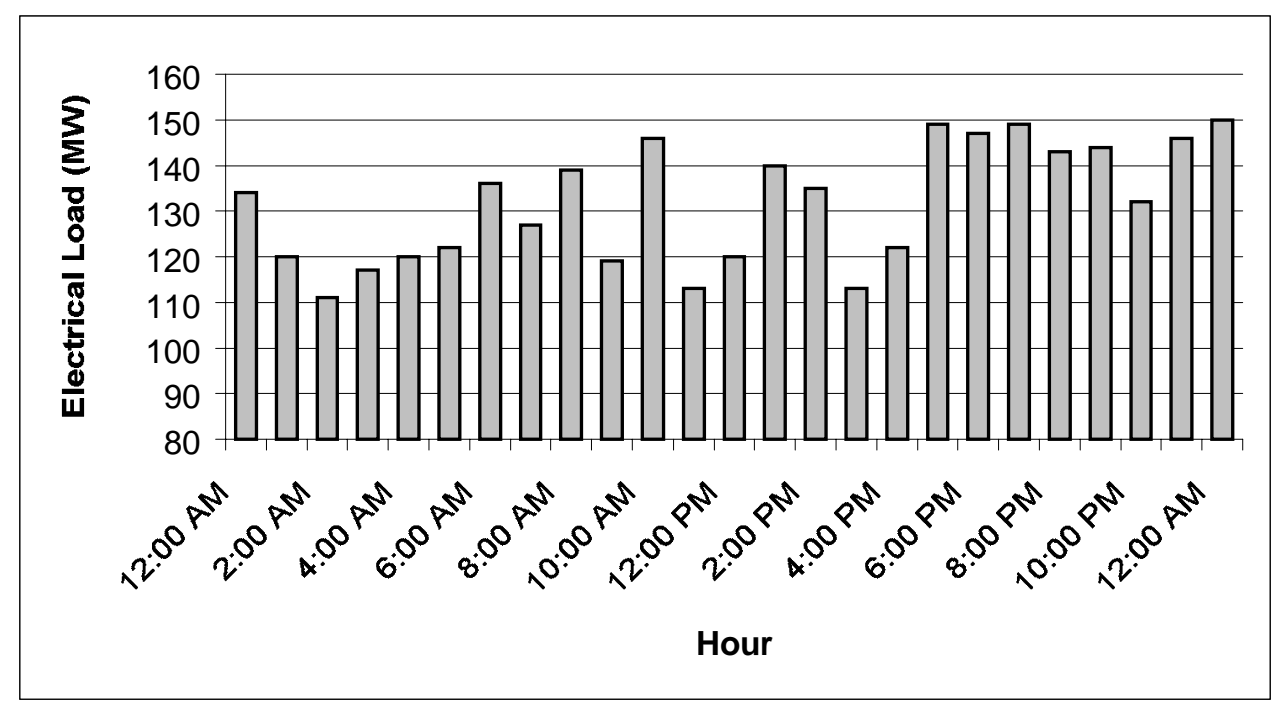

Fig. 2-4 Electrical load profile of weekend in steel company.

\section{2-3 Aluminum Company}

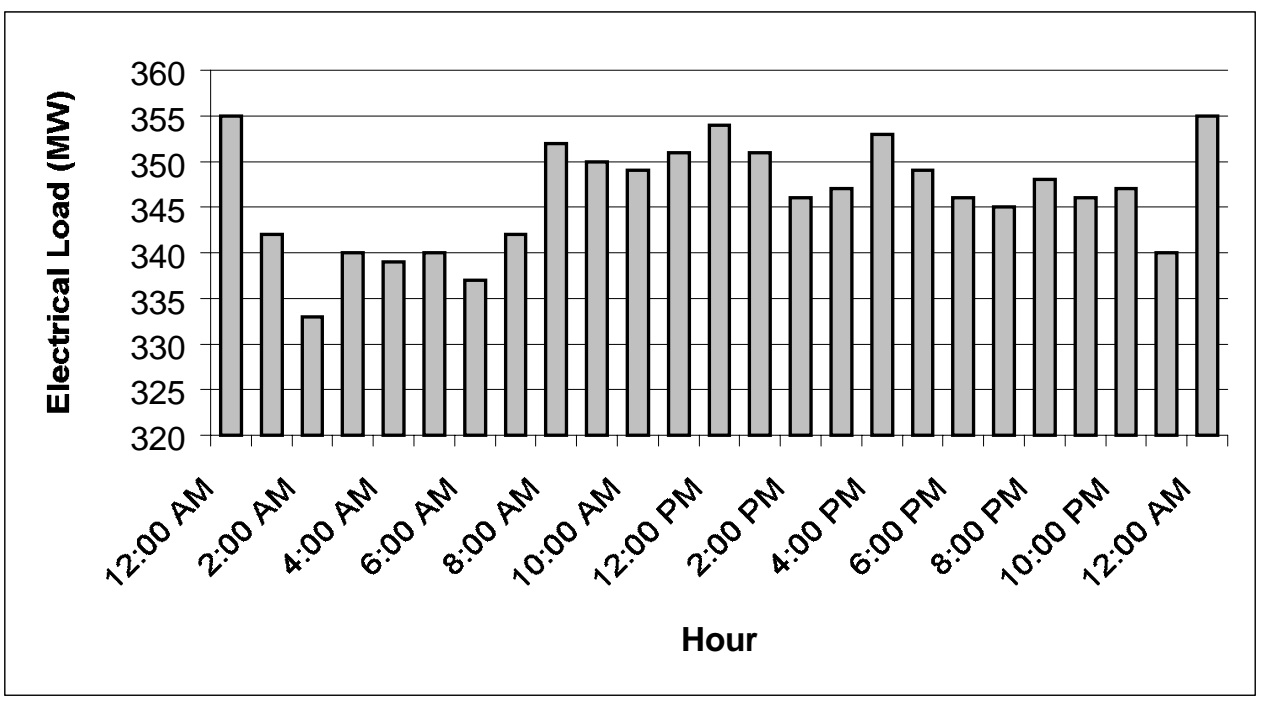

Fig. 2-5 Electrical load profile of weekdays in aluminum company. 


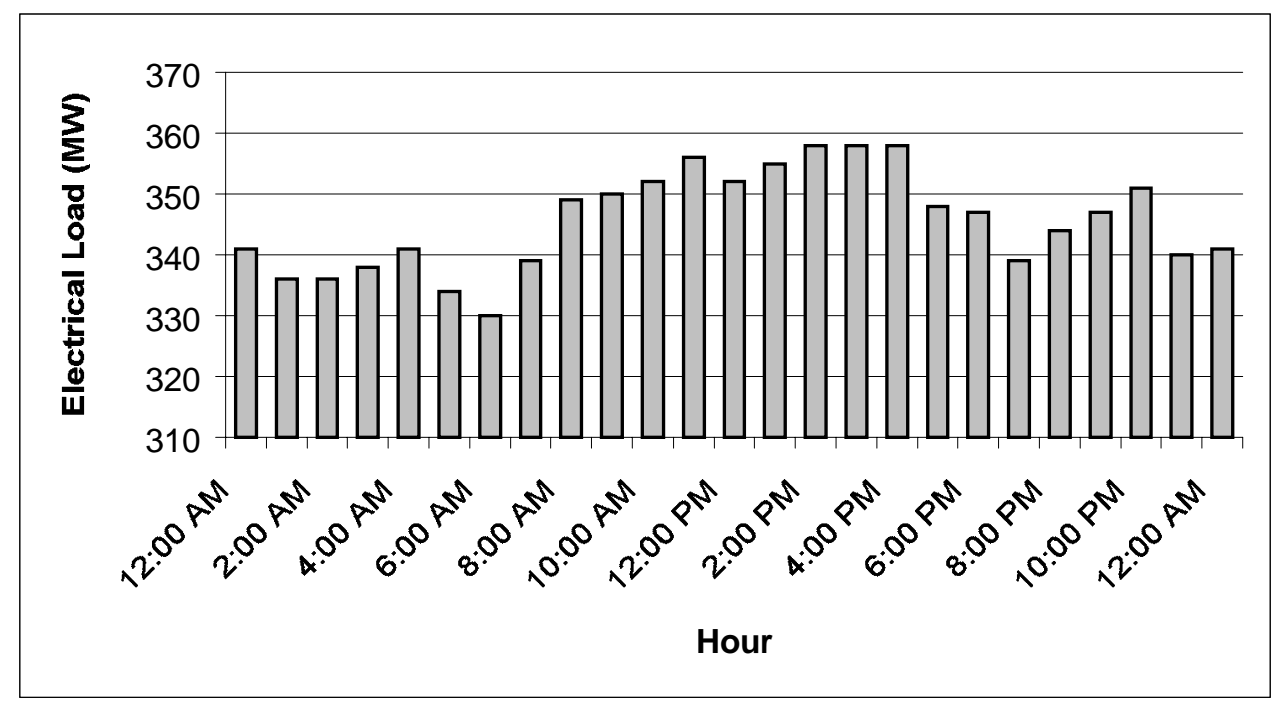

Fig. 2-6 Electrical load profile of weekend in aluminum company.

\section{2-4 Glass Company}

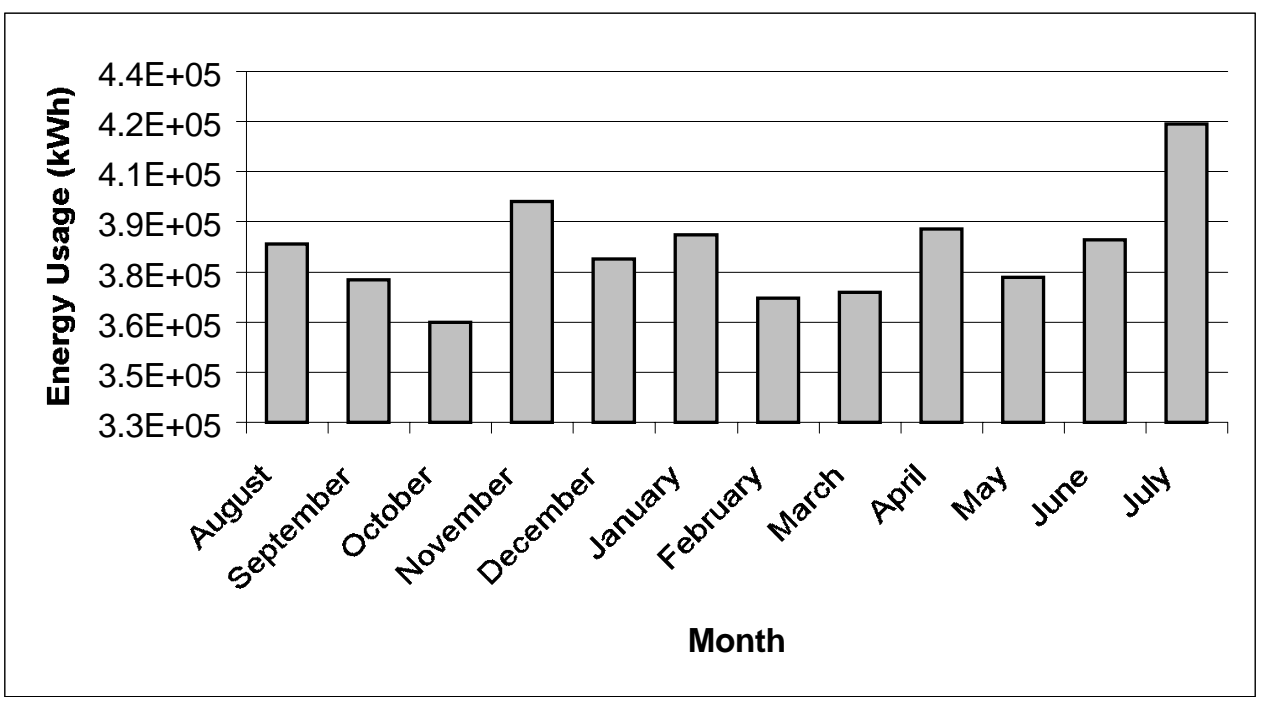

Fig. 2-7 Energy usage in the glass company. 


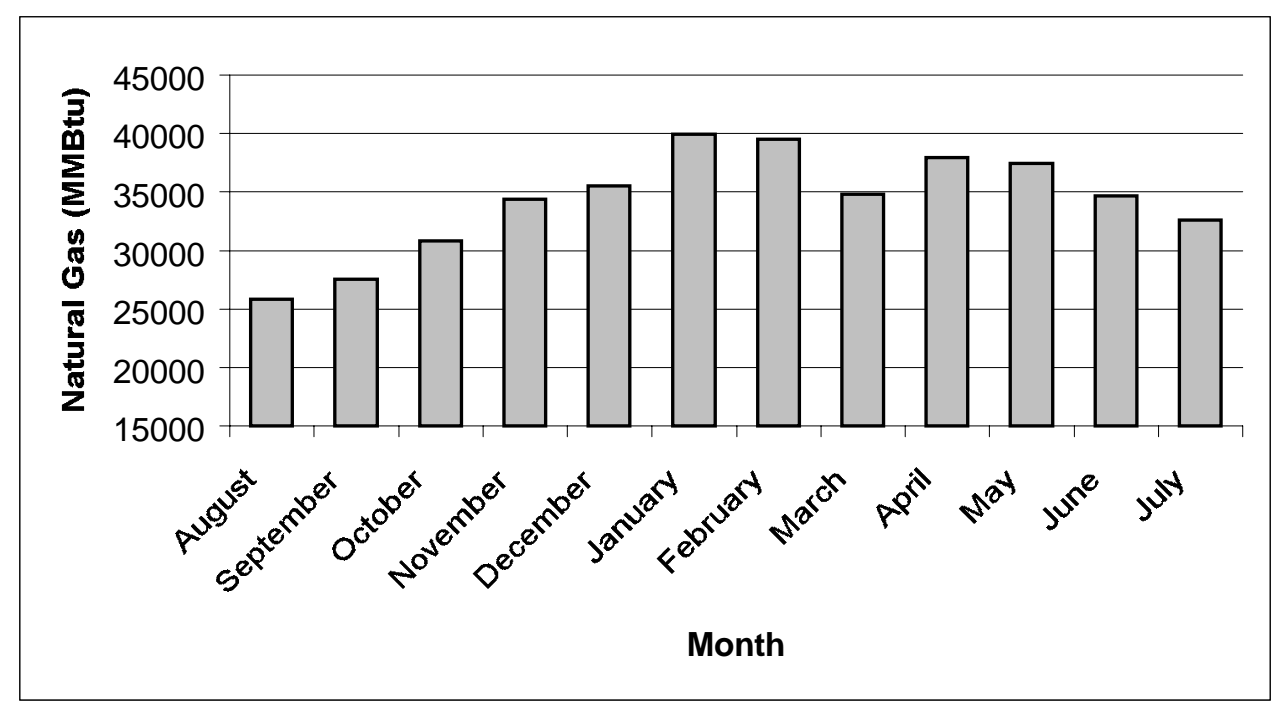

Fig. 2-8 Natural gas usage profile in the glass company.

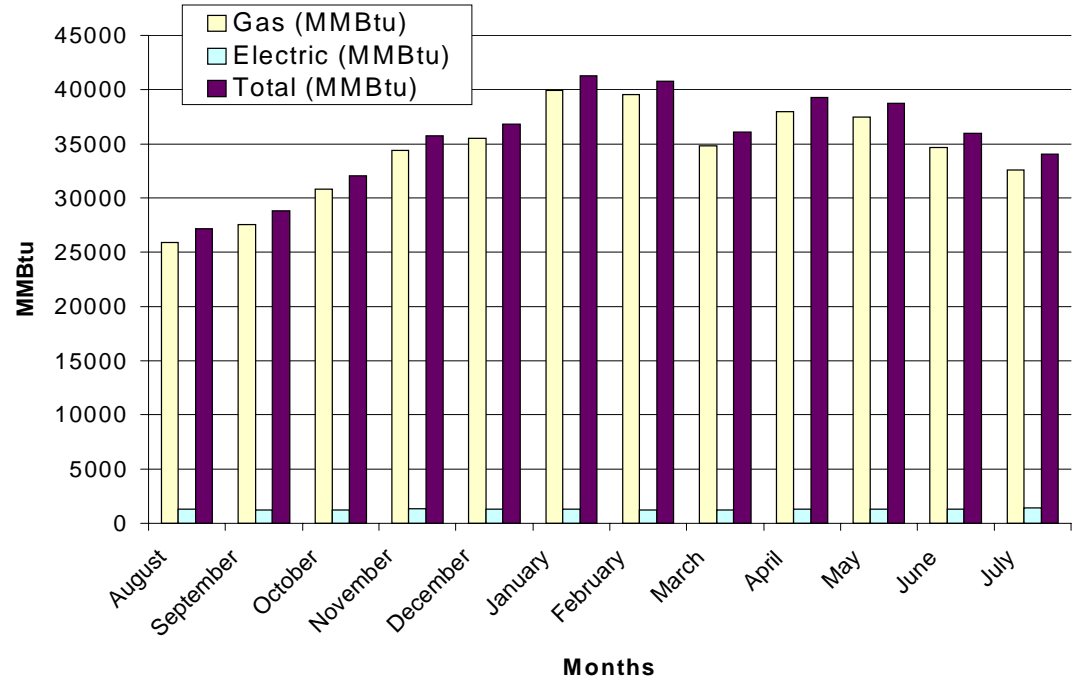

Fig. 2-9 Electrical and natural gas usage in a glass company. 


\subsection{Load Classification}

Another information collected is a load classification for each company. The typical load classification is shown in table 2-1. The first row represents the companies and first column represents the type of load. For an aluminum company the electrical power is used around $40 \%$ for motor and $30 \%$ for each lighting and air conditioning or computer and electric heating. The $90 \%$ electrical power is used for motor in a wood product company. The rest of the power $10 \%$ is used for lighting, air conditioning, computer, and electric heating. A glass company uses the electrical power around $60 \%$ for motors, $10 \%$ for lighting, 5\% for air conditioning, 5\% for computer, and $20 \%$ for electric heating. A steel company has $85 \%$ electrical power usage for motors, $10 \%$ for lighting, and less than $1 \%$ for each air conditioning, computer, electrical heating. The final company for a load classification is chemical/polymer. Around $85 \%$ electrical power is used for motors in the chemical/polymer company. They use electrical power for lighting around $4 \%$, for air conditioning around $8 \%$, for computer around $2 \%$.

Table 2.1 Typical load classification of the companies

\begin{tabular}{|c|c|c|c|c|c|}
\hline Type of Load & Aluminum & $\begin{array}{c}\text { Wood } \\
\text { Product }\end{array}$ & Glass & Steel & $\begin{array}{c}\text { Chemical/ } \\
\text { Polymer }\end{array}$ \\
\hline Motor & $40 \%$ & $90 \%$ & $60 \%$ & $85 \%$ & $85 \%$ \\
\hline Lighting & $30 \%$ & $5 \%$ & $10 \%$ & $10 \%$ & $4 \%$ \\
\hline Air Conditioning & & $2 \%$ & $5 \%$ & $<1 \%$ & $8 \%$ \\
\hline Computer & \multirow{2}{*}{$30 \%$} & $1 \%$ & $5 \%$ & $<1 \%$ & $2 \%$ \\
\hline \multirow{2nnyyy}{*}{ Electric Heating } & & $2 \%$ & $20 \%$ & $<1 \%$ & $0 \%$ \\
\hline Other & & & & $2-3 \%$ & $1 \%$ \\
\hline
\end{tabular}




\section{Chapter three DYNAMIC MODELING}

\subsection{Gas Turbine Model}

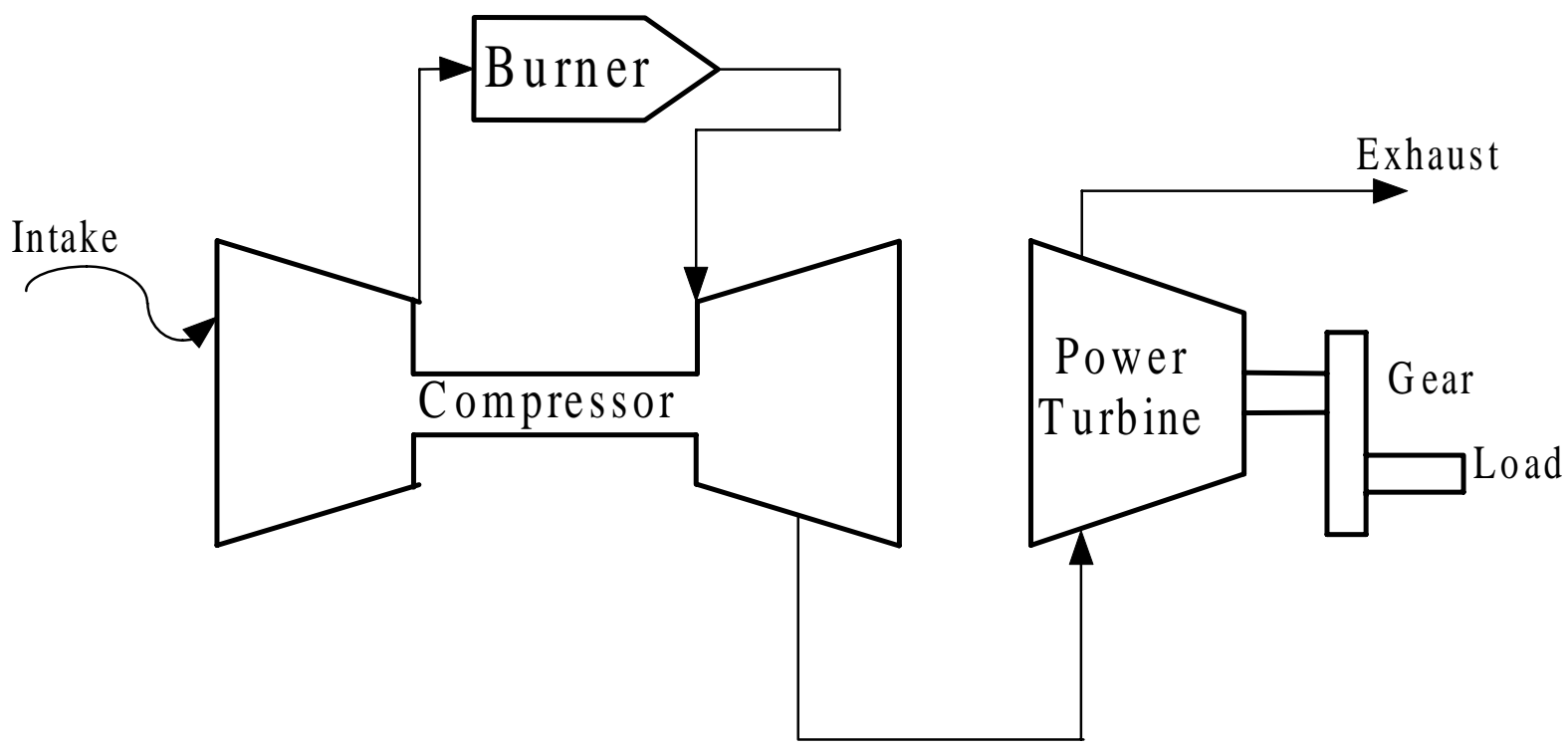

Fig. 3-1 Simple-cycle gas turbine-engine.

The combustion turbine can be either a single-shaft machine or a split-shaft machine. The simple cycle gas turbine involves an air compression section, a burner or combustor, and a power turbine driving a load. The exhaust gas from the combustion chamber forces the high-pressure compressor turbine that drives the compressor. A generator is driven through a gearbox by the power turbine. The overall diagram of the single-shaft combustion turbine is shown Fig. 3-1. In addition, the other two commonly used combustion turbines are shown in Fig. 3-2 and Fig. 3-3. In Fig. 3-2, a recuperated combustion turbine model is represented. 


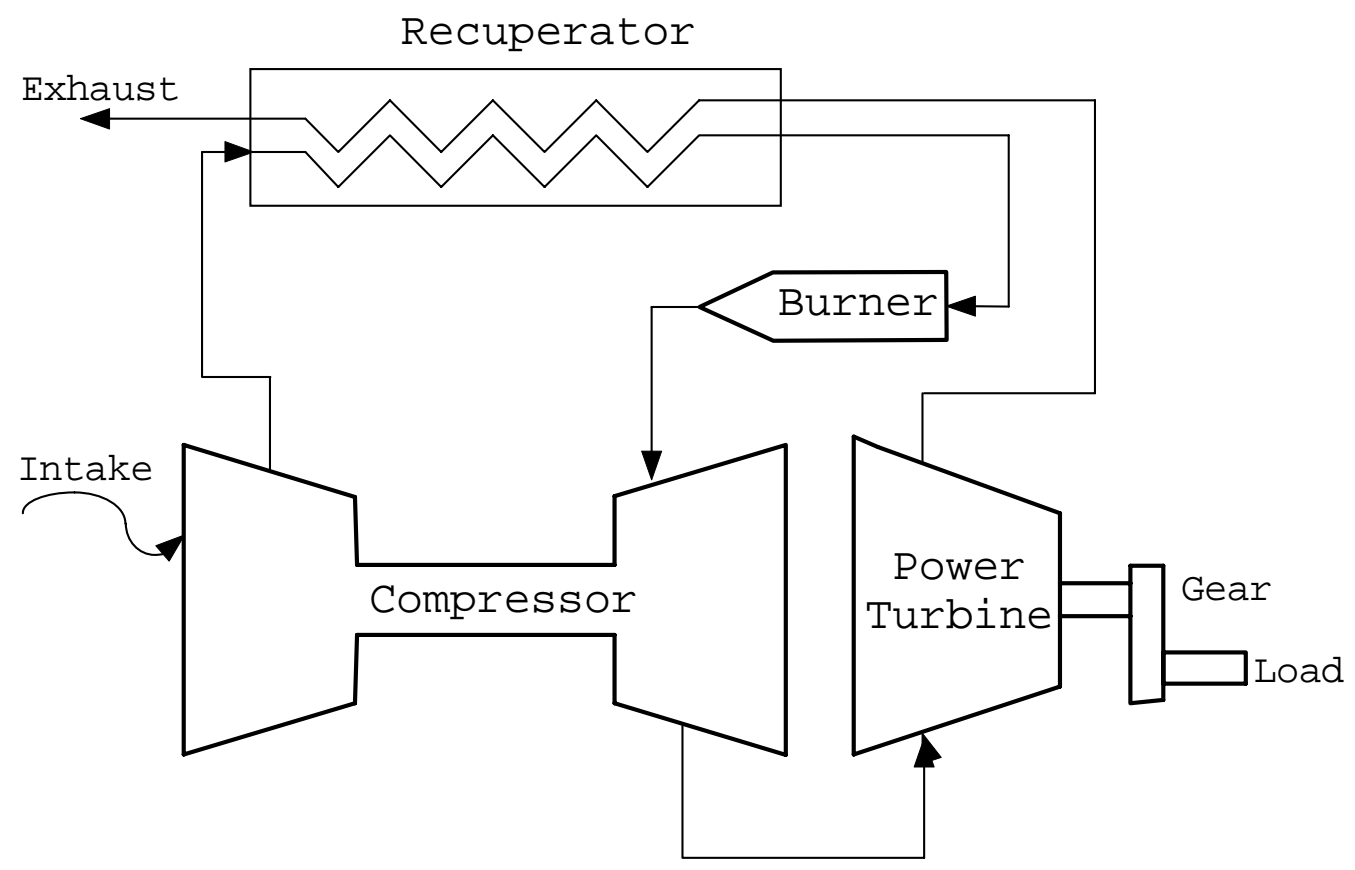

Fig. 3-2 Recuperated combustion turbine.

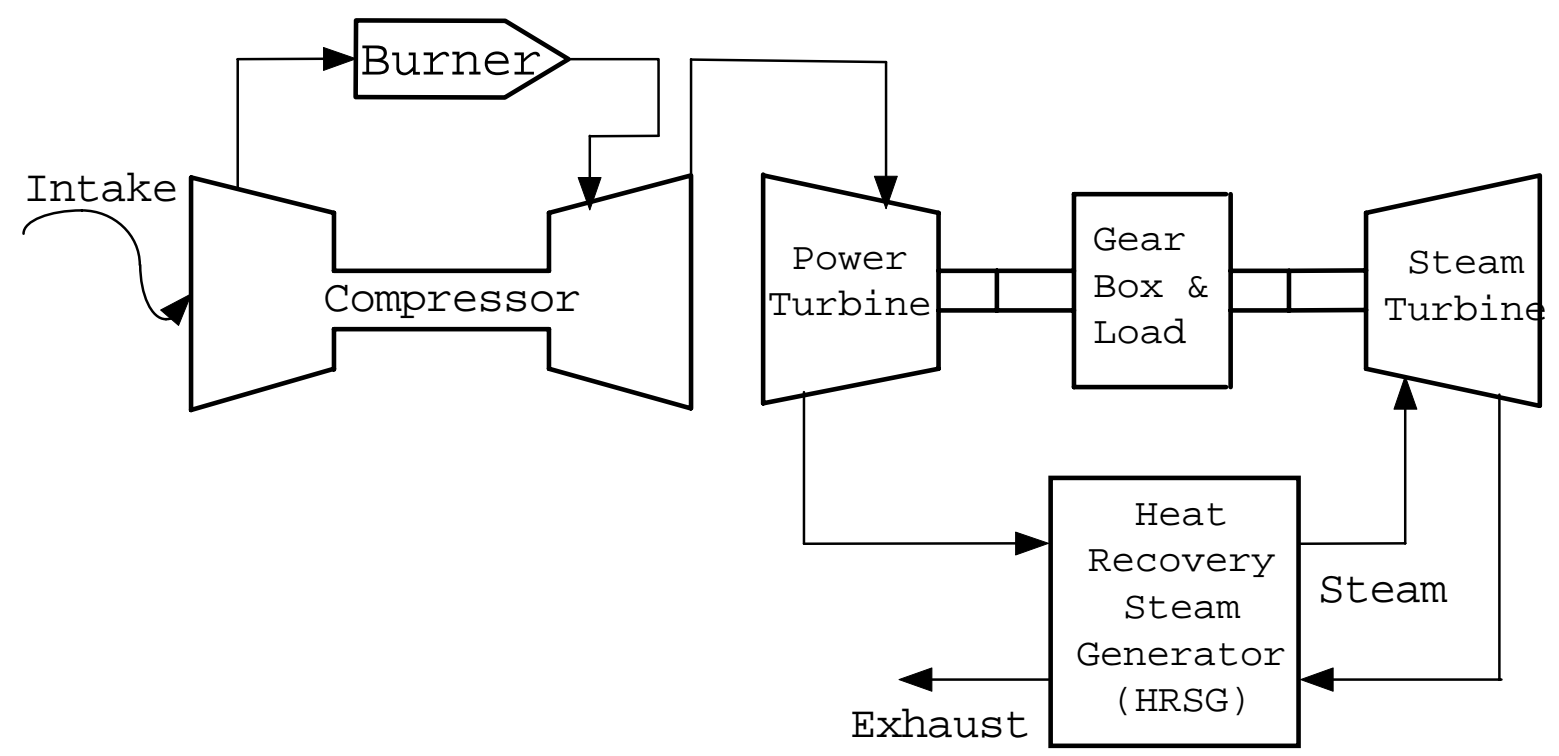

Fig. 3-3 Combined-cycle combustion turbine. 
This model is similar to the simple cycle gas turbine model, but it has a special heat exchanger, and a recuperator that captures the exhausted thermal energy from the power turbine to preheat compressed air. This action improves the electrical efficiency in contrast to a simple-cycle gas turbine. On the other hand, in Fig. 3-3 the combined cycle combustion turbine is shown. These turbines include a heat recovery steam generator (HRSG) to capture the exhaust energy. With a HRSG device, the combined gas turbine power plants significantly improve power generation output and efficiency in contrast to a simple cycle gas turbine.

\section{1-1 Basic Gas Turbine Dynamics}

A combustion turbine can be represented by an approximate linear model, assuming that the engine can be modeled as a combination of multi-variable functions, linearized by writing them in an ordinary differential equation form. To represent gas turbines as a linearized model, the assumption that allows transient thermodynamic and flow processes to be considered as quasi-static is represented. Conditions progressing from one equilibrium state to another along an equilibrium curve permit functional relationships to be written between the different input and output variables. The fuel flow $W_{f}$ can be considered an independent variable with respect to the engine. Other variables such as the engine speed $\mathrm{N}$, which is independent with respect to the thermodynamics cycle, the compressor discharge pressure $P_{2}$, the exhaust gas pressure $P_{4}$, the exhaust gas temperature (EGT) are chosen as the dependent variables. Furthermore, each engine performance parameter can be defined as a function of the fuel flow $W_{F}$.

\section{1-2 Gas Turbine Control System Model}

The entire scheme of a gas-turbine governor control system and a gas turbine is shown in Fig. 3-4. The power turbine speed $N_{T}$, the gas generator speed $N_{G}$, and the 
exhaust gas temperature $T_{4}$ are monitored by the electronic governor. These signals are fed back to a lowest win logic gate, which produces the control function signal $V_{c}$. Normally, the control signal measured from $N_{T}$ maintains the generator speed. However, when $N_{G}$ or $T_{4}$ exceed their limits, the signal $V_{N G}$ or $V_{T 4}$ operates to decrease the power turbine speed, which reduces the fuel flow until the engine is operating within a safe level. $V_{c}$, the final control signal is modified, if required, by jump and rate limit circuits, to ensure that the gas turbine is operating within a limit. This circuit output voltage $V_{d}$ is then compared with feedback voltage $V_{p}$ from the compressor discharge pressure (CDP).

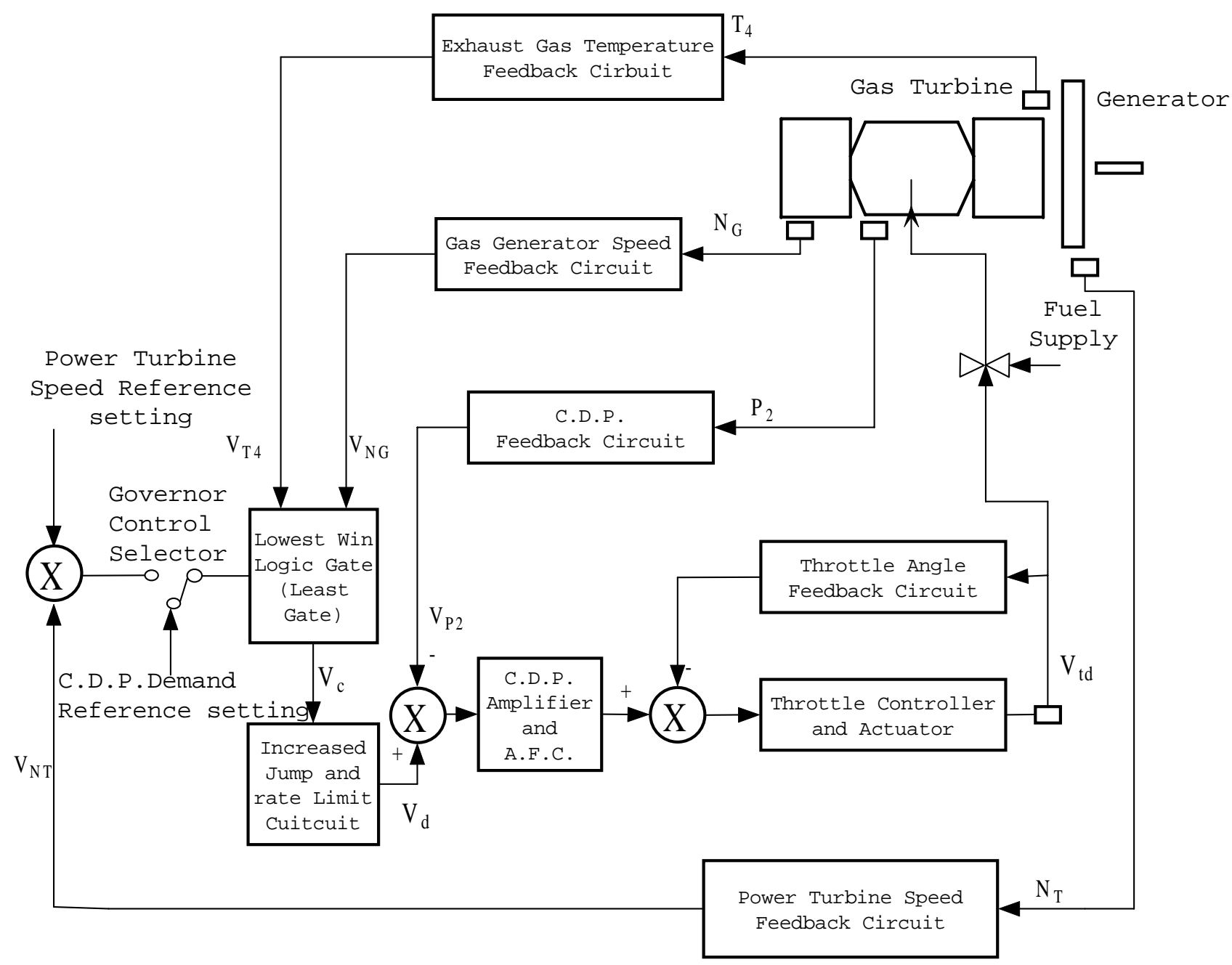

Fig. 3-4 Combustion turbine control system. 
After amplified error signals are produced, these signals are fed to the air fuel controller (AFC), which acts as an interface between the electronic governor and the fuel valve package. If required, the acceleration and deceleration fuel schedule is imposed on the governor demand voltage in the AFC before getting through the throttle control amplifier as a throttle demand voltage, VTD. This voltage and the throttle angle feedback voltage $V_{e}$ are compared at the throttle amplifier. The output finally controls the fuel valve actuator and the engine fuel flow by adjusting the fuel throttle valve opening.

\section{1-3 Mathematical Representation}

\section{Nomenclature}

$a b c=$ Fuel system transfer function coefficients

$w x y z=$ Governor transfer function coefficients

$K_{d}=$ Governor gain

$K_{F}=$ Fuel system feedback

$s=$ Laplace operator

$T_{R}=$ Turbine rated exhaust temperature

$T_{X}=$ Turbine exhaust temperature

$V C E^{\prime}=$ Per unit fuel command or per unit speed

$W_{f}=$ Per unit fuel flow

$\varepsilon_{C R}=$ Combustion reaction time delay

$\varepsilon_{T D}=$ Turbine and exhaust system transport delay

$\tau_{C D}=$ Compressor discharge volume time constant

$\tau_{F}=$ Fuel system time constant 
$\tau_{1}=$ Turbine rotor time constant

$\tau_{T}=$ Temperature controller integration rate

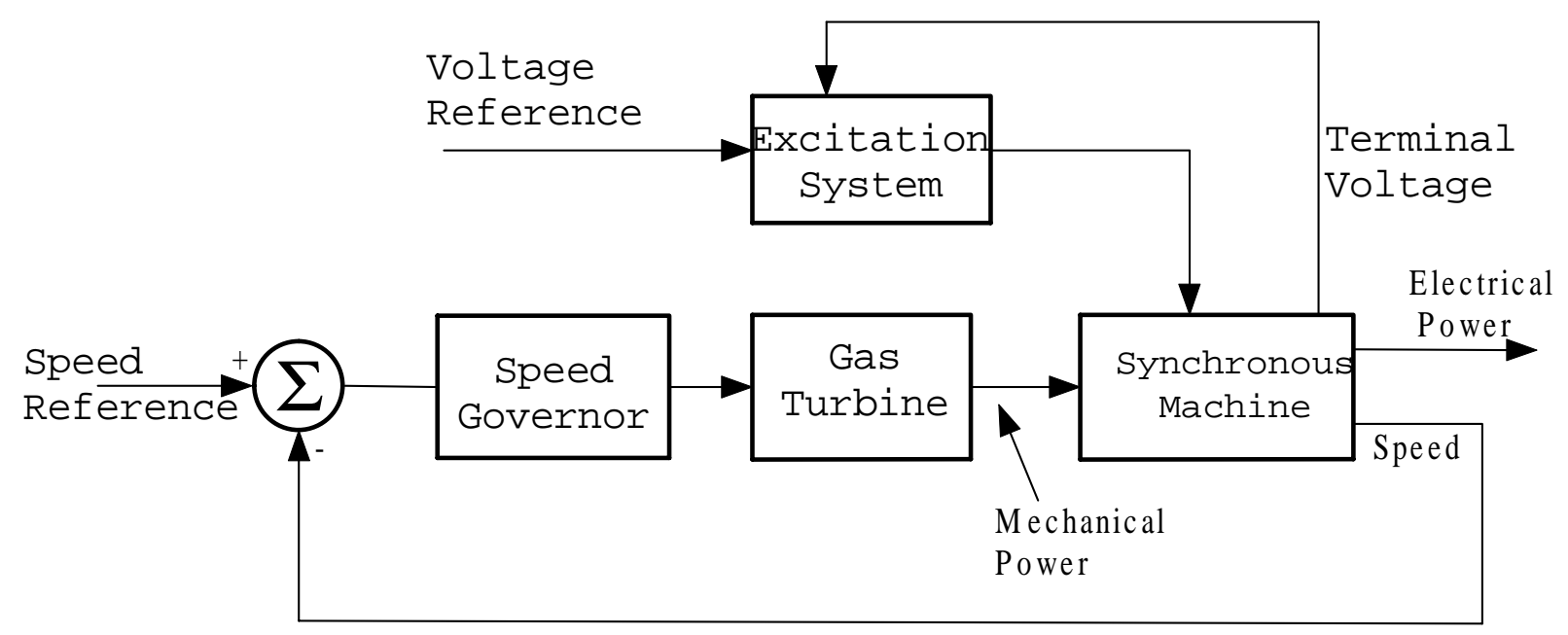

Fig. 3-5 A block diagram of gas turbine and governor model.

The block diagram of the simple dynamic model for the gas turbine is shown in Fig. 3-5. At this time the synchronous machine model is applied to a classical first order transfer function $\frac{a s}{\tau_{s}+b}$. On the other hand, the speed governor model is also a first order transfer function $\frac{W(X s+1)}{Y s+Z}$. A detailed single shaft gas turbine block diagram with a speed governor and a synchronous machine is next shown in Fig. 3-6. In Fig. 3-7, the temperature control block of the gas turbine is shown. The detailed gas turbine dynamics are shown in Fig. 3-8.

The control block includes the speed control, the temperature control, the acceleration control, and the upper and lower fuel limits. The governor controls can be modified to either droop or isochronous governor by adjusting the given parameters, $\mathrm{W}$, $\mathrm{X}, \mathrm{Y}$ and $\mathrm{Z}$. The signals for the speed governor are compared with the reference per unit signal and the speed per unit deviation as measured from synchronous machine block. To produce a fuel demands signal, $V_{c e}$, a low value select block compares signals coming from the speed governor and the temperature control. 


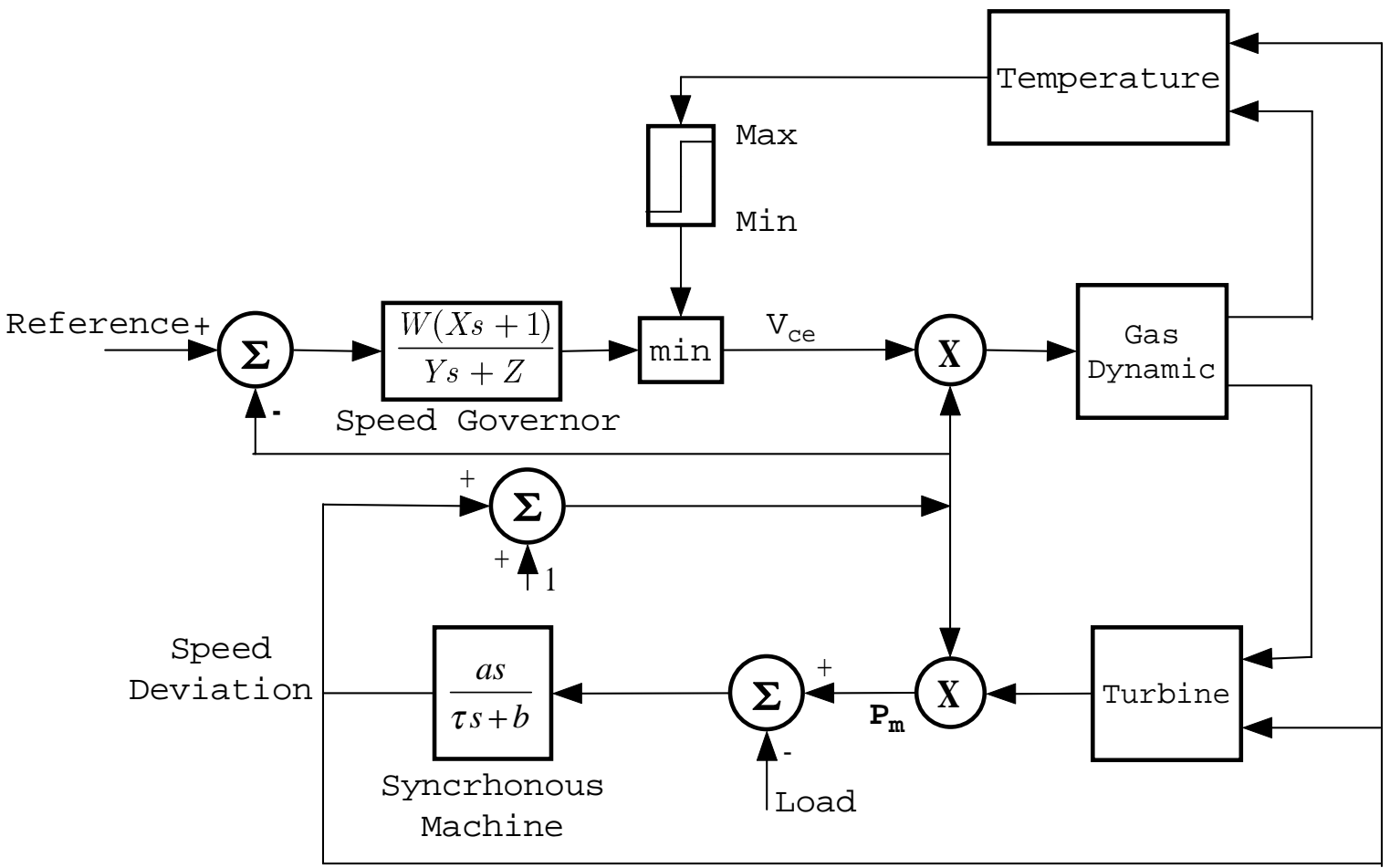

Fig. 3-6 The block diagram for gas turbine, speed governor, and synchronous machine.

This per unit value, $V_{c e}$, corresponds directly to the per unit value of mechanical power on turbine base in the steady state. For instance, if $V_{c e}$ is 0.5 per unit the mechanical power for the steady state is 0.5 per unit. The $V_{c e}$ signal goes through, scaled by a gain $K_{3}$ moreover a time delay block is used because the governor control using digital logic is replaced by analog devices. This signal is again offset by $K_{6}$, which is the fuel flow at a no load, rated speed condition. The fuel flow is burned in the combustor. This signal results in turbine torque, and through a radiation shield offsets and in exhaust gas temperature measured by a thermocouple. 


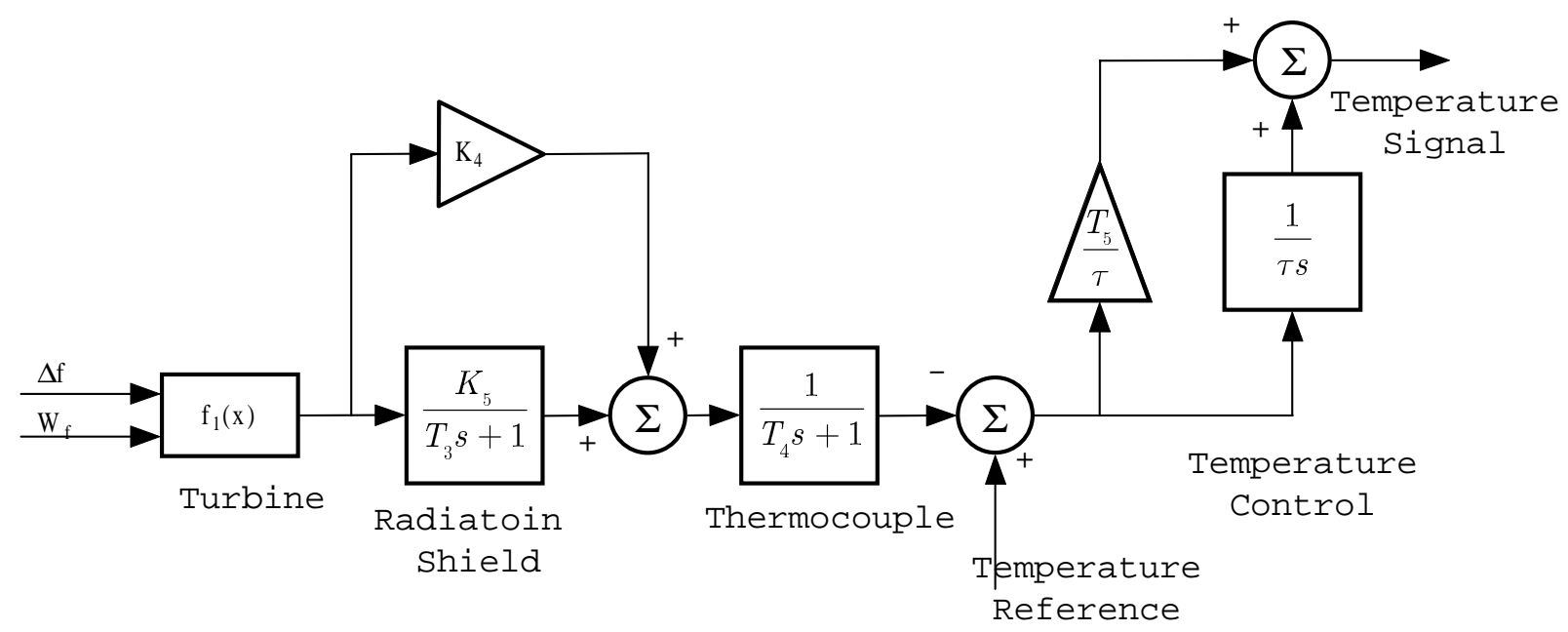

Fig. 3-7 Temperature control block diagram.

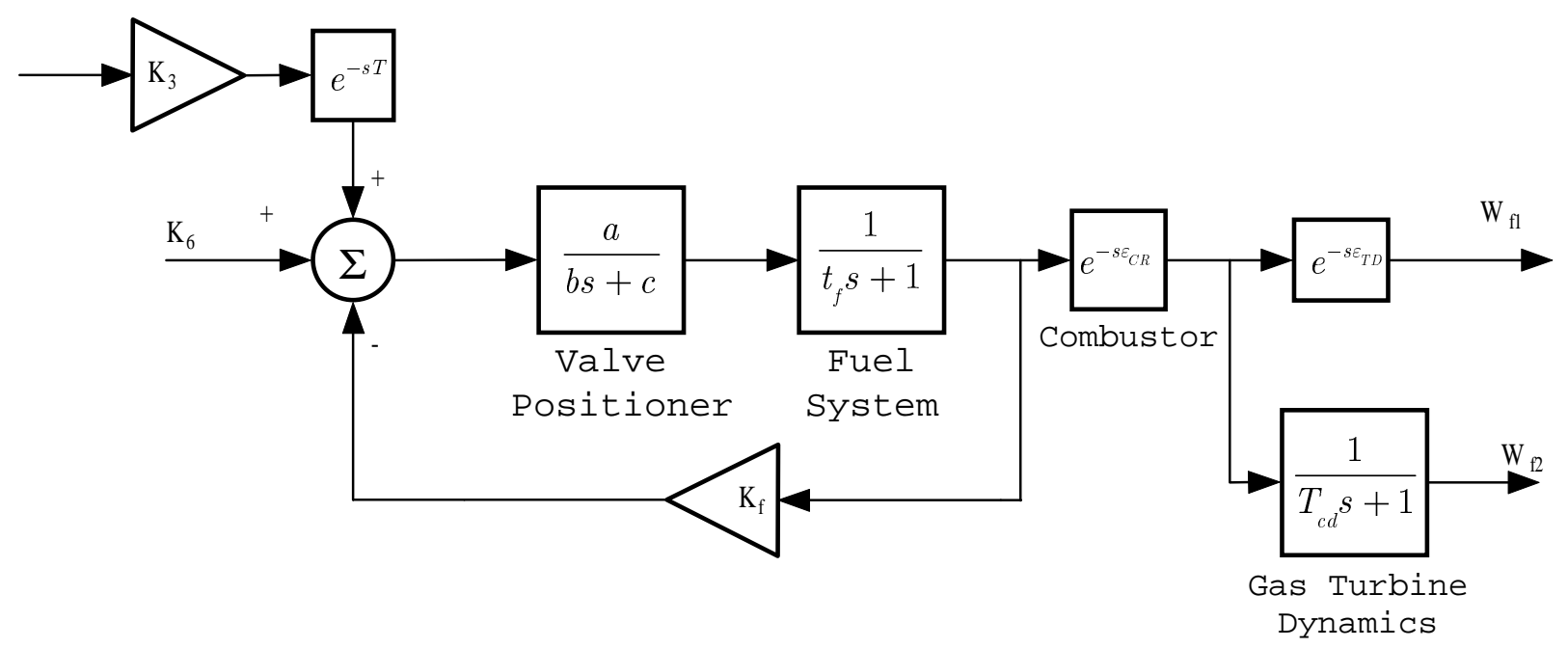

Fig. 3-8 Gas turbine dynamic model diagram.

The output signal from the thermocouple is compared with the reference signal. Normally, the signal compared with the reference and thermocouple is positive, which makes the temperature control stay on the maximum limit, permitting an uninhibited governor or speed control. When the thermocouple output exceeds the reference temperature, the output would be negative and it starts lowering the temperature control. 
Furthermore, when the temperature control output is less than the governor output, the former value passes through the low value selector to limit the CT's MW output, in which case, the unit is operating on temperature control.

\subsection{Excitation System Model}

The excitation systems can be classified as three of the main types from IEEE Std. 421.5-1992.

1. DC type excitation systems, which utilize a direct current generator with a commutator as the source of excitation system power.

2. AC type excitation systems, which use an alternator and either stationary or rotating rectifiers to produce the direct current needed for the synchronous machine field.

3. ST type excitation systems, in which excitation power is supplied through transformers or auxiliary generator windings and rectifiers.

These detailed excitation system models are in IEEE Recommended Practice for Excitation System for Power System Stability Studies. Excitation system models can include a terminal voltage transducer and a local compensator, excitation control elements, an exciter, and, a power system stabilizer.

Next, a simple exciter (Separately excited DC exciter) is considered. The circuit of a simple DC exciter is shown in Fig. 3-10. A simple equation from Fig. 3-10 is as follows

$$
i=i_{0}+f\left(v_{s}\right)=\frac{1}{k} v_{s}+f\left(v_{s}\right)
$$

and the voltage equation is written as follows

$$
v_{R}=R i+\frac{d \lambda}{d t}
$$

where $\lambda=$ Total flux linkage.

If the above two equations are combined, the voltage equation becomes

$$
\therefore v_{R}=\frac{R}{k} v_{s}+R f\left(v_{s}\right)+\frac{d \lambda}{d t}
$$


where $f\left(v_{s}\right)=$ Nonlinear function for voltage relationship

$k=$ Slope of the air gap line

Since $v_{s}$ is proportional to the speed times the air gap flux, $v_{s}$ can be represented by the constant times some flux linkage that is, $v_{s}=\beta \lambda$

Therefore, the equation is represented as follows

$$
v_{R}=\frac{R}{k} v_{s}+R f\left(v_{s}\right)+\frac{1}{\beta} \frac{d v_{s}}{d t}
$$

with definition of the new saturation function $S\left(v_{s}\right)$, as

$$
S\left(v_{s}\right)=\frac{k f\left(v_{s}\right)}{v_{s}}
$$

the equation (3-4) becomes

$$
\frac{k}{R} v_{R}=v_{s}+v_{s} s\left(v_{s}\right)+\frac{k}{\beta R} \frac{d v_{s}}{d t}
$$

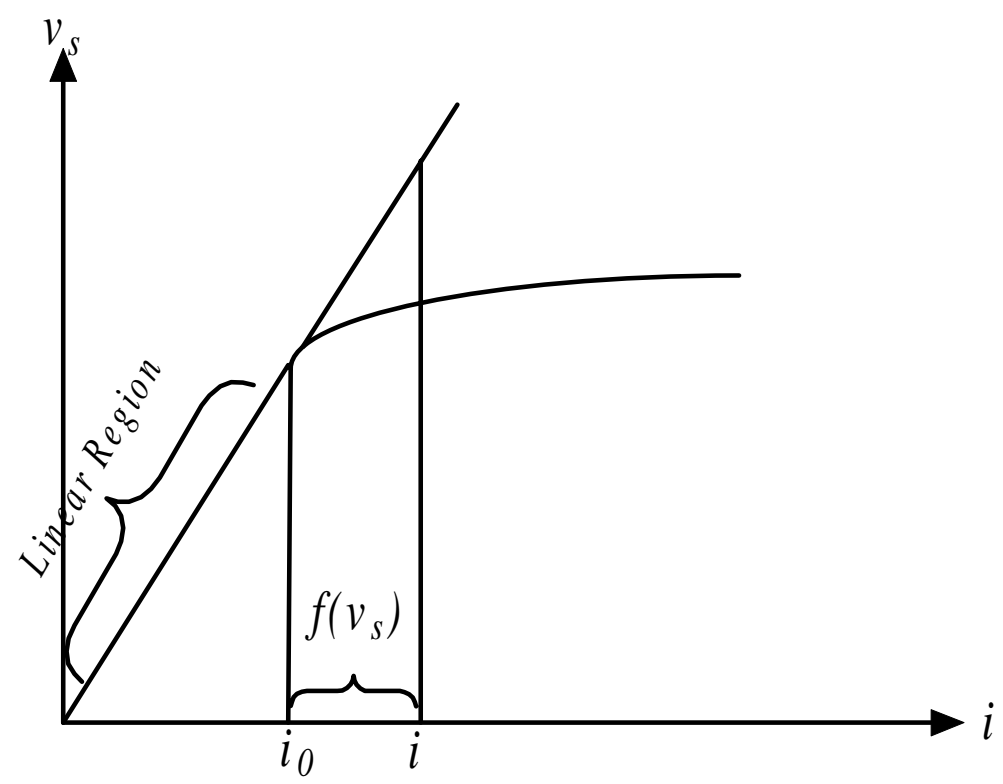

Fig. 3-10 The relationship between the current and voltage. 


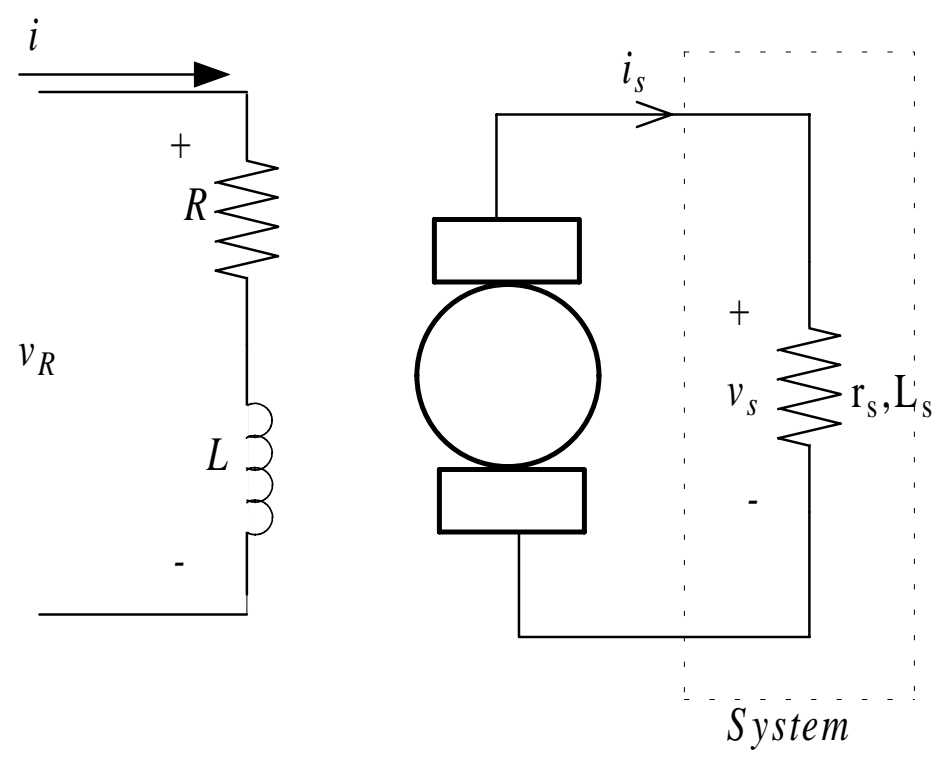

Fig. 3-11 Simple exciter system circuit.

This equation (3-6) is represented with an actual unit, the system equation can be transferred to a per unit system as chosen $E_{f d} \triangleq \alpha v_{s}$ with $\alpha$ as a scaling factor. The following other useful notations can be defined

$$
\begin{aligned}
& T_{E} \triangleq \frac{1}{\beta} \text { Time constant for exciter } \\
& K_{E} \triangleq \frac{R}{k} \text { Gain constant }
\end{aligned}
$$

then finally, the first order differential nonlinear equation for the DC excitation system is obtained as follows

$$
\frac{\alpha}{K_{E}} v_{R}=E_{f d}+E_{f d} S\left(E_{f d}\right)+\frac{T_{E}}{K_{E}} \frac{d}{d t}\left(E_{f d}\right)
$$

If the saturation function is neglected and we take the Laplace Transform, this equation can be represented in Fig. 3-11 by a first order linear transfer function with the time constant, $T_{e}$ and gain $K_{e}$ defined as follows

$$
\begin{aligned}
& T_{e} \triangleq \frac{T_{E}}{K_{E}} \\
& K_{e} \triangleq 1 / K_{E}
\end{aligned}
$$




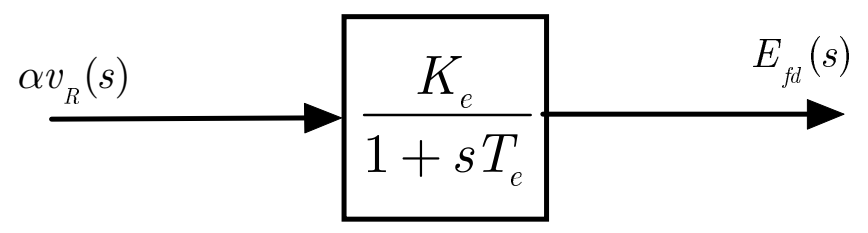

Fig. 3-11 A block diagram of a DC exciter.

Next, the exciter is transformed as the first order transfer function with an amplifier. In general, the $K_{A}$ (Amplifier Gain) can be chosen to make the error as small as possible. On the other hand, $K_{A}$ can be chosen as a large value, as long as the system is stable because if the amplifier gain were increased, the system would be unstable. The system can avoid this unstability by introducing the addition of the stabilization block of the excitation system with a first-order transfer function. An overall diagram for an excitation system with a simple synchronous machine model is shown in Fig. 3-12.

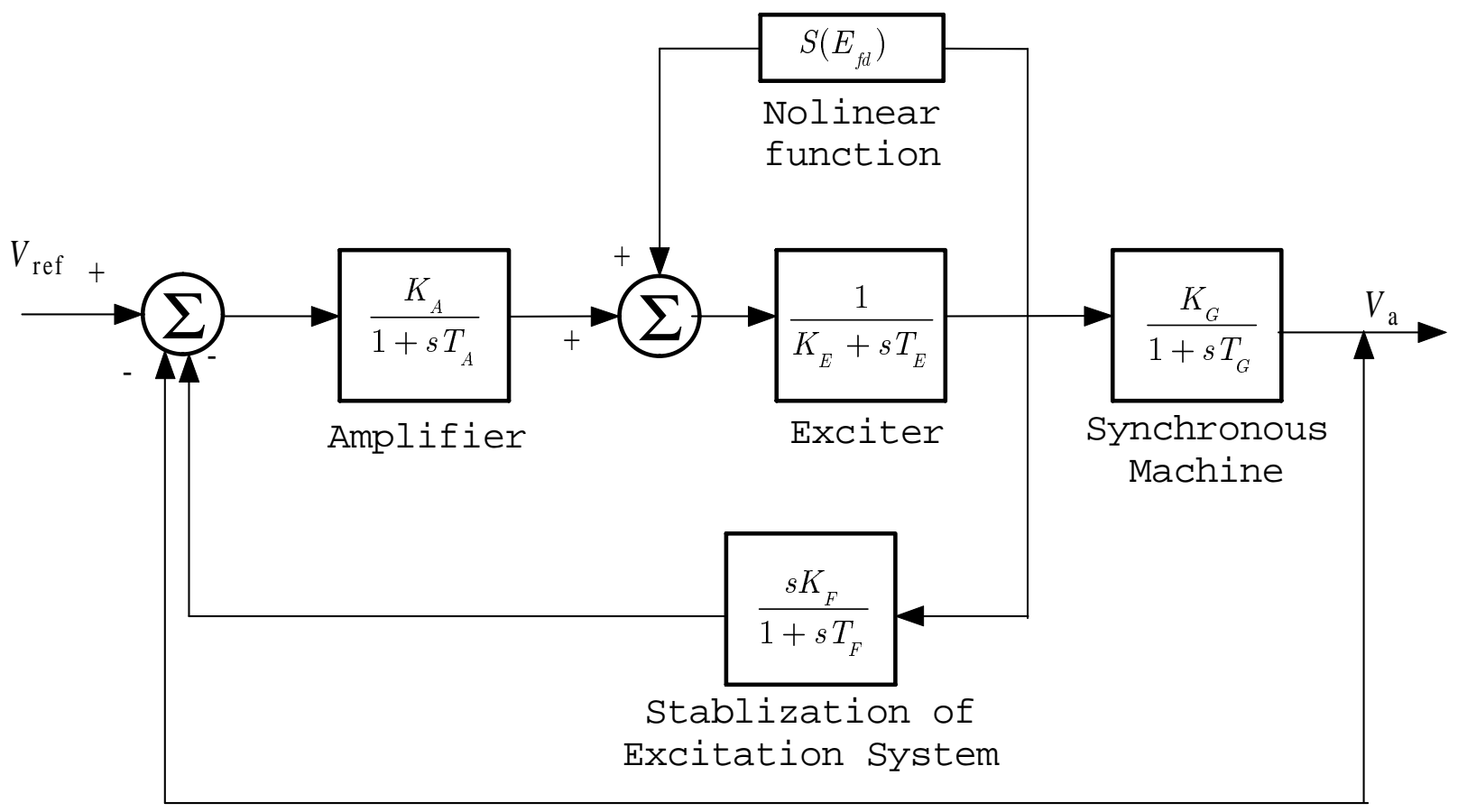

Fig. 3-12 An overall block diagram for a DC excitation system. 
Also, the time constants and gain constants must be defined as follows

$T_{A}=$ Time constant for an amplifier, typically from 0.01 to $10 \mathrm{sec}$

$K_{A}=$ Gain constant for an amplifier, typically from 1 to 250

$K_{G}=$ Gain constant for a synchronous machine

$T_{G}=$ Time constant for a synchronous machine

$K_{F}=$ Gain constant for a stabilization block

$T_{F}=$ Time constant for a stabilization block

Next, the implemented excitation system model using the MATLAB SIMULINK is shown in Fig. 3-13. All the parameters for gain constants and time constants are given below for the entire simulation.

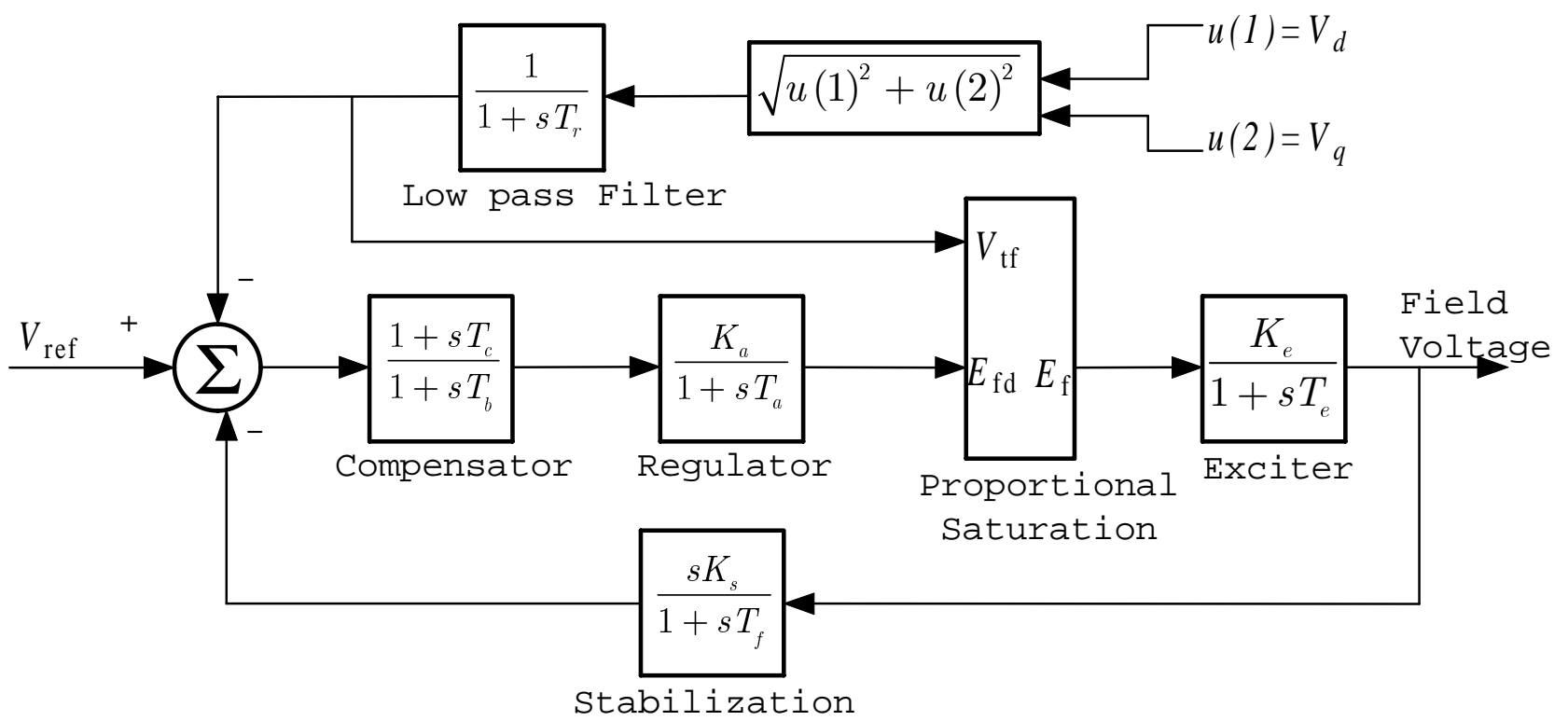

Fig. 3-13 A block diagram for implementing with MATLAB SIMULINK.

$T_{r}=$ Time constant for a Low Pass Filter, 0.02

$T_{c}=$ Time constant for Compensator, 0

$T_{b}=$ Time constant for Compensator, 0 
$K_{a}=$ Gain for Regulator, 300

$T_{a}=$ Time constant for a Regulator, 0.001

$T_{e}=$ Time constant for an Exciter, 0

$K_{e}=$ Gain for an Exciter, 0

$K_{f}=$ Time constant for a Stabilization, 0.01

$T_{f}=$ Time constant for a Stabilization, 0.1

This block diagram comes from the MATLAB POWER SYSTEM BLOCKSET example. The several new blocks that need to be explained are added (i.e., a positive sequence block, a low pass filter block, a lead and lag compensator block, and finally a proportional saturation block). The positive sequence and low pass filter produce the command signals from voltages coming from the synchronous machine $\mathrm{d}$ and $\mathrm{q}$ axis (Park's Transformation, later on explained). The proportional saturation block saturates the signals depending on $E_{f d}$ and $V_{t f}$ with a maximum or minimum value. The maximum and minimum values can be determined by an exciter system characteristic. During the entire simulation, the output from the proportional saturation block would be regulated as $\max =6.0$ and $\min =0$ for an excitation system. 


\subsection{Diesel Engine Dynamic Model}

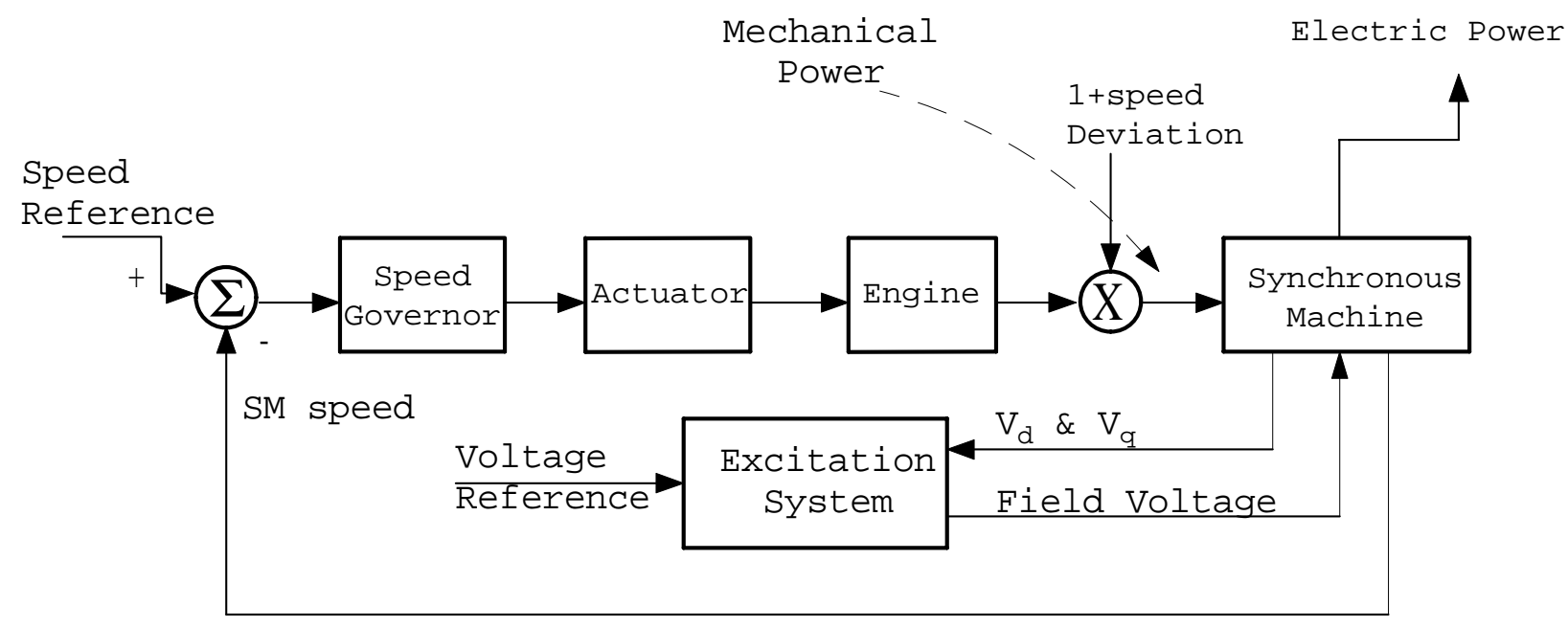

Fig. 3-14 A block diagram for the diesel engine.

The overall block diagram of the diesel engine with governor, actuator and synchronous machine is shown in Fig. 3-14. The differences between the desired speed and the synchronous machine speed or engine speed produce the control signal, causing a change in the torque of the prime mover. The diesel engine then produces the torque, driving the synchronous machine generating the electrical power output. The diesel engine generates the torque and the mechanical power would be given in the following equation as

$$
P_{m}=\omega \times T_{e}
$$

where

$$
\begin{aligned}
& P_{m}=\text { Mechanical Power (per unit) } \\
& \omega_{r}=\text { Rated Speed (per unit) } \\
& T_{e}=\text { Engine Torque (per unit) }
\end{aligned}
$$

Then the measured synchronous machine speed is fed back to compare with the reference signal to control the governor. The diesel engine model implemented by the MATLAB SIMULINK is shown in Fig. 3-15. 


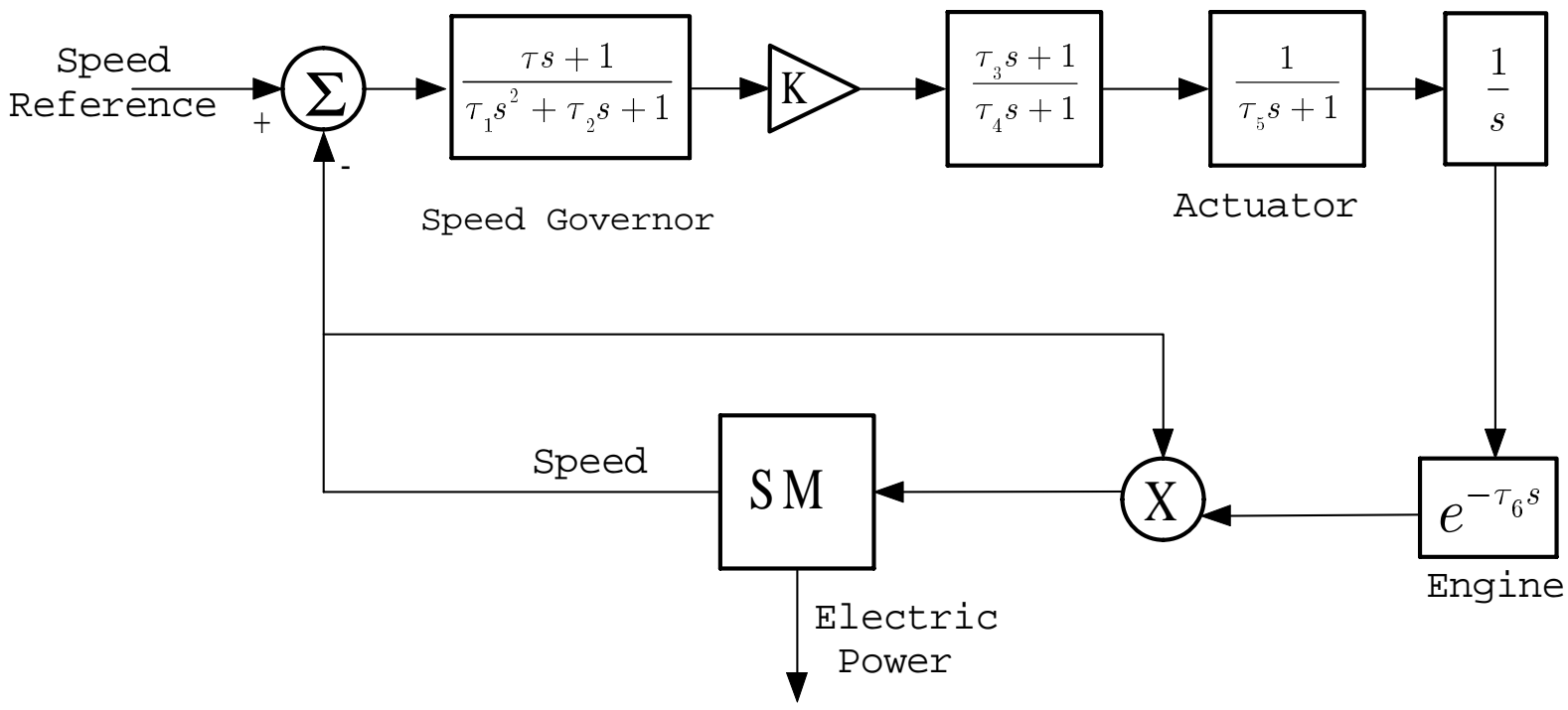

Fig. 3-15 An implemented diesel engine dynamic model.

The numerical values are given below

Time constant for a speed governor

$$
\begin{aligned}
& \tau=0.2(\mathrm{sec}) \\
& \tau_{1}=0.0002(\mathrm{sec}) \\
& \tau_{2}=0.01(\mathrm{sec})
\end{aligned}
$$

Time constant for an actuator

$$
\begin{aligned}
\tau_{3} & =0.25(\mathrm{sec}) \\
\tau_{4} & =0.009(\mathrm{sec}) \\
\tau_{5} & =0.0384(\mathrm{sec})
\end{aligned}
$$

Time delay for the diesel engine

$$
\tau_{6}=0.024(\mathrm{sec})
$$

Gain

$$
K=40
$$


The speed deviation produced by comparing reference and synchronous speed generates the command signal in the speed governor represented by the second order transfer function. This signal is scaled by a gain constant. The actuator is implemented by two block transfer functions, and finally the engine is represented by a simple time delay. Between the engine delay and the actuator, there is a possible limiter. The machine can't produce over its maximum output, so the mechanical power output is regulated by this limiter with a maximum $=1.1$ and minimum $=0$.

\subsection{Synchronous Machine Model}

\section{4-1 Simple model}

$$
\frac{2 H}{\omega_{b}} \frac{d}{d t}\left(\omega_{r}\right)=P_{T}-P_{e}-D \omega_{r}
$$

Where $\mathrm{H}$ is an inertia time constant for a synchronous machine

$$
\begin{aligned}
& \omega_{b}=\text { A rated speed for a synchronous machine } \\
& \omega_{r}=\text { A rotor speed for a synchronous machine } \\
& P_{T}=\text { A mechanical power input } \\
& P_{e}=\text { An electrical power } \\
& D=\text { A damping coefficient }
\end{aligned}
$$

In the simple model for a synchronous machine, $P_{e}$ and $P_{T}$ are assumed to be constant. All of the parameters are per unit systems. Applying the Laplace Transform to both sides of equation (3-10), equation becomes

$$
\begin{aligned}
& L\left(T_{p} \frac{d}{d t}\left(\omega_{r}\right)\right)=L\left(P_{T}-P_{e}-D \omega_{r}\right) \\
& \text { where } T_{p} \triangleq \frac{2 H}{\omega_{b}}
\end{aligned}
$$

However, the Laplace Transform is a linear operator so the equation (3-11) is arranged as 


$$
\begin{aligned}
& T_{p} s \omega_{r}(s)=P_{T}(s)-P_{e}(s)-D \omega(s) \\
& \left(D+s T_{p}\right) \omega_{r}(s)=P_{T}(s)-P_{e}(s) \\
& \therefore \omega_{r}(s)=\frac{1}{D+s T_{p}}\left(P_{T}(s)-P_{e}(s)\right)
\end{aligned}
$$

The simple synchronous machine block diagram is shown in Fig. 3-16 based on equation (3-12).

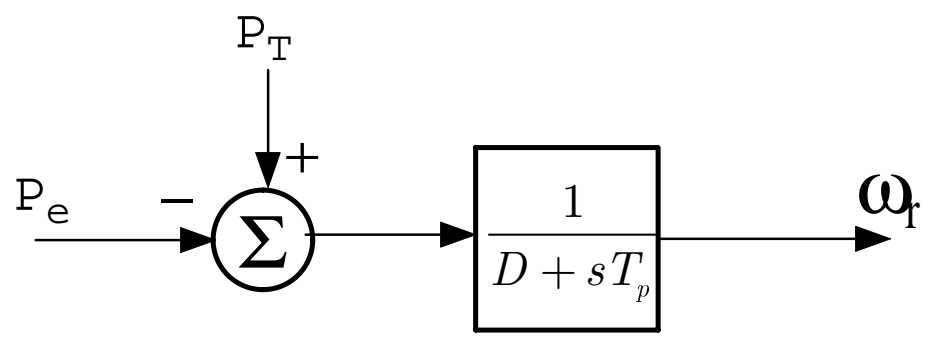

Fig. 3-16 A simple synchronous machine model

\section{4-2 Detailed Model}

The 3-phase salient-pole synchronous machine shown in Fig. 3-18 can predict the electrical and electromechanical behavior of most synchronous machine [3]. In general, the rotor of a synchronous machine has a field winding and one or more damper windings. Furthermore, all rotor windings have different electrical characteristics. In the model, there are one field winding, one damper winding on the d-axis, and two rotor damper windings on the q-axis. In the model, all of the rotor parameters are viewed from stator.

In Fig. 3-18 two-pole, 3-phase, wye-connected salient-pole synchronous machine is shown. Since the rotor of a salient-pole synchronous machine is magnetically unsymmetrical, there is no advantage in utilizing a change of variables for rotor variables the way there is for the induction machine. However, there is a benefit to utilizing a 
change of variables for the stator variables. In most cases, we can apply the rotor fixed reference frame for the stator variables, assuming that the stator windings are identical sinusoidal distributed windings. All rotor currents, voltages, resistances, and inductances are viewed from the stators.

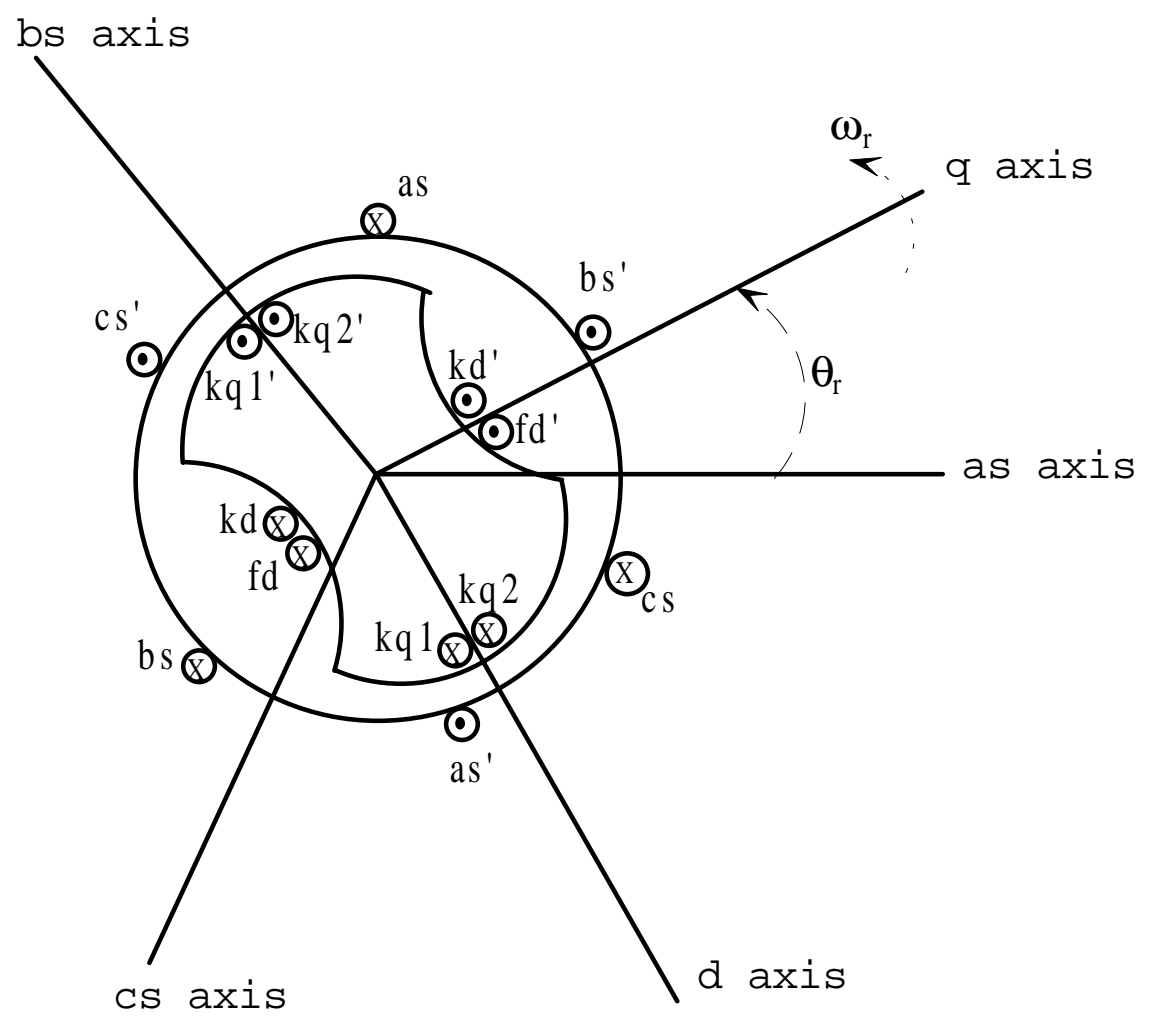

Fig. 3-18 A two-pole, 3-phase, wye-connected salient-pole synchronous machine.

Every subscript represents below

$$
\begin{aligned}
& r_{s}=\text { A stator resistance } \\
& N_{s}=\text { An equivalent turn } \\
& f d=\text { The field windings } \\
& k_{d} k_{q}=\text { The damper windings } \\
& a b c=\text { Phase A, Phase B, Phase C for real } \\
& q d 0=\mathrm{Q}, \mathrm{D}, \mathrm{O} \text { axis }
\end{aligned}
$$




$$
\begin{aligned}
& f=\text { Currents, voltages, and flux linkages } \\
& s=\text { A stator reference frame } \\
& p=\frac{d}{d t}
\end{aligned}
$$

In general, the voltage equations are given when inductance and resistance are included in the circuits.

$$
\begin{aligned}
& v_{a b c s}=-r_{s} i_{a b c s}+p \lambda_{a b c s} \\
& v_{q d r}=r_{r} i_{q d r}+p \lambda_{q d r} \\
& \left(f_{a b c s}\right)^{T}=\left[\begin{array}{lll}
f_{a s} & f_{b s} & f_{c s}
\end{array}\right] \\
& \text { where } \quad\left(f_{q d r}\right)^{T}=\left[\begin{array}{llll}
f_{k q 1} & f_{k q 2} & f_{f d} & f_{k d}
\end{array}\right] \\
& r_{s}=\left[\begin{array}{ccc}
r & 0 & 0 \\
0 & r & 0 \\
0 & 0 & r
\end{array}\right] \quad r_{r}=\left[\begin{array}{cccc}
r_{k q 1} & 0 & 0 & 0 \\
0 & r_{k q 2} & 0 & 0 \\
0 & 0 & r_{f d} & 0 \\
0 & 0 & 0 & r_{k d}
\end{array}\right]
\end{aligned}
$$

and the relationship between the currents and flux linkage is given in the matrix form as follows

$$
\left[\begin{array}{c}
\lambda_{a b c s} \\
\lambda_{q d r}
\end{array}\right]=\left[\begin{array}{cc}
L_{s} & L_{s r} \\
\left(L_{s r}\right)^{T} & L_{r}
\end{array}\right]\left[\begin{array}{c}
-i_{a b c s} \\
i_{q d r}
\end{array}\right]
$$

It is convenient to apply Park's transformation with a rotor fixed reference frame. If Park's transformation is applied to all of the voltage equations and flux linkage equations, the equations with time dependence become time independent equations. So, the inductance between the rotor damper windings or stator and damper windings is a constant matrix with Park's transformation on the rotor fixed reference frame. The Park's transformation matrix is given as follows 


$$
K_{s}=\frac{2}{3}\left[\begin{array}{ccc}
\cos (\theta) & \cos \left(\theta-\frac{2 \pi}{3}\right) & \cos \left(\theta+\frac{2 \pi}{3}\right) \\
\sin (\theta) & \sin \left(\theta-\frac{2 \pi}{3}\right) & \sin \left(\theta+\frac{2 \pi}{3}\right) \\
\frac{1}{2} & \frac{1}{2} & \frac{1}{2}
\end{array}\right]
$$

where

$$
\theta=\int_{0}^{t} \omega_{r}(\xi) d \xi+\theta(0)
$$

Next, applying Park's transformation,

$$
v_{q d 0 r}=K_{s} v_{a b c s}
$$

Other parameters, such as inductance, flux linkage, resistance, and currents can also be applied. The stator equation (3-13) and equation (3-14) become

$$
\begin{aligned}
& v_{q d 0 s}^{r}=-r_{s} i_{q d o s}^{r}+\omega_{r} \lambda_{d q s}^{r}+p \lambda_{q d o s}^{r} \\
& v_{q d r}^{r}=r_{r} i_{q d r}^{r}+p \lambda_{q d r}^{r} \\
& \text { where }\left(\lambda_{d q s}^{r}\right)^{T}=\left[\begin{array}{lll}
\lambda_{d s}^{r} & -\lambda_{q s}^{r} & 0
\end{array}\right]
\end{aligned}
$$

while the flux linkage and the current's equations become

$$
\left[\begin{array}{c}
\lambda_{q d 0 s}^{r} \\
\lambda_{q d r}^{r}
\end{array}\right]=\left[\begin{array}{cc}
K_{s}^{r} L_{s}\left(K_{s}^{r}\right)^{T} & K_{s}^{r} L_{s r} \\
\frac{2}{3} L_{s r}\left(K_{s}^{r}\right)^{-1} & L_{r}
\end{array}\right]\left[\begin{array}{c}
-i_{q d 0 s}^{r} \\
i_{q d r}^{r}
\end{array}\right]
$$

where

$$
\begin{aligned}
K_{s}^{r} L_{s}\left(K_{s}^{r}\right)^{-1} & =\left[\begin{array}{ccc}
L_{l s}+L_{m q} & 0 & 0 \\
0 & L_{l s}+L_{m d} & 0 \\
0 & 0 & L_{l s}
\end{array}\right] \\
K_{s}^{r} L_{s r} & =\left[\begin{array}{cccc}
L_{m q} & L_{m q} & 0 & 0 \\
0 & 0 & L_{m d} & L_{m d} \\
0 & 0 & 0 & 0
\end{array}\right]
\end{aligned}
$$




$$
\begin{array}{cc}
\frac{2}{3}\left(L_{s r}\right)^{T}\left(K_{s}^{r}\right)^{-1}= & {\left[\begin{array}{ccc}
L_{m q} & 0 & 0 \\
L_{m q} & 0 & 0 \\
0 & L_{m d} & 0 \\
0 & L_{m d} & 0
\end{array}\right]} \\
\text { where } \quad L_{m q} & =\frac{3}{2}\left(L_{A}-L_{B}\right) \\
L_{m d} & =\frac{3}{2}\left(L_{A}+L_{B}\right)
\end{array}
$$

Next, it is convenient to express the voltage and flux linkage equations in terms of reactance rather than inductance, so all equations are divided by a base frequency, $\omega_{b}$ We have below the detailed equation, (3-18) with rotor fixed reference frame. In the flux linkage equations, the negative sign of stator currents appear because the direction of the currents is defined as a generator action in the synchronous machine.

$$
\begin{aligned}
& v_{q s}^{r}=-r_{s} i_{q s}^{r}+\frac{\omega_{r}}{\omega_{b}} \psi_{d s}^{r}+\frac{p}{\omega_{b}} \psi_{q s}^{r} \\
& v_{d s}^{r}=-r_{s} i_{d s}^{r}-\frac{\omega_{r}}{\omega_{b}} \psi_{q s}^{r}+\frac{p}{\omega_{b}} \psi_{d s}^{r} \\
& v_{0 s}=-r_{s} i_{0 s} \frac{p}{\omega_{b}} \psi_{0 s} \\
& v_{k q 1}=r_{k q 1} i_{k q 1}+\frac{p}{\omega_{b}} \psi_{k q 1} \\
& v_{k q 2}=r_{k q 2} i_{k q 2}+\frac{p}{\omega_{b}} \psi_{k q 2} \\
& v_{f d}=r_{f d} i_{f d}+\frac{p}{\omega_{b}} \psi_{f d} \\
& v_{k d}=r_{k d} i_{k d}+\frac{p}{\omega_{b}} \psi_{k d}
\end{aligned}
$$


The flux linkages per second are

$$
\begin{aligned}
& \psi_{q s}^{r}=-X_{l s} i_{q s}^{r}+X_{m q}\left(-i_{q s}^{r}+i_{k q 1}+i_{k q 2}\right) \\
& \psi_{d s}^{r}=-X_{l s} i_{d s}^{r}+X_{m d}\left(-i_{d s}^{r}+i_{f d}+i_{k d}\right) \\
& \psi_{0 s}=-X_{l s} i_{0 s} \\
& \psi_{k q 1}=X_{l k q 1} i_{k q 1}+X_{m q}\left(-i_{q s}^{r}+i_{k q 1}+i_{k q 2}\right) \\
& \psi_{k q 2}=X_{l k q 2} i_{k q 2}+X_{m q}\left(-i_{q s}^{r}+i_{k q 1}+i_{k q 2}\right) \\
& \psi_{f d}=X_{l f d} i_{f d}+X_{m d}\left(-i_{d s}^{r}+i_{f d}+i_{k d}\right) \\
& \psi_{k d}=X_{l k d} i_{k d}+X_{m d}\left(-i_{d s}^{r}+i_{f d}+i_{k d}\right)
\end{aligned}
$$

From these two equations (3-18) and (3-19), the three-phase stator currents and flux linkages can be found. Next, both equations (3-18) and (3-19) have to be rearranged to the integration forms to find currents and flux linkages. The assumption that the damper windings are shorted is considered so that the voltages on them are zero. The equations for simulation are given as follows

$$
\begin{aligned}
& \psi_{q s}^{r}=\omega_{b} \int\left(v_{q s}-\frac{\omega_{r}}{\omega_{b}} \psi_{d s}^{r}+\frac{r_{s}}{X_{l s}}\left(\psi_{m q}-\psi_{q s}^{r}\right)\right) d t \\
& \psi_{d s}^{r}=\omega_{b} \int\left(v_{d s}-\frac{\omega_{r}}{\omega_{b}} \psi_{q s}^{r}+\frac{r_{s}}{X_{l s}}\left(\psi_{m d}-\psi_{d s}^{r}\right)\right) d t \\
& \psi_{0 s}=\omega_{b} \int\left(v_{0 s}-\frac{r_{s}}{X_{l s}} \psi_{0 s}\right) d t
\end{aligned}
$$

From the equations (3-20), the stator flux linkages can be found. On the other hand, the rotor flux linkages and voltages could be related by equation (3-21). Furthermore, the currents also are decided from flux linkages by using equations (3-22). 


$$
\begin{aligned}
& \psi_{k q 1}=\omega_{b} \int\left(v_{k q 1}+\frac{r_{k q 1}}{X_{l k q 1}}\left(\psi_{m q}-\psi_{k q 1}\right)\right) d t \\
& \psi_{k q 2}=\omega_{b} \int\left(v_{k q 2}+\frac{r_{k q 2}}{X_{l k q 2}}\left(\psi_{m q}-\psi_{k q 2}\right)\right) d t \\
& \psi_{f d}=\omega_{b} \int\left(\frac{r_{f d}}{X_{m d}} E_{x f d}+\frac{r_{f d}}{X_{l f d}}\left(\psi_{m d}-\psi_{f d}\right)\right) d t \\
& \psi_{k d}=\omega_{b} \int\left(v_{k d}+\frac{r_{k d l}}{X_{l k d}}\left(\psi_{m d}-\psi_{k d d}\right)\right) d t \\
& i_{q s}^{r}=-\frac{1}{X_{l s}}\left(\psi_{q s}^{r}-\psi_{m q}\right) \\
& i_{d s}^{r}=-\frac{1}{X_{l s}}\left(\psi_{d s}^{r}-\psi_{m d}\right) \\
& i_{0 s}=-\frac{1}{X_{l s}} \psi_{0 s} \\
& i_{k q 1}=-\frac{1}{X_{l k q 1}}\left(\psi_{k q 1}-\psi_{m q}\right) \\
& i_{k q 2}=-\frac{1}{X_{l k q 2}}\left(\psi_{k q 2}-\psi_{m q}\right) \\
& i_{f d}=-\frac{1}{X_{l f d}}\left(\psi_{f d}-\psi_{m d}\right) \\
& i_{k d}=-\frac{1}{X_{l k d}}\left(\psi_{k d}-\psi_{m d}\right)
\end{aligned}
$$

where

$$
\begin{aligned}
& \psi_{m q}=X_{a q}\left(\frac{\psi_{q s}^{r}}{X_{l s}}+\frac{\psi_{k q 1}}{X_{l k q 1}}+\frac{\psi_{k q 2}}{X_{l k q 2}}\right) \\
& \psi_{m d}=X_{a d}\left(\frac{\psi_{d s}^{r}}{X_{l s}}+\frac{\psi_{f d}}{X_{l f d}}+\frac{\psi_{k d}}{X_{l k d}}\right)
\end{aligned}
$$


In equation (3-23), the reactive constant is given by

$$
\begin{aligned}
& X_{a q}=\left(\frac{1}{X_{m q}}+\frac{1}{X_{l s}}+\frac{1}{X_{l k q 1}}+\frac{1}{X_{l k q 2}}\right)^{-1} \\
& X_{a d}=\left(\frac{1}{X_{m d}}+\frac{1}{X_{l s}}+\frac{1}{X_{l f d}}+\frac{1}{X_{l k d}}\right)^{-1}
\end{aligned}
$$

Next, the speed of the synchronous machine can be found by using follow equation,

$$
\omega_{r}=-\frac{\omega_{b}}{2 H} \int\left(T_{e}-T_{I}\right) d t
$$

\section{4-3 Per Unitize the System}

The expressions of the electromagnetic torque in rotor reference frame variables can be obtained by applying the transformation to energy stored equations [3]. The torque equation is given below

$$
T_{e}=\left(\frac{3}{2}\right)\left(\frac{P}{2}\right)\left(\frac{1}{\omega_{b}}\right)\left(\psi_{d s}^{r} i_{q s}^{r}-\psi_{q s}^{r} i_{d s}^{r}\right)
$$

If this is to be a per unit system, the base torque is expressed by

$$
T_{B}=\frac{P_{B}}{(2 / P) \omega_{b}}=\frac{(3 / 2) V_{B(q d 0)} I_{B(q d 0)}}{(2 / P) \omega_{b}}
$$

Next, we can find the per unit electromagnetic torque by dividing equation (3-25) by (326)

$$
\begin{aligned}
T_{e}(p u) & =\frac{T_{e}}{T_{B}} \\
& =\frac{(3 / 2)(P / 2)\left(1 / \omega_{b}\right)\left(\psi_{d s}^{r} i_{q s}^{r}-\psi_{q s}^{r} i_{d s}^{r}\right)}{\frac{(3 / 2) V_{B(q d 0)} I_{B(q d 0)}}{(2 / P) \omega_{b}}}
\end{aligned}
$$


Therefore, in the per unit system the torque equation becomes

$$
T_{e}(p u)=\psi_{d s}^{r} i_{q s}^{r}-\psi_{q s}^{r} i_{d s}^{r}
$$

Next, we have to relate the torque equation and rotor speed equation. This relationship is given by

$$
\begin{aligned}
& T_{e}=-J\left(\frac{2}{P}\right) p \omega_{r}+T_{I} \\
& \text { where } \begin{aligned}
J & =\text { The inertia of machine }\left(\mathrm{kg} \cdot \mathrm{m}^{2}\right) \\
\omega_{r} & =\text { The rotor speed (per unit) } \\
T_{I} & =\text { Input Torque (Mechanical Torque) } \\
P & =\text { Number of poles for Synchronous Machine }
\end{aligned}
\end{aligned}
$$

Since we can define the inertia constant $\mathrm{H}$ (sec) as

$$
H=\left(\frac{1}{2}\right)\left(\frac{P}{2}\right) \frac{J \omega_{b}}{T_{B}}=\left(\frac{1}{2}\right)\left(\frac{2}{P}\right)^{2} \frac{J \omega_{b}^{2}}{P_{B}}
$$

if this value is considered, then the torque equation becomes

$$
T_{e}=-2 H p \frac{\omega_{r}}{\omega_{b}}+T_{I}
$$

with rearranging this equation, the following equation can be found

$$
\omega_{r}=-\frac{\omega_{b}}{2 H} \int\left(T_{e}-T_{I}\right) d t
$$

The equivalent circuits of the synchronous machine can be shown in Fig. 3-19. 

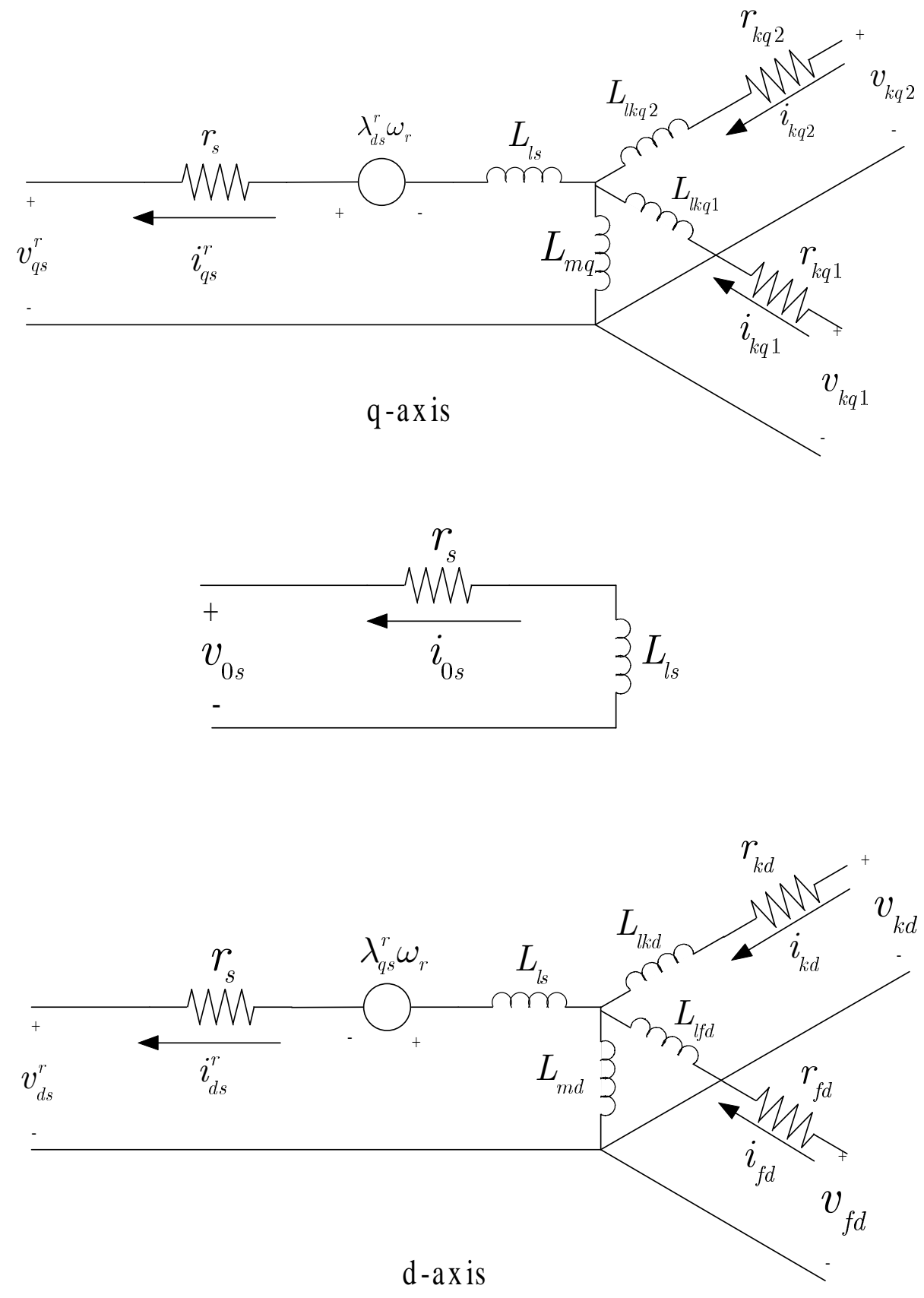

Fig. 3-19 An equivalent circuit of a synchronous machine. 


\subsection{Fuel Cell and inverter system}

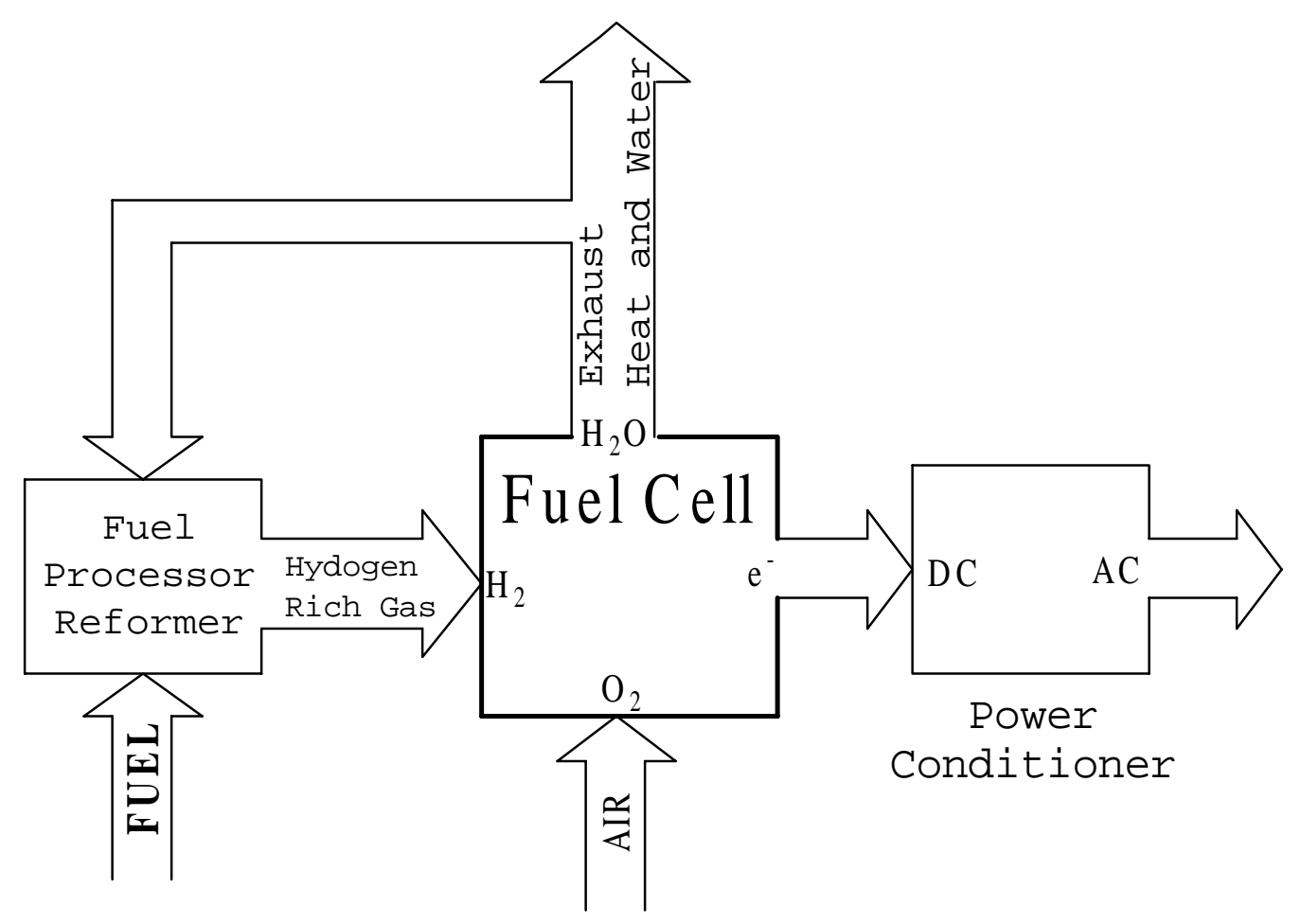

Fig. 3-20 A diagram for a fuel cell and inverter.

A fuel cell generation produces the DC power from natural gas or other practical fuels. Once again, the fuel cells generator produces clean electrical energy and generates less pollution. The number of commercially available generators are few, but the cost of fuel cells such as the molten carbonate fuel cell (MCFC), the proton exchange membrane fuel cell (PEMFC), and the solid oxide fuel cell (SOFC) is starting to decline. It is more efficient if fuel cell power generation and traditional power generation are combined. The fuel cells, however, generate the DC, so the utilities need to convert DC to AC for the power grid system. A fuel cell generator is assumed to produce ideal DC power. However, the currents of the DC source will be examined, so the fuel cell DC source can withstand the surge current. First, DC power is converted to AC power using electronic devices. 


\section{5-1 A simple Inverter Operation}

The basic operation can be understood with a simple one-phase inverter diagram, as shown in Fig. 3-21. The characteristic waveforms with these circuits are shown in Fig. 3-22. The ideal diode is turned off when the voltage is reversed biased and it is turned on when the voltage is forward biased. On the other hand, the transistors will operate as an ideal switch, depending on the base current. If the base current is flowing at more than a threshold current, the transistor will be on in the manner in which an ideal switch is on. On the contrary, the transistors are in an off state if the base current is less than the threshold current. The output voltages are alternative depending on a time period. Until a half of the time period, the transistor $Q_{1}$ will be on and $Q_{2}$ will be off, while the output voltage across the resistance will be half of the DC voltage. During the rest of the time period, the transistor $Q_{2}$ will be on and the transistor $Q_{1}$ will be off, so the output voltage will be the negative half of the DC voltage.

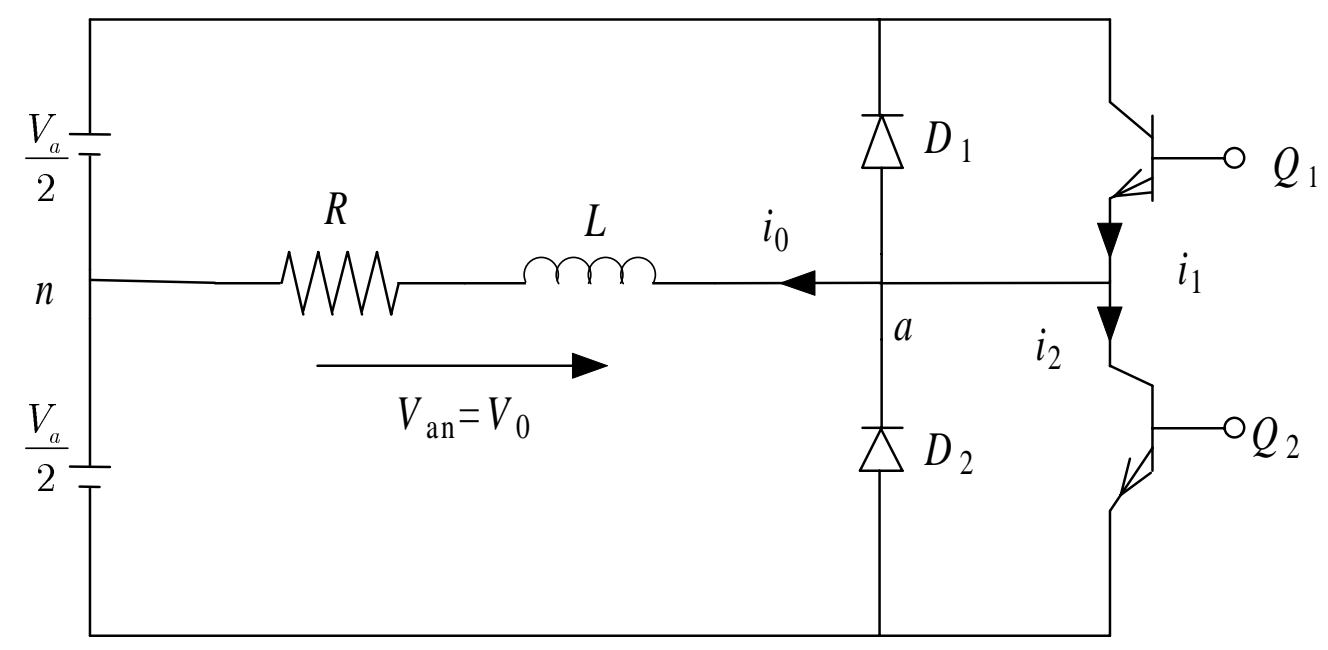

Fig. 3-21 A simple inverter circuit with resistance and inductance. 

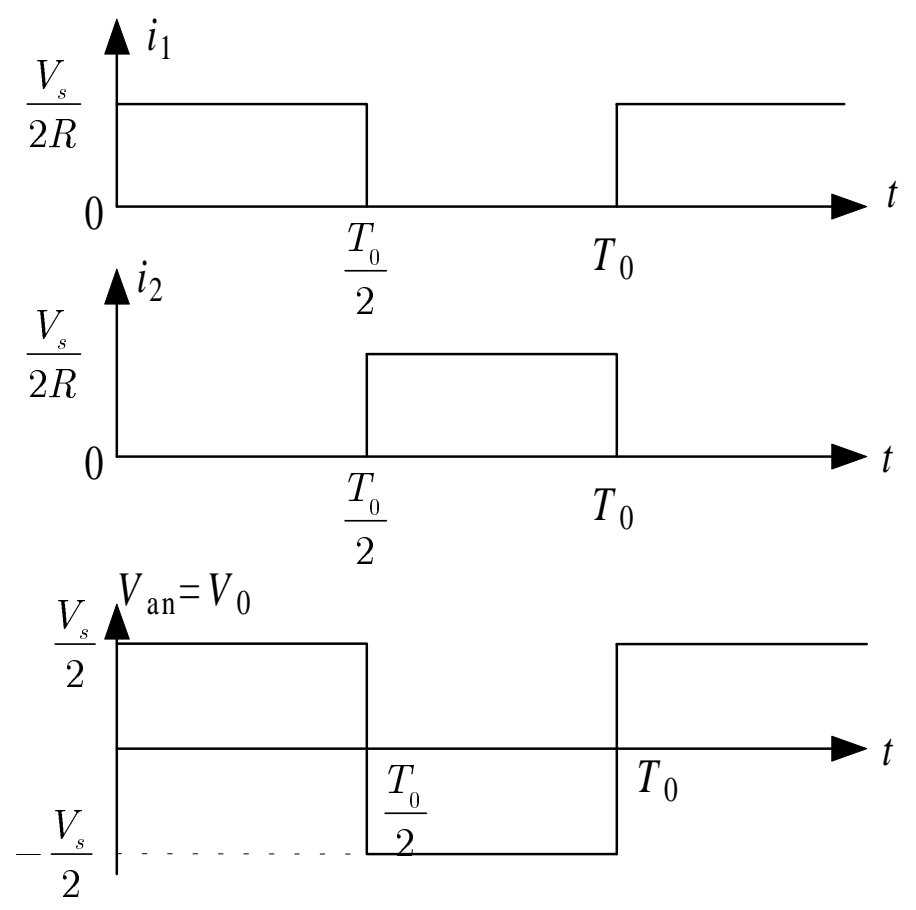

Fig. 3-22 Waveforms with resistive load.

Furthermore, if the inductive load is applied on a single inverter system, the currents can't change instantly with the output voltage. Even though the transistor $Q_{1}$ is turned off at $t=T_{0} / 2$, the load current keeps flowing through the diode $D_{2}$ and the lower half of the dc source until the current falls to zero. Similarly, when the transistor, $Q_{2}$ is turned off at $t=T_{0}$, the current flows through diode $D_{1}$ until it reaches the upper half of the dc source. The current waveforms with inductive load are shown in Fig. 3-23. 


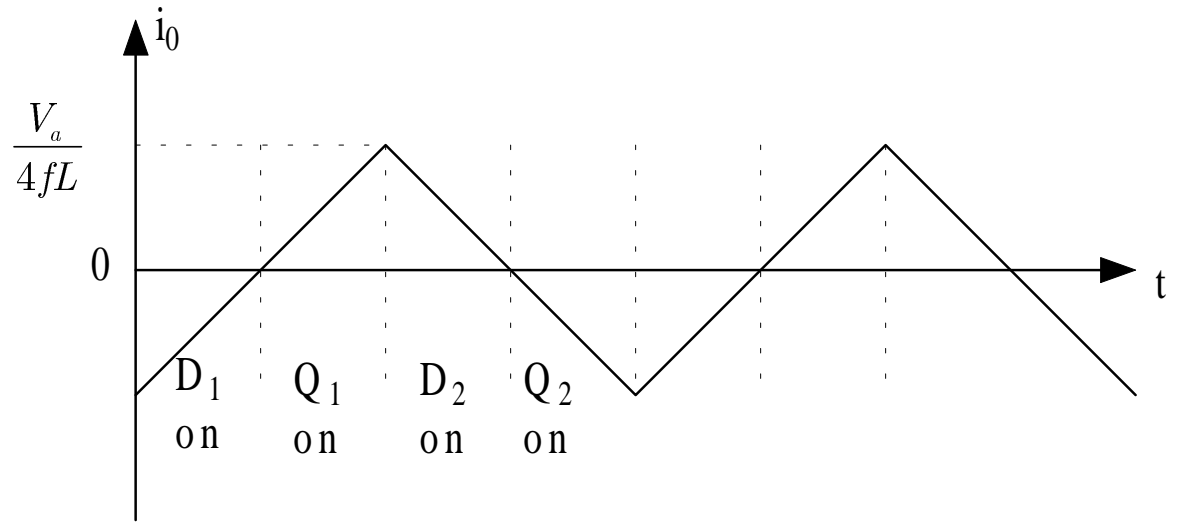

Fig. 3-23 Waveform with inductive load.

Now, the rms voltage output can be found from

$$
V_{0}=\left(\frac{2}{T_{0}} \int_{0}^{T_{0} / 2} \frac{V_{s}^{2}}{4} d t\right)^{1 / 2}=\frac{V_{s}}{2}
$$

If using the Fourier series to represent the instantaneous output voltage, the expressions for voltages would be,

$$
\begin{array}{r}
v_{0}=\sum_{n=1,3,5, \ldots}^{\infty} \frac{2 V_{s}}{n \pi} \sin n \omega t \\
=0 \quad \text { for } n=2,4, \ldots \\
\text { Where, } \omega=2 \pi f_{0}
\end{array}
$$

\section{5-2 Performance Parameters}

1. Harmonic factor, HF

$$
H F_{n}=\frac{V_{n}}{V_{1}}
$$

Where $V_{1}$ is the rms value of the fundamental component and $V_{n}$ is the rms value of the nth harmonic component.

2. Total harmonic distortion, THD 
$T H D=\frac{1}{V_{1}}\left(\sum_{n=2,3 \ldots}^{\infty} V_{n}^{2}\right)^{1 / 2}$

THD represents how close the shape between a waveform and its fundamental component is.

3. Distortion Factor, DF

The DF is a measure of the effectiveness of a second-order load filter and is given as

$$
D F=\frac{1}{V_{1}}\left[\sum_{n=2,3 \ldots}^{\infty}\left(\frac{V_{n}}{n^{2}}\right)^{2}\right]^{1 / 2}
$$

For the individual harmonic component, DF is

$$
D F_{n}=\frac{V_{n}}{V_{1} n^{2}}
$$

\section{5-3 Three-phase Inverters}

The simple 6-pulse, voltage-source inverter with phases A and B are short-

circuited at time $t=t_{1}=\frac{2 \pi}{6 \omega}$ as shown in the diagram, Fig. 3-24. The circuit includes the simple load impedance for phase $\mathrm{A}, \mathrm{B}$ and $\mathrm{C}, Z_{\mathrm{a}}, Z_{\mathrm{b}}, Z_{\mathrm{c}}$, respectively. The currents flowing to the load and the DC source are indicated. The DC voltage sources can be either controlled rectifiers or the dc generations, such as a battery, a fuel cell, or a solar cell. The switches are replaced by the transistors, MOSFET, or devices that can operate like an ideal switch. This system uses self-commutated switches $S_{1}$ to $S_{6}$ to produce the variable-frequency, while the amplitude of voltage is fixed. So, the circuit needs a controllable direct-voltage source to provide the variable alternating-voltage output with constraints as follows

$$
\frac{E}{f}=4.44 \cdot N \cdot A \cdot B_{\max }=\text { const. }
$$

Where $\mathrm{E}$ is the $\mathrm{AC}$ induced voltage

$$
\mathrm{f}=\text { the frequency of the applied voltages or currents }
$$


To protect and maintain the machine with the normal operating point, the $B_{\max }$ will have the limit

$$
0.3 B_{\text {maxrated }} \leq B_{\max } \leq 1.1 B_{\text {maxrated }}
$$

Where, $B_{\text {maxrated }}=$ rated flux density of the machine

The load is Y connected, the equivalent circuits can be represented by three modes such as mode 1 for $0 \leq \omega t<\pi / 3$, mode 2 for $\pi / 3 \leq \omega t<2 \pi / 3$, and mode 3 for $2 \pi / 3 \leq \omega t<\pi$

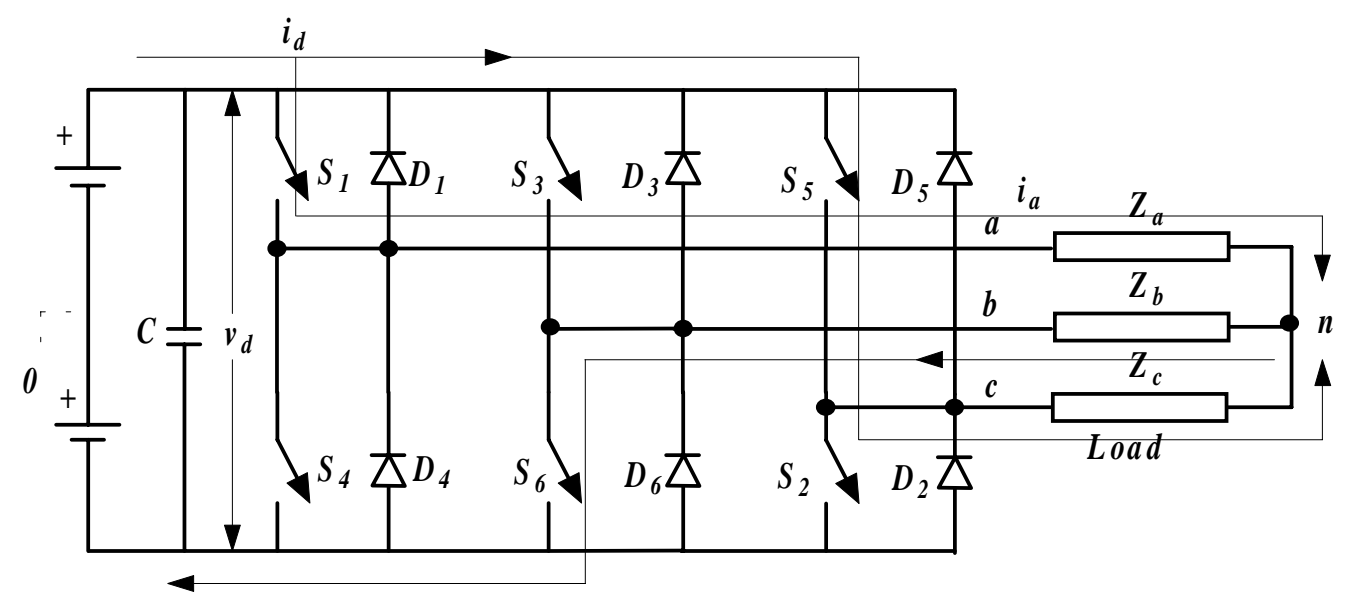

Fig. 3-24 A simple voltage source inverter with a and b are short-circuited.

The equivalent circuits for three modes are shown in Fig. 3-25. Now the voltages are found for each phase by using the three different modes as following,

During mode 1 for $0 \leq \omega t<\pi / 3$,

$$
\begin{aligned}
& R_{e q}=R+\frac{R}{2}=\frac{3 R}{2} \\
& i_{1}=\frac{V_{s}}{R_{e q}}=\frac{2 V_{s}}{3 R} \\
& v_{a n}=v_{c n}=\frac{i_{1} R}{2}=\frac{V_{s}}{3} \\
& v_{b n}=-i_{1} R=\frac{-2 V_{s}}{3}
\end{aligned}
$$




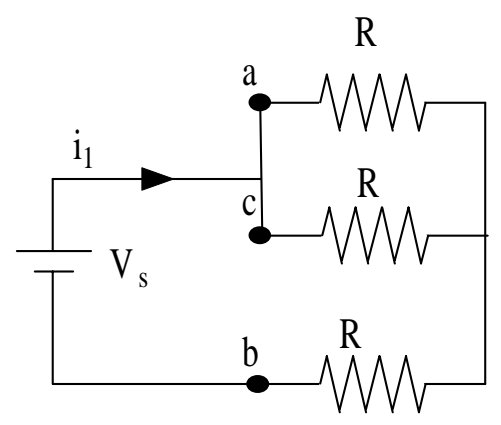

Mode 1
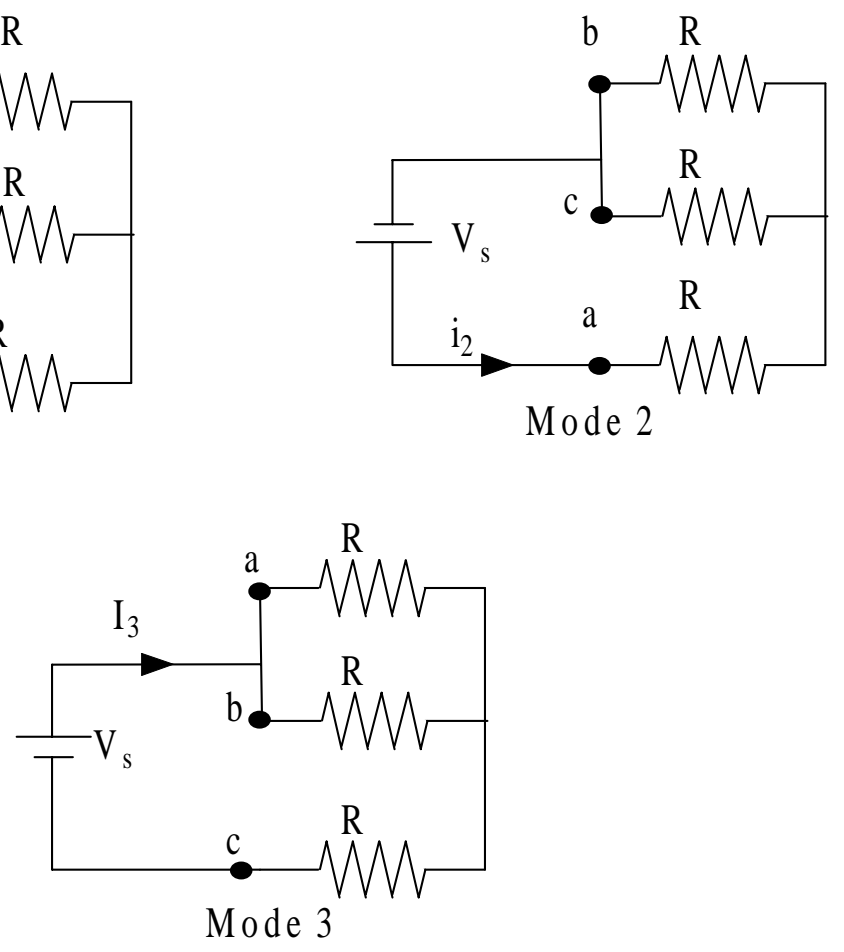

Fig. 3-25 Load equivalent circuits for modes.

During mode 2 for $\pi / 3 \leq \omega t<2 \pi / 3$,

$$
\begin{aligned}
& R_{e q}=R+\frac{R}{2}=\frac{3 R}{2} \\
& i_{2}=\frac{V_{s}}{R_{e q}}=\frac{2 V_{s}}{3 R} \\
& v_{a n}=i_{2} R=\frac{2 V_{s}}{3} \\
& v_{b n}=v_{c n}=\frac{-i_{2} R}{2}=\frac{-V_{s}}{3}
\end{aligned}
$$

During mode 3 for $2 \pi / 3 \leq \omega t<\pi$, 


$$
\begin{aligned}
& R_{e q}=R+\frac{R}{2}=\frac{3 R}{2} \\
& i_{3}=\frac{V_{s}}{R_{e q}}=\frac{2 V_{s}}{3 R} \\
& v_{a n}=v_{b n}=\frac{i_{3} R}{2}=\frac{V_{s}}{3} \\
& v_{c n}=-i_{3} R=\frac{-2 V_{s}}{3}
\end{aligned}
$$

The voltage waveforms constructed by depending on the controllable alternative voltage sources are shown in Fig. 3-25. In Fig. 3-25, only phase A is shown, but the other two phases are also constructed according to the same operating scheme. If the Fourier series were applied to this waveform, the instantaneous line-to-line voltage can be found as follows,

$$
v_{a b}=\sum_{n=1,3,5, \ldots}^{\infty} \frac{4 V_{s}}{n \pi} \cos \frac{n \pi}{6} \sin n\left(\omega t+\frac{\pi}{6}\right)
$$

The $v_{b c}$ and $v_{c a}$ can be found from Eq. (2-64) by phase shifting $v_{a b}$ by $120^{\circ}$ and $240^{\circ}$

$$
\begin{aligned}
& v_{a b}=\sum_{n=1,3,5, \ldots}^{\infty} \frac{4 V_{s}}{n \pi} \cos \frac{n \pi}{6} \sin n\left(\omega t-\frac{\pi}{2}\right) \\
& v_{a b}=\sum_{n=1,3,5, \ldots}^{\infty} \frac{4 V_{s}}{n \pi} \cos \frac{n \pi}{6} \sin n\left(\omega t-\frac{7 \pi}{6}\right)
\end{aligned}
$$

and the line-to-line rms voltage can be found from

$$
V_{L}=\left[\frac{2}{2 \pi} \int_{0}^{2 \pi / 3} V_{s}^{2} d(\omega t)\right]^{1 / 2}=\sqrt{\frac{2}{3}} V_{s}=0.8165 V_{s}
$$




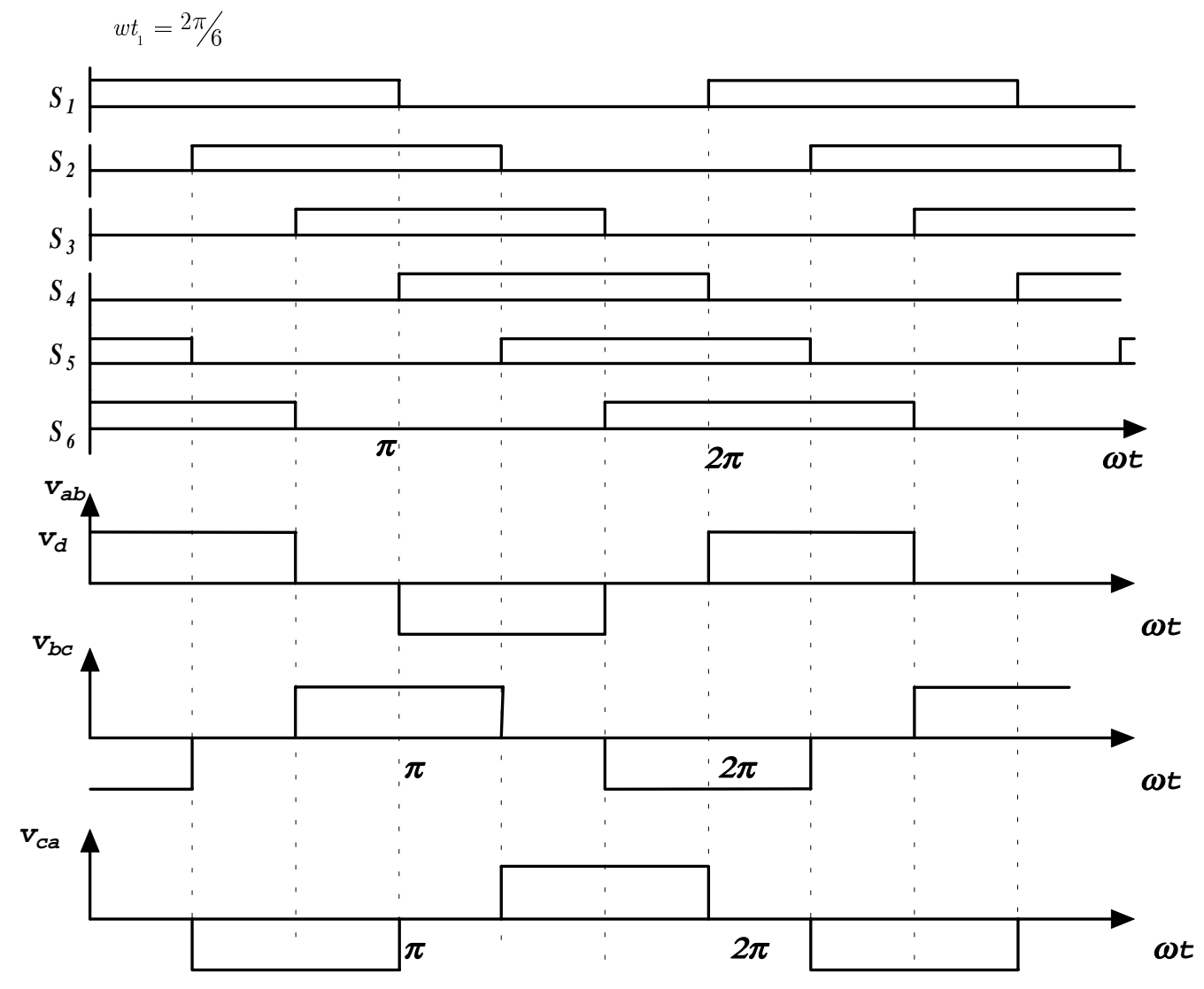

Fig. 3-26 The waveforms for the inverter. 


\section{Chapter four}

\section{SIMULATION SCHEME}

\subsection{The Simulation of Synchronous Machine with an Infinite Bus}

To develop the terminal voltages on the computer simulation, the line current needs to be differentiated without a load at the terminals of the generator. The terminal voltages may be developed, if we add a small resistive load. If the resistance is large, the approximate differentiation may be achieved. The overall diagram for one synchronous machine and an infinite bus system is shown in Fig. 4-1.

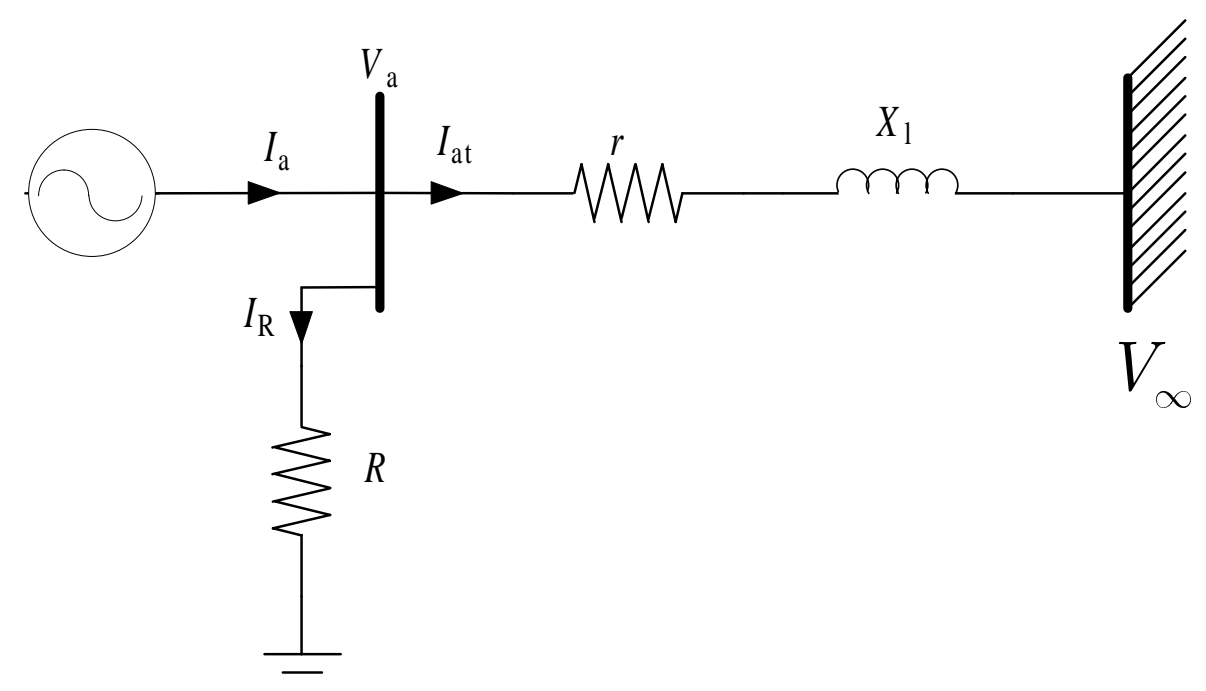

Fig. 4-1 A synchronous machine and an infinite bus system.

This figure shows only Phase A, but same scheme can be applied for the other two phases. The voltages and currents are delayed by 120 and by 240 degree for phase B and phase $\mathrm{C}$, respectively. For the machine variables, the voltages can be found by using the following equation, 


$$
V_{a b c}=R\left(I_{a b c}-I_{a b c t}\right)
$$

where,

$$
\begin{aligned}
& V_{a b c}=\left[\begin{array}{lll}
V_{a} & V_{b} & V_{c}
\end{array}\right]^{T} \\
& I_{a b c}=\left[\begin{array}{lll}
I_{a} & I_{b} & I_{c}
\end{array}\right]^{T} \\
& I_{a b c t}=\left[\begin{array}{lll}
I_{a t} & I_{b t} & I_{c t}
\end{array}\right]^{T}
\end{aligned}
$$

$V_{a b c}=$ The three-phase terminal voltages for a synchronous machine

$I_{a b c}=$ The three-phase terminal currents for a synchronous machine

$I_{a b c t}=$ The three-phase currents for a transmission line

By applying the Park's transformation with rotor fixed reference frame, the following equation is obtained

$$
P V_{a b c}=R\left(P I_{a b c}-P I_{a b c t}\right)
$$

and from definition of $\mathrm{d}$ and $\mathrm{q}$ axis parameters

$$
V_{q d 0}=R\left(I_{q d 0}-I_{q d 0 t}\right)
$$

However, in the case of balanced voltage sources, the zero sequence voltage and current are zero, so the terminal voltage can be expressed with the $\mathrm{d}$ and $\mathrm{q}$ axis,

$$
\begin{aligned}
& V_{q}=R\left(I_{q}-I_{q t}\right) \\
& V_{d}=R\left(I_{d}-I_{d t}\right)
\end{aligned}
$$

The transmission line also needs to be transformed with Park's transformation with rotor fixed reference frame. The voltage equation for the transmission line is given by

$$
V_{a b c}=r I_{a b c t}+\frac{X_{l}}{\omega_{b}} \frac{d}{d t} I_{a b c t}+V_{a b c \infty}
$$

where,

$$
V_{a b c \infty}=\text { The infinite bus voltage }
$$

As one has seen before, one knows the relationship between $a b c$ phase quantities and $q d 0$ quantities, 


$$
\begin{aligned}
& P V_{a b c}=V_{q d 0} \\
& P I_{a b c t}=I_{q d 0 t} \\
& P V_{a b c \infty}=V_{q d 0 \infty}
\end{aligned}
$$

and assumption that the Infinite bus voltages are unity and balanced is given. That is

$$
V_{a b c \infty}=V_{\infty}\left[\begin{array}{c}
\cos \alpha \\
\cos (\alpha-2 \pi / 3) \\
\cos (\alpha+2 \pi / 3)
\end{array}\right]
$$

where,

$$
\alpha=\int_{0}^{t} \omega_{e} d \xi+\alpha_{0}
$$

If Park's transformation is applied to these infinite bus voltages,

$$
P V_{a b c \infty}=V_{\infty} \frac{2}{3}\left[\begin{array}{ccc}
\cos \theta & \cos (\theta-2 \pi / 3) & \cos (\theta+2 \pi / 3) \\
\sin \theta & \sin (\theta-2 \pi / 3) & \sin (\theta+2 \pi / 3) \\
\frac{1}{2} & \frac{1}{2} & \frac{1}{2}
\end{array}\right]\left[\begin{array}{c}
\cos \alpha \\
\cos (\alpha-2 \pi / 3) \\
\cos (\alpha+2 \pi / 3)
\end{array}\right]
$$

where,

$$
\theta=\int_{0}^{t} \omega_{r}(\xi) d \xi+\theta_{0}
$$

with a little algebra for equation (4-8), the voltage equations become

$$
V_{q d 0 \infty}=V_{\infty}\left[\begin{array}{c}
\cos (\theta-\alpha) \\
\sin (\theta-\alpha) \\
0
\end{array}\right]
$$

Therefore, the $\mathrm{d}$ and $\mathrm{q}$ components can be expressed as follows

$$
\begin{aligned}
& V_{q \infty}=V_{\infty} \cos (\theta-\alpha) \\
& V_{d \infty}=V_{\infty} \sin (\theta-\alpha)
\end{aligned}
$$

Now, let the $\theta_{0}=\delta$ and $\alpha_{0}=0$, then

$$
\begin{aligned}
& V_{q \infty}=V_{\infty} \cos \delta \\
& V_{d \infty}=V_{\infty} \sin \delta
\end{aligned}
$$


The rest of the terms for the voltage equations are also derived by applying Park's transformation, let us consider the current term.

$$
\frac{d}{d t} P^{-1} I_{q d 0 t}=\left(\frac{d}{d t} P^{-1}\right) I_{q d 0 t}+P^{-1} \frac{d}{d t} I_{q d 0 t}
$$

Then the voltage equation becomes

$$
\begin{aligned}
V_{q d 0} & =r I_{q d 0 t}+P \frac{X_{l}}{\omega_{b}}\left(\frac{d}{d t} P^{-1}\right) I_{q d 0 t} \frac{X_{l}}{\omega_{b}} P P^{-1} \frac{d}{d t} I_{q d 0 t}+V_{q d 0 \infty} \\
& =r I_{q d 0 t}+P \frac{X_{l}}{\omega_{b}}\left(\frac{d}{d t} P^{-1}\right) I_{q d 0 t} \frac{X_{l}}{\omega_{b}} \frac{d}{d t} I_{q d 0 t}+V_{q d 0 \infty}
\end{aligned}
$$

However, the relationship is

$$
P \frac{d}{d t} P^{-1} I_{q d 0 t}=\left[\begin{array}{c}
\omega I_{d t} \\
-\omega I_{q t} \\
0
\end{array}\right]
$$

If this result in equation (4-13) is used, the transmission line voltage equations can be found for the $\mathrm{d}$ and $\mathrm{q}$ axes using rotor fixed reference frame as follows

$$
\begin{aligned}
& V_{q}=r I_{q t}+\frac{X_{l}}{\omega_{b}} \omega I_{d t}+\frac{X_{l}}{\omega_{b}} \frac{d}{d t} I_{q t}+V_{\infty} \cos \delta \\
& V_{d}=r I_{d t}-\frac{X_{l}}{\omega_{b}} \omega I_{q t}+\frac{X_{l}}{\omega_{b}} \frac{d}{d t} I_{d t}+V_{\infty} \sin \delta
\end{aligned}
$$

If the only steady state conditions are considered, the speed is equal to the base frequency, which is,

$$
\omega_{b}=\omega
$$

Rearranging equation (4-15), the currents $I_{q t}$ and $I_{d t}$ can be decided as follows

$$
\begin{aligned}
& I_{q t}=\frac{\omega_{b}}{X_{l}} \int\left(V_{q}-V_{q \infty}-r I_{q t}-X_{l} I_{d t}\right) d t \\
& I_{d t}=\frac{\omega_{b}}{X_{l}} \int\left(V_{d}-V_{d \infty}-r I_{d t}+X_{l} I_{q t}\right) d t
\end{aligned}
$$




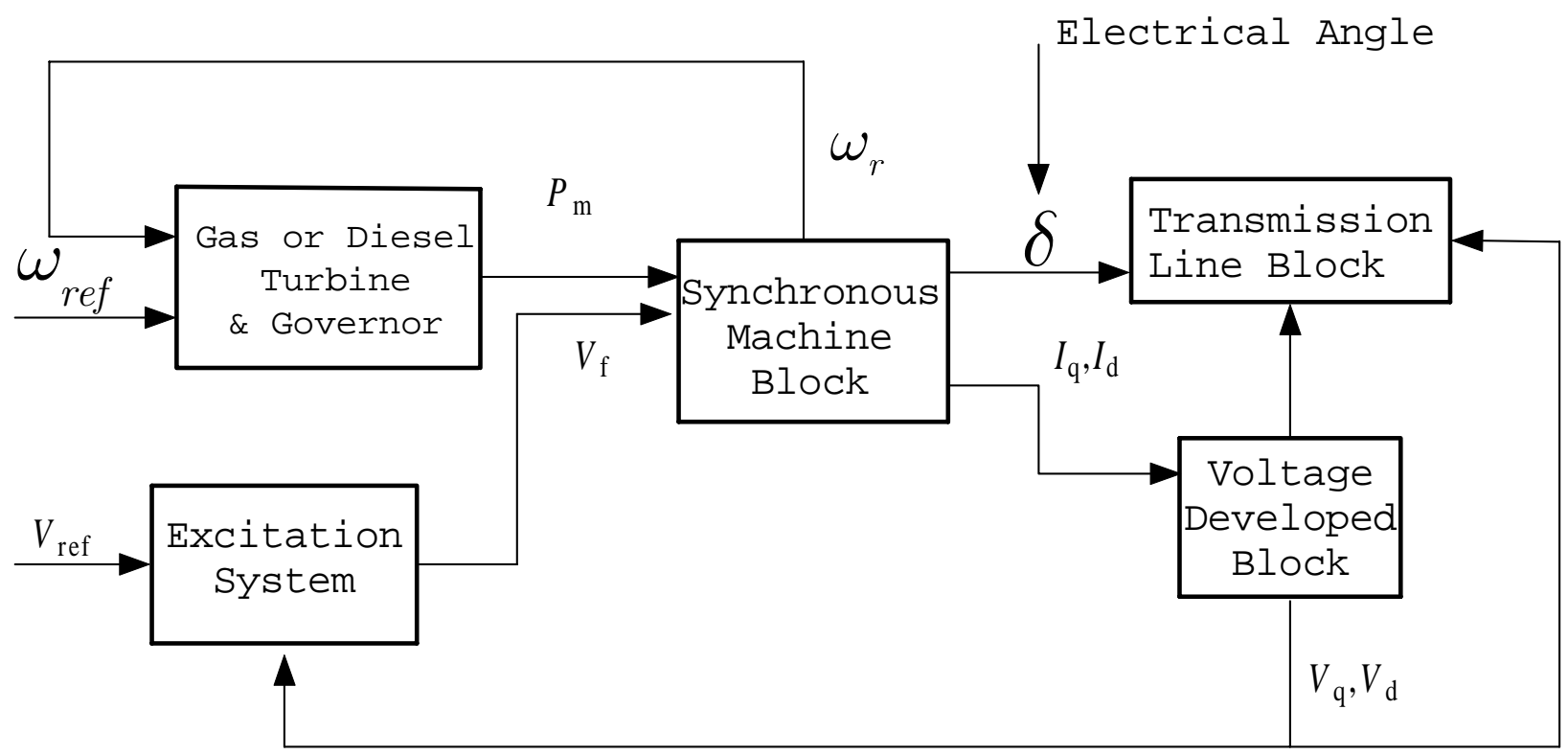

Fig. 4-2 A simulation diagram for a synchronous machine and an infinite bus system.

\subsection{Find Steady State Values}

The overall diagram for the computer simulation for one synchronous machine, a diesel or gas turbine, an excitation system and an Infinite Bus System is shown in Fig. 42.

Next, find the electrical angle, $\delta$

In order to do this let assume

$$
\begin{aligned}
& S_{\infty}=0.5 \underline{0^{\circ}} \\
& V_{\infty}=1.0\left\lfloor 0^{\circ}\right. \\
& r=0.02(p u), \\
& R=20(p u)
\end{aligned}
$$




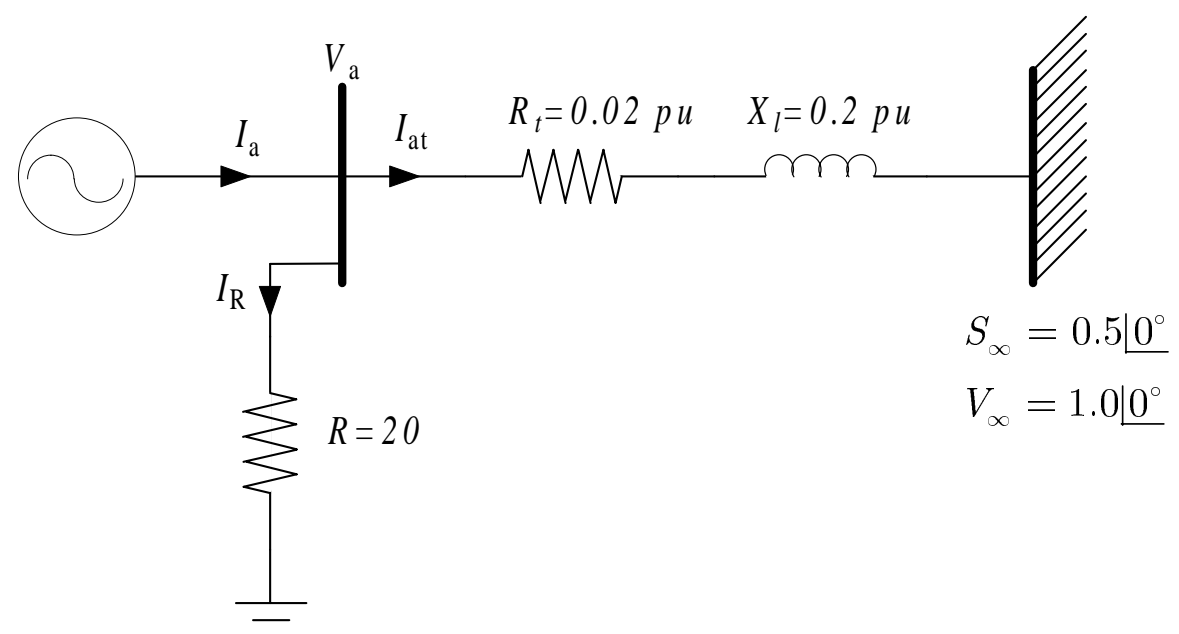

Fig. 4-3 A one-machine and an infinite bus with numerical values.

The delivered power is given by following

$$
S=V I^{*}
$$

From this equation, the transmission currents can be found,

$$
I_{a t}=\frac{S^{*}}{V^{*}}=\frac{0.5\left\lfloor 0^{\circ}\right.}{1.0\left\lfloor\underline{0^{\circ}}\right.}=0.5\left\lfloor 0^{\circ}\right.
$$

and the terminal voltage for the synchronous machine,

$$
\begin{aligned}
V_{t} & =V_{\infty}+\left(R_{t}+j X_{l}\right) I_{a t} \\
& =1 \underline{0^{\circ}}+(0.02+j 0.2) 0.5 \underline{0^{\circ}} \\
& =1.01+j 0.1 \\
V_{t} & =1.0149 \underline{5.6544^{\circ}}
\end{aligned}
$$

The terminal resistance current is found as follows,

$$
\begin{aligned}
I_{R} & =\frac{V_{t}}{R} \\
& =\frac{1.0149 \lcm{5.6544^{\circ}}}{20} \\
& =0.05075 .6544^{\circ}
\end{aligned}
$$

Therefore, the synchronous machine current is 


$$
\begin{aligned}
I_{a} & =I_{R}+I_{a t} \\
& =0.0507 \underline{5.6544^{\circ}}+0.5 \underline{0^{\circ}}=1.0656+j 0.005 \\
& =1.0656 \underline{0.2688^{\circ}}
\end{aligned}
$$

The machine voltages $E_{a}$ and $E_{x f d}$ are given as follows

$$
\begin{aligned}
& E_{a}=V_{t}+\left(r_{s}+j X_{q}\right) I_{a} \\
& \left\lfloor E_{x f d}\right\rfloor=\left\lfloor E_{a}\right\rfloor+\left\lfloor I_{d}\right\rfloor\left(X_{d}-X_{q}\right)
\end{aligned}
$$

So, now we can find the electrical angle and the magnitude of the voltage as follow,

$$
\begin{aligned}
E_{a} & =1.0149 \underline{5.6544^{\circ}}+(0.005+j 0.9)(1.0656 \underline{0.2588}) \\
& =1.011+j 1.0591=1.4642\left\lfloor 46.3299^{\circ}\right.
\end{aligned}
$$

and

$$
\begin{aligned}
\left\lfloor I_{d}\right\rfloor & =\left\lfloor I_{a}\right\rfloor \sin \delta \\
& =1.0656 \sin (46.3299) \\
& =0.7708
\end{aligned}
$$$$
\left\lfloor E_{x f d}\right\rfloor=1.4642+1.0656 \times 0.2
$$$$
=1.6773
$$$$
\therefore E_{x f d}=1.6773446 .3299^{\circ}
$$

The phaser diagram for voltages and currents for a synchronous machine is shown in Fig. $4-4$. 


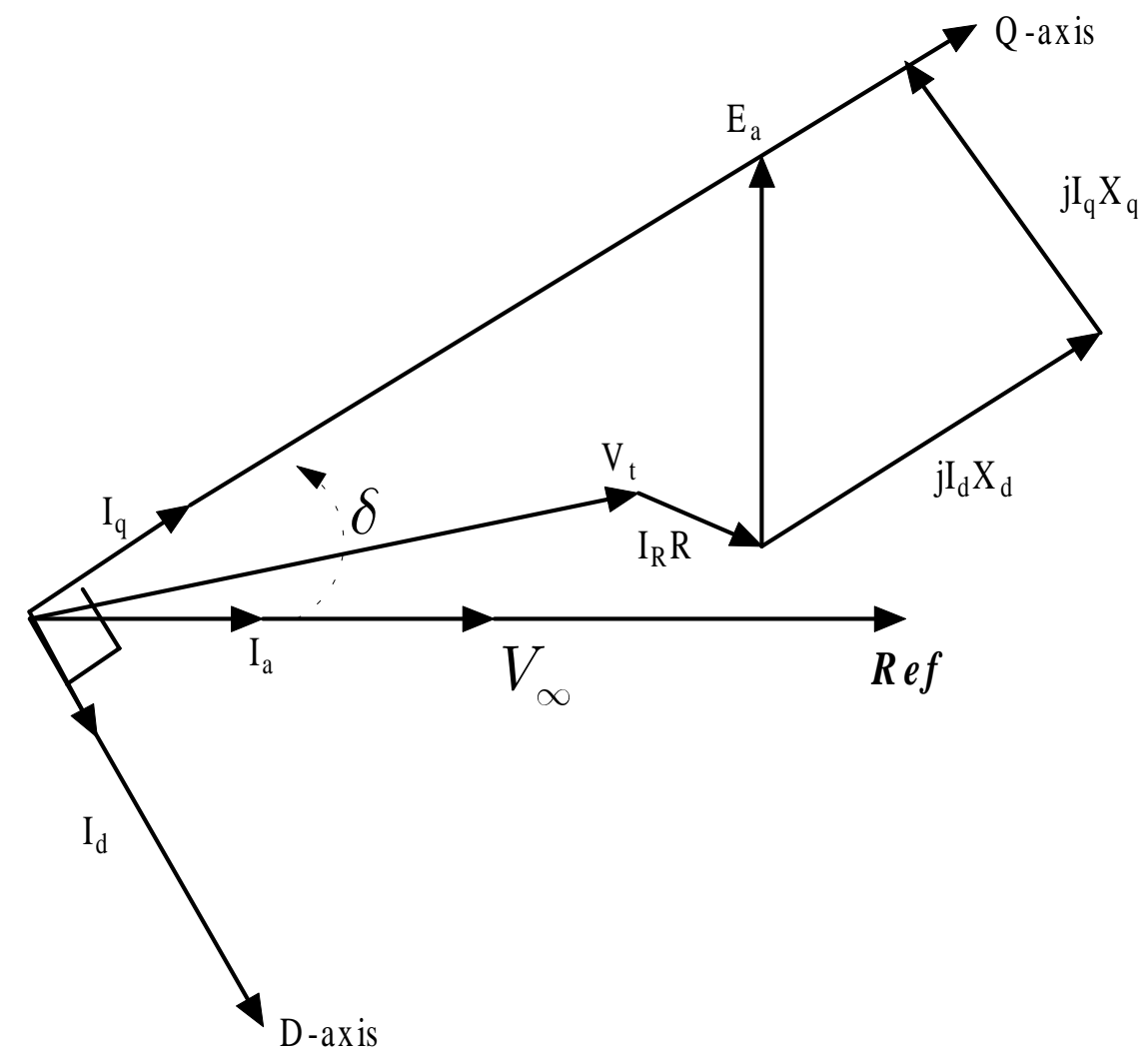

Fig. 4-4 A phaser diagram for synchronous machine with infinite voltage reference.

\subsection{An Inverter}

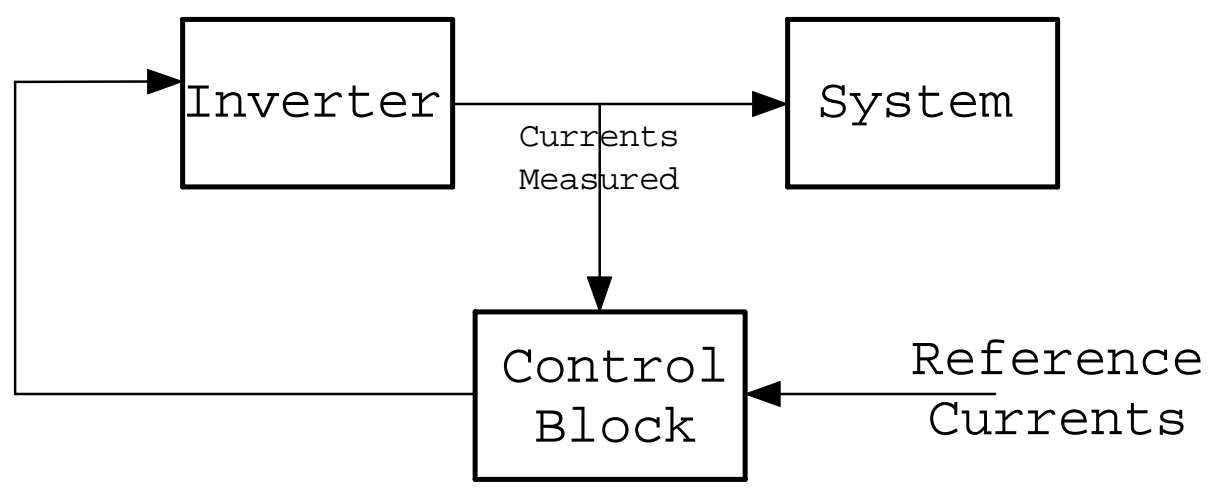

Fig. 4-5 An overall diagram for the simulation of the inverter. 
The simulation diagram for an inverter with an AC machine and a control block is shown in Fig. 4-5. The AC machine is represented by resistances and the AC voltage sources. To generate the command signals, the measured current signals are compared with the reference signals. In the control block, the transfer functions with small time constants are added to avoid the algebraic loops.

\subsection{A Local Generator Simulation}

The generators (i.e. gas turbine and diesel engine models) connected to an induction machine and a local load will be simulated by POWER SYSTEM BLOCKSET. First, the combustion turbine or diesel engine supplies the mechanical power to the load, and the three-phase fault occurs at the line connected from the bulk generation. After few seconds, the breaker disconnects the transmission line so that the local turbines are only the sources. The overall simulation diagram is shown in Fig. 4-6.

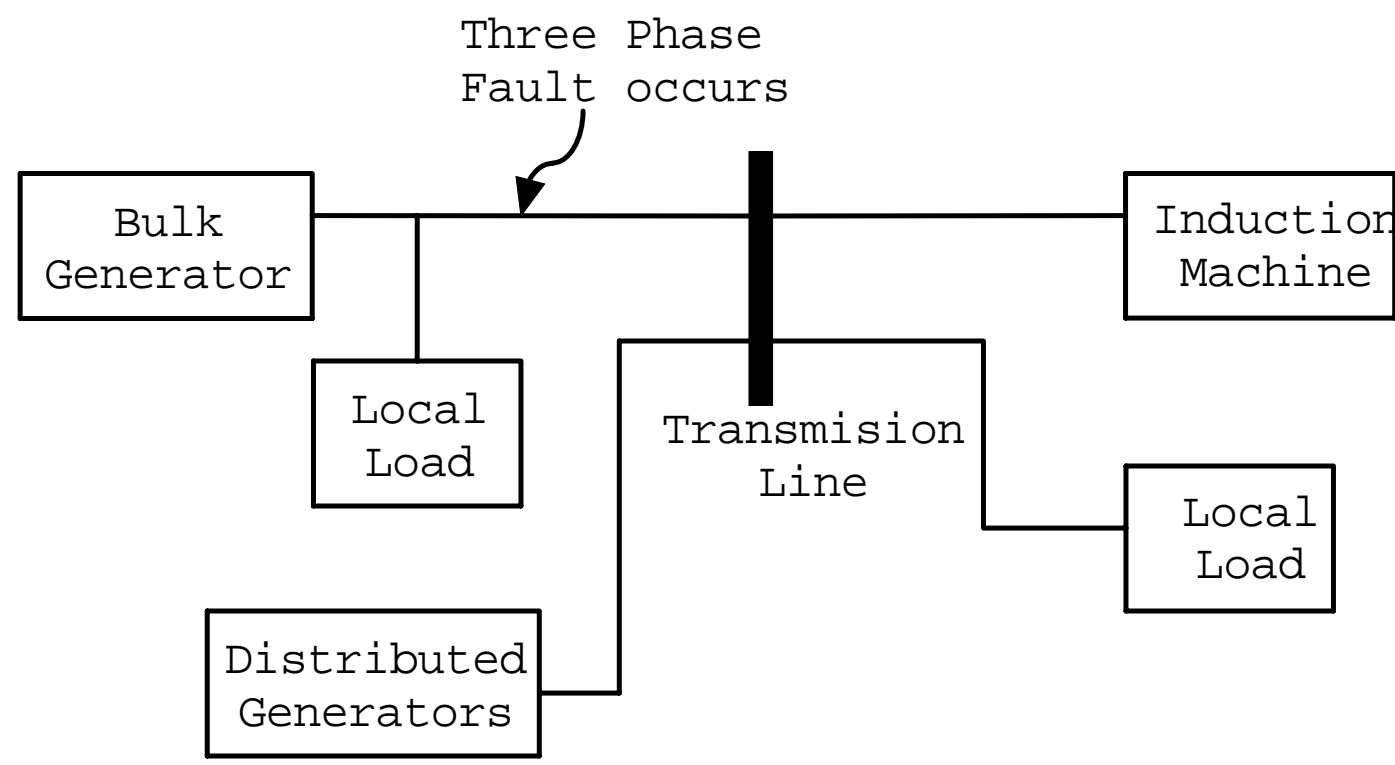

Fig. 4-6 An overall diagram of the simulation. 


\section{THE SIMULATION RESULTS}

\subsection{Simulation Results for a Combustion Turbine}

From the calculation of steady state conditions, operating angle $\delta_{0}$ and other values are determined. Next, the responses are examined when the $\pm 1 \%$ and $\pm 10 \%$ disturbances of the speed and the voltage are applied. The speed of the machine, the voltage of the regulator, the mechanical power output from the energy sources (i.e. diesel engine and gas turbine), the currents and the voltages are shown.

In section 5.1-1, the figures show the simulation results for gas turbine with synchronous machine and the exciter. Fig. 5-1 shows the speed of the synchronous machine, Fig. 5-2 shows the regulator voltage respond, and Fig. 5-3 shows the mechanical power when a $1 \%$ disturbance is added to the speed reference. Figures 5-4, 5-5, and 5-6 show the speed of synchronous machine, voltage magnitude of the exciter, and mechanical power when a $-1 \%$ disturbance is added to the speed reference. In case of $10 \%$ disturbance of regulator voltage reference, the speed of the machine, magnitude of field voltage, and the mechanical power of the machine are shown in Fig. 5-7, Fig. 5-8, and Fig. 5-9 respectively. When the voltage regulator reference signals are decreased 10 $\%$ the speed of machine, the magnitude of field voltage, and the mechanical power are shown in Fig. 5-10, Fig. 5-11, and Fig. 5-12. 


\section{1-1 A Gas Turbine for a Speed Reference Disturbance}

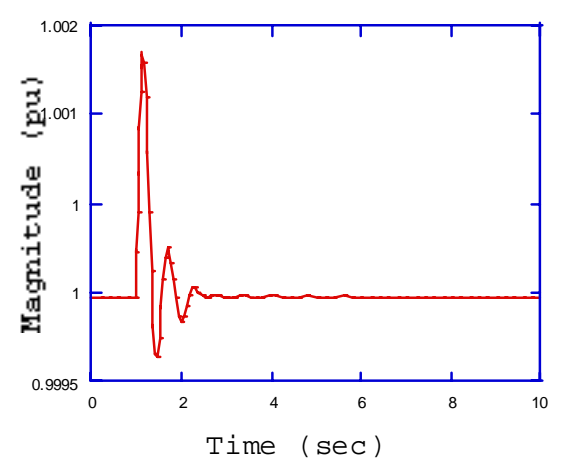

Fig. 5-1 speed of the synchronous machine for a $1 \%$ change in reference speed of gas turbine.

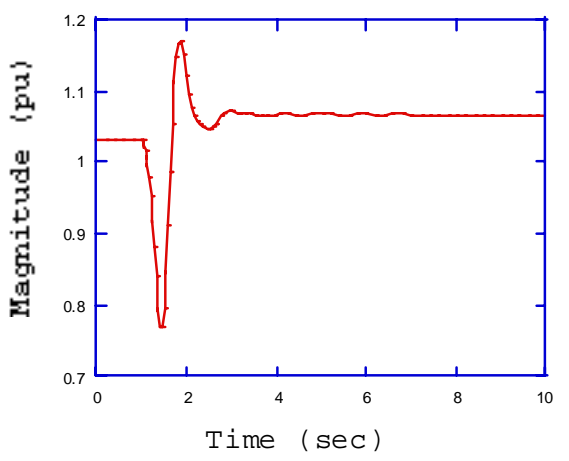

Fig. 5-2 Exciter voltage output for a 1\% change in reference speed of gas turbine.

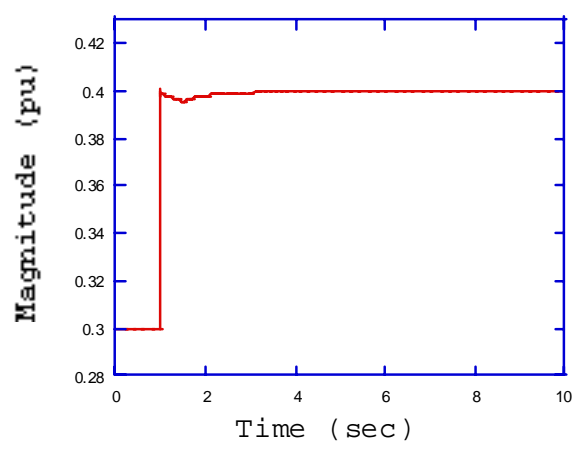

Fig. 5-3 Output power of gas turbine for a $1 \%$ change in reference speed of gas turbine.

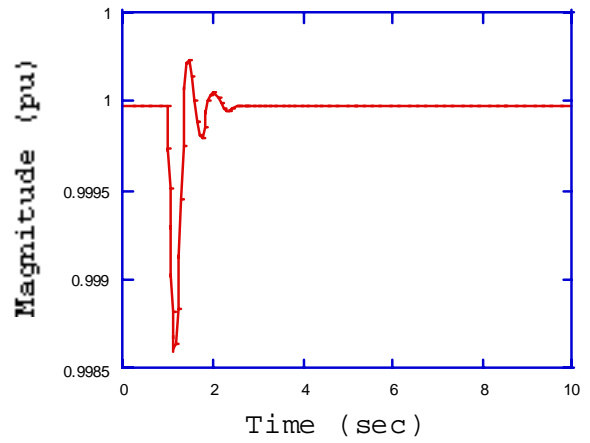

Fig. 5-4 Speed of the synchronous machine for a $-1 \%$ change in reference speed of gas turbine.

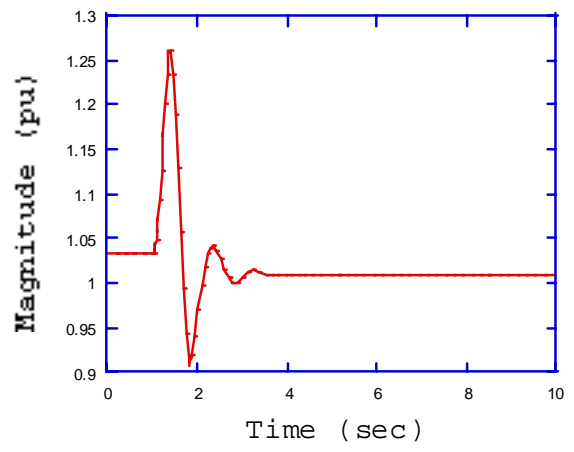

Fig. 5-5 Exciter voltage output for a $-1 \%$ change in

reference speed of gas turbine.

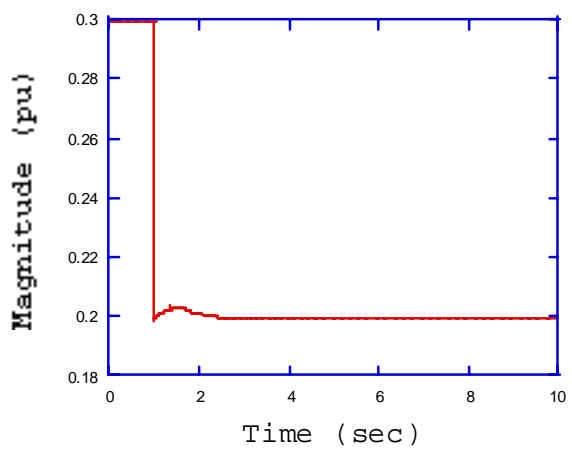

Fig. 5-6 Output power of gas turbine for a $-1 \%$ change in reference speed of gas turbine. 


\section{1-2 A Gas Turbine for Exciter Reference Disturbance}

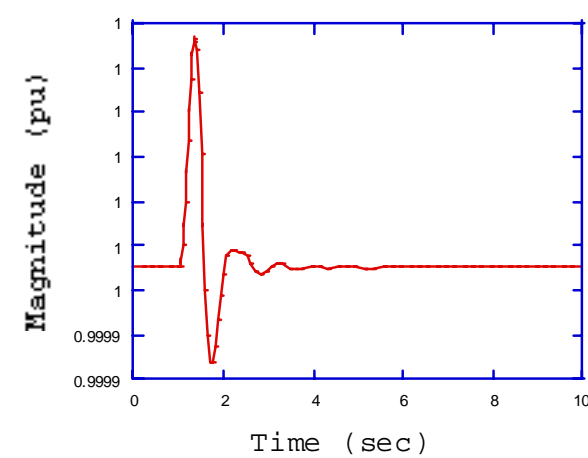

Fig. 5-7 speed of synrhonous machine for a $10 \%$ change in reference voltage of exciter.

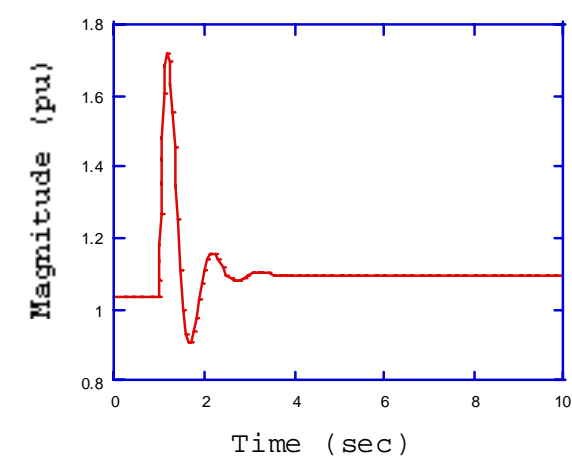

Fig. 5-8 Exciter voltage output for a $10 \%$ change in reference voltage of exciter.

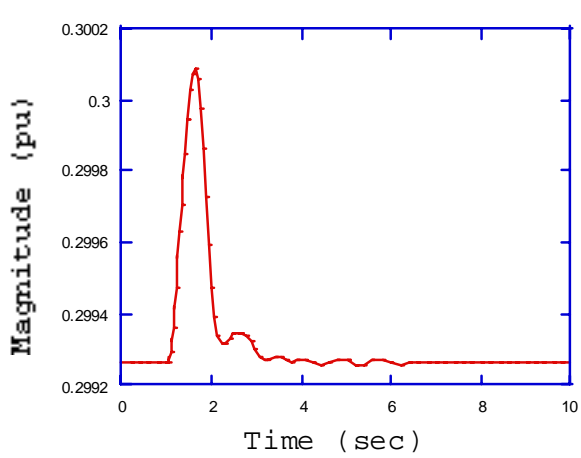

Fig. 5-9 Output power of gas turbine for a $10 \%$ change in reference voltage of exciter

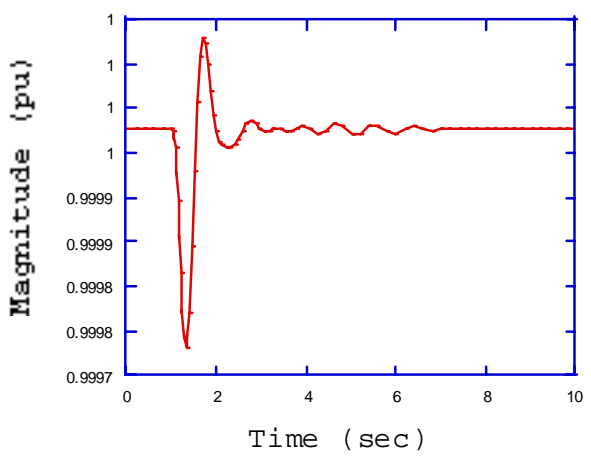

Fig. 5-10 Speed of synrhonous machine for a $-10 \%$ change in reference voltage of exciter.

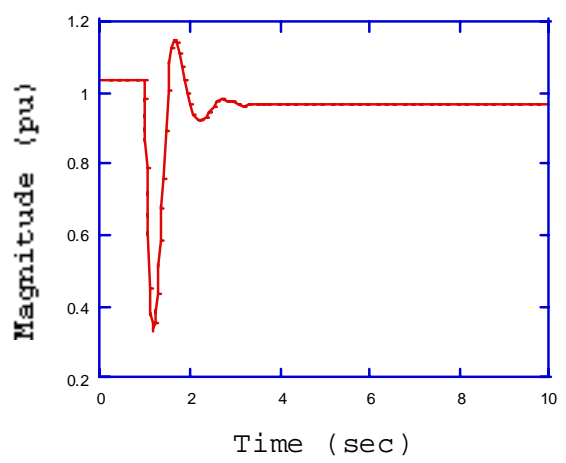

Fig. 5-11 Exciter voltage output for a $-10 \%$ change in reference voltage of exciter.

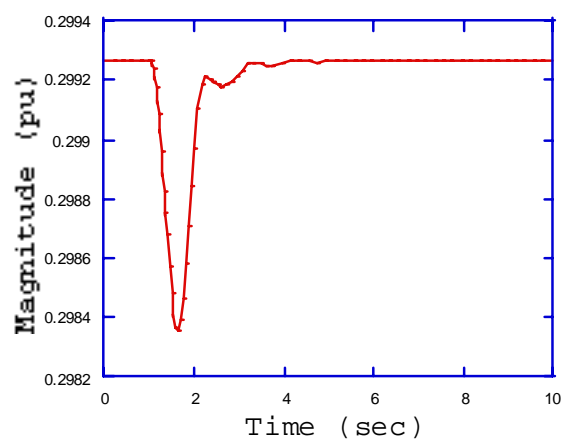

Fig. 5-12 Output power of gas turbine for a $-10 \%$ change in reference voltage of exciter. 


\subsection{Simulation Results for a Diesel Engine}

The simulation results for diesel engine with a synchronous machine and an exciter are shown in section 5.1-2. Figure 5-13 shows the speed of synchronous machine for a 1\% change in speed reference. In Fig. 5-14 and Fig. 5-15 the magnitude of the field voltage and the mechanical power of the machine are shown respectively when a $1 \%$ disturbance is added to the speed reference. The speed of the machine, the magnitude of the field voltage, and the mechanical power of the machine are shown in Fig. 5-16, Fig. 5-17, and Fig. 5-18 respectively with a -1\% disturbance of the speed reference. In Fig. 519, Fig. 5-20, and Fig. 5-21 the speed of the machine, the magnitude of the field voltage, and the mechanical power of the machine are shown respectively when a $10 \%$ disturbance is added to the exciter voltage reference. The speed of the machine, the magnitude of the field voltage, and the mechanical power of the machine are shown in Fig. 5-22, Fig. 5-23, and Fig. 5-24 respectively for a $-10 \%$ of the excitation reference. 


\section{2-1 A Diesel Engine for a Speed Reference Disturbance}

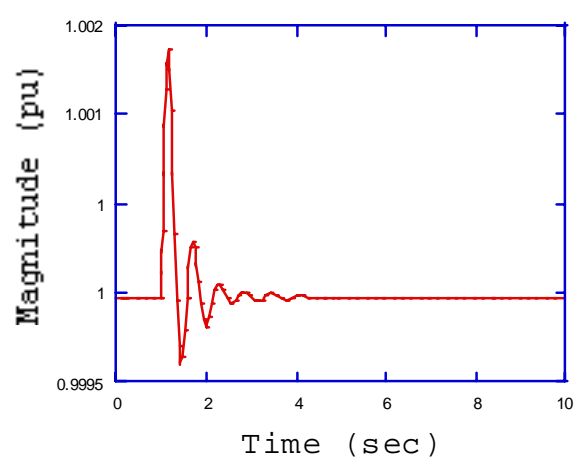

Fig. 5-13 Speed of synchronous machine for a $1 \%$ change in reference speed of diesel engine.

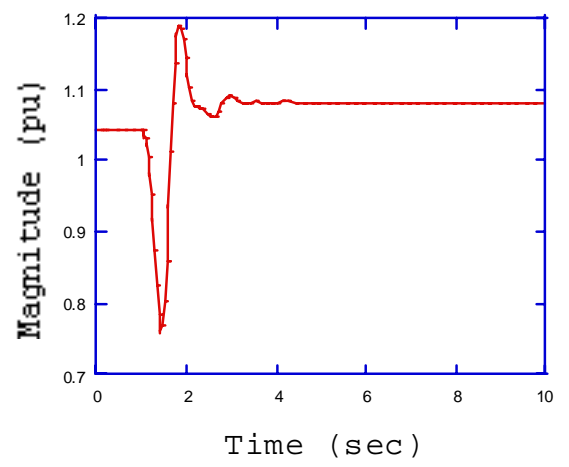

Fig. 5-14 Exciter voltage output for a 1\% change in reference speed of diesel engine.

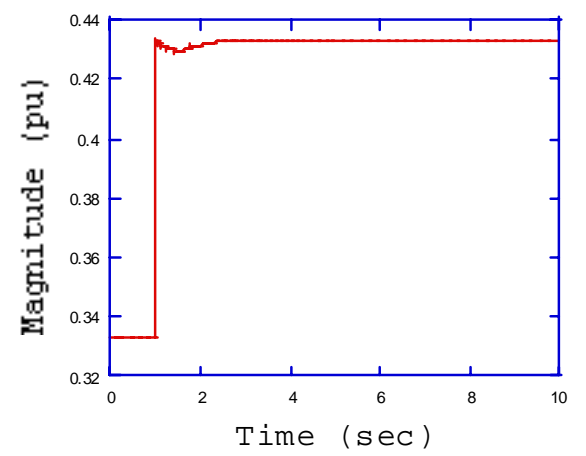

Fig. 5-15 Output power of diesel engine for a $1 \%$ change in reference speed of diesel engine.

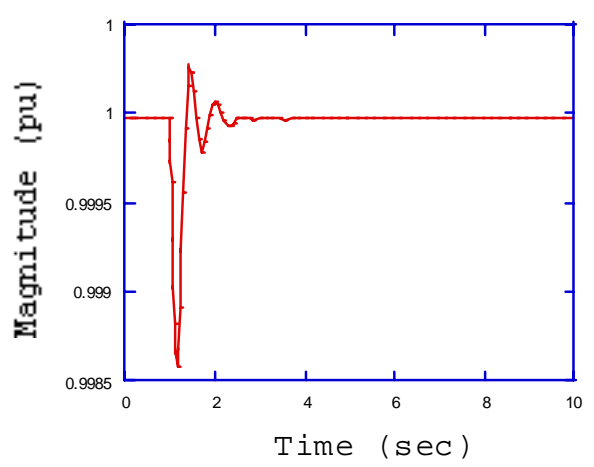

Fig. 5-16 Speed of synchronous machine for a $-1 \%$ change in reference speed of diesel engine.

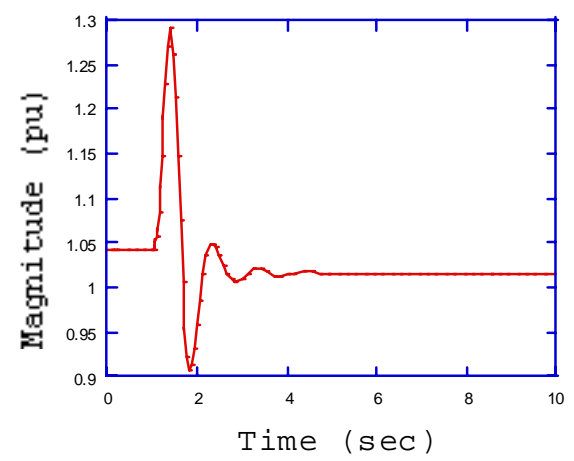

Fig. 5-17 Exciter voltage output for a $-1 \%$ change in

reference speed of diesel engine.

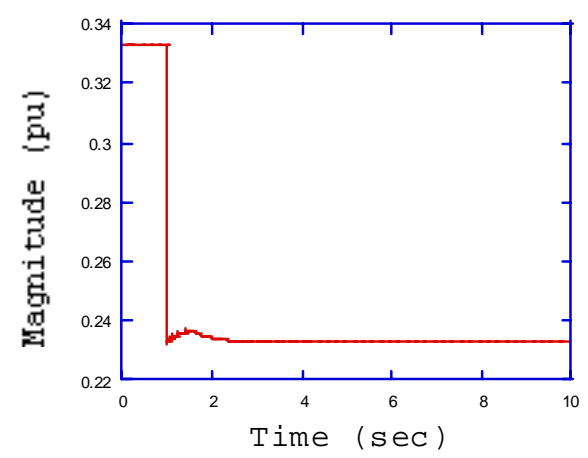

Fig. 5-18 Output power of diesel engine for a $-1 \%$ change in reference speed of diesel engine. 


\section{2-2 A Diesel Engine for Exciter Reference Disturbance}

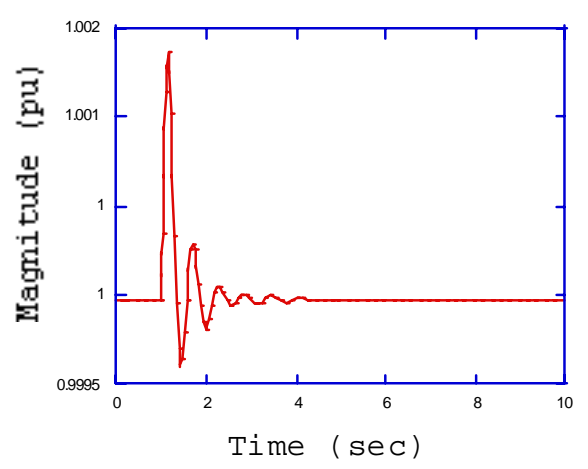

Fig. 5-19 Speed of synchronous machine for a $10 \%$ change in reference voltage of exciter.

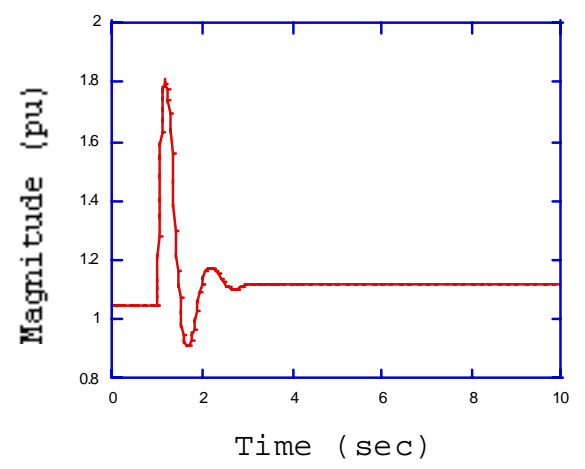

Fig. 5-20 Exciter voltage output for a $10 \%$ change in reference voltage of exciter.

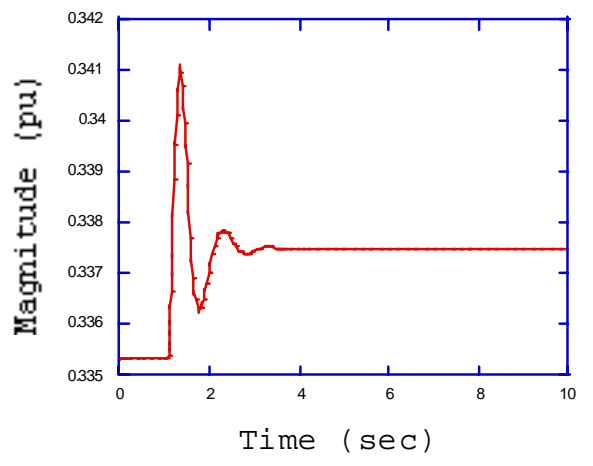

Fig. 5-21 Output power of diesel engine for a $10 \%$ change in reference voltage of exciter.

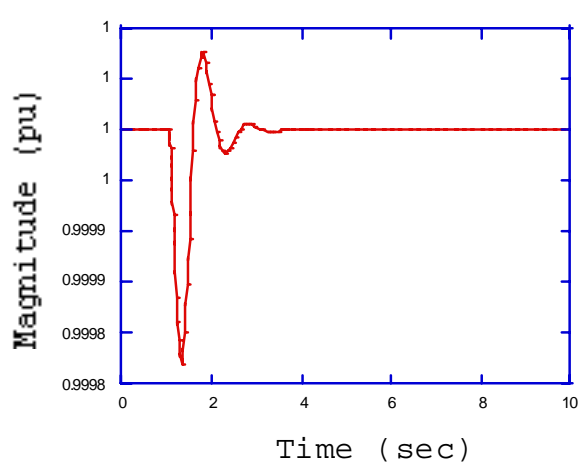

Fig. 5-22 speed of synchronous machine for a $-10 \%$ change in reference voltage of exciter.

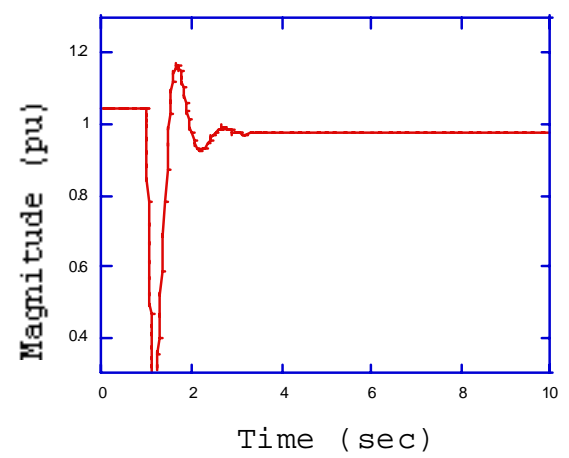

Fig. 5-23 Exciter voltage output for a $-10 \%$ change in reference voltage of exciter.

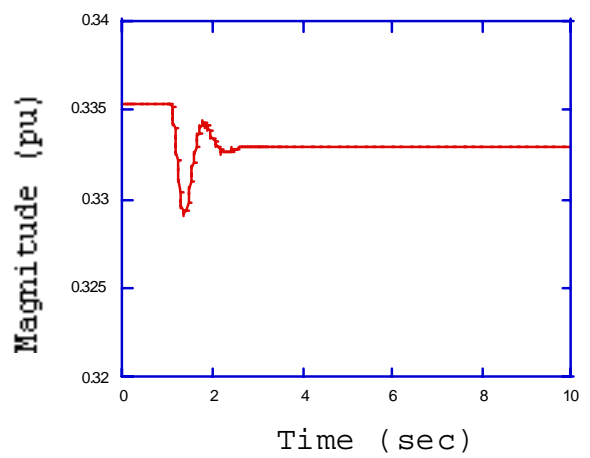

Fig. 5-24 Output power of diesel engine for a $-10 \%$ change in reference voltage of exciter. 


\subsection{A Local Load Simulation with a Fault}

For a local load simulation, a fault occurs at 0.2 second and the breaker will disconnect the line at 0.4 second. The mechanical power, the exciter voltage, and the speed of the machine are examined.

In the section 5.3 local load simulations with a three-phase fault at the transmission line connected to the bulk generation are shown. In case of diesel engine as a source of mechanical power of the machine, the magnitude of the field voltage, and the speed of the synchronous machine are shown in Fig. 5-25, Fig. 5-26, and Fig. 5-27 respectively. For the combustion turbine in Fig. 5-28, Fig. 5-29, and Fig. 5-30 the mechanical power of the machine, the magnitude of the field voltage, and the speed of the machine are shown respectively.

\section{3-1 A Diesel Engine}

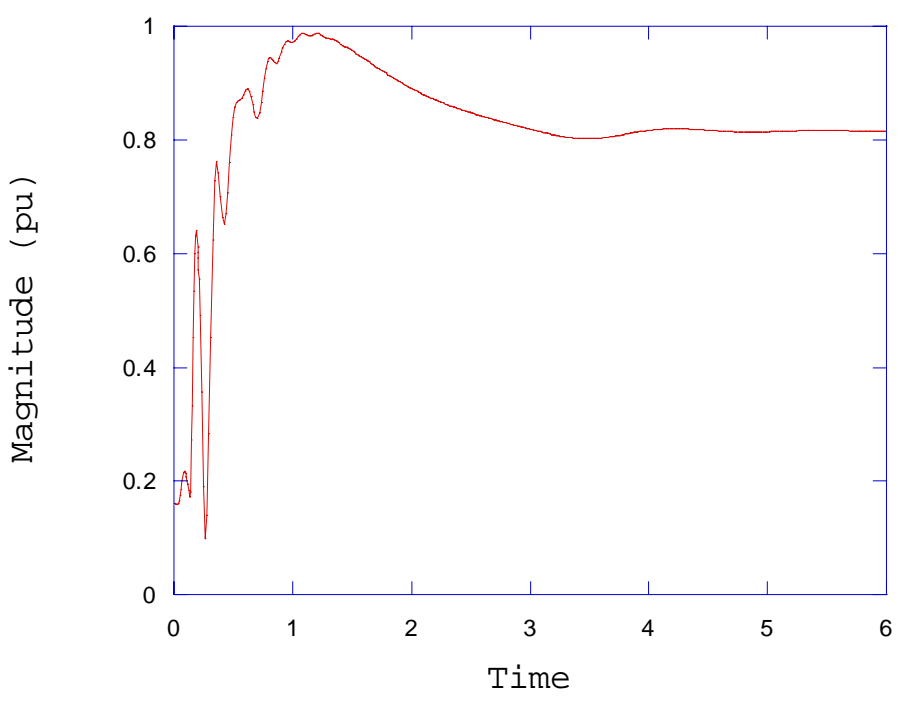

Fig. 5-25 The mechanical power of diesel egine when three-phase fault occurs at transmission line. 


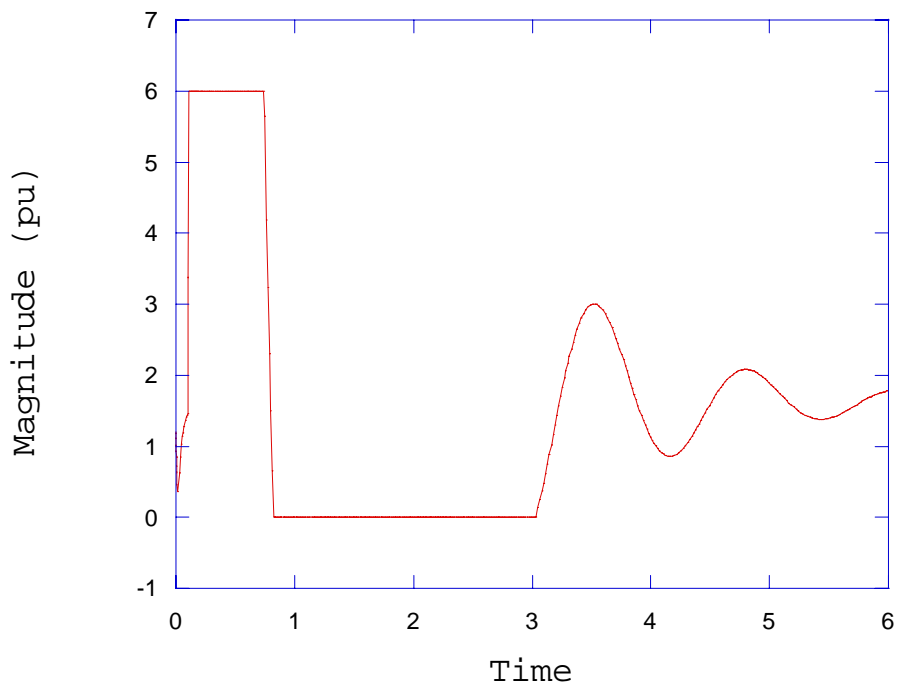

Fig. 5-26 The exciter voltage output

when a three-phase fault occurs at transmission line.

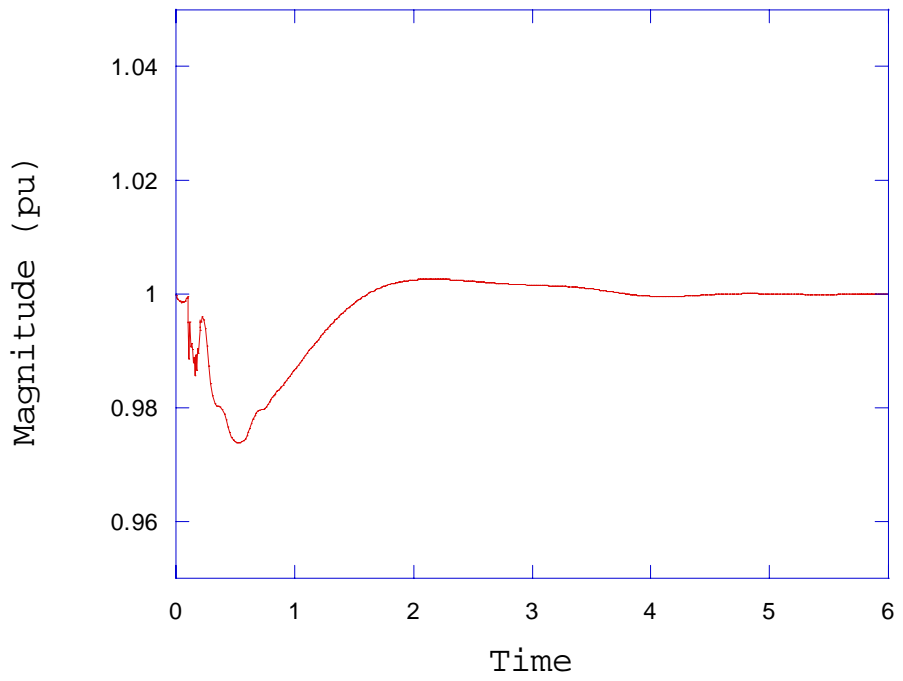

Fig. 5-27 The speed of synchronous machine when a three-phase fault occurs at transmission line. 


\section{3-2 A Combustion Turbine}

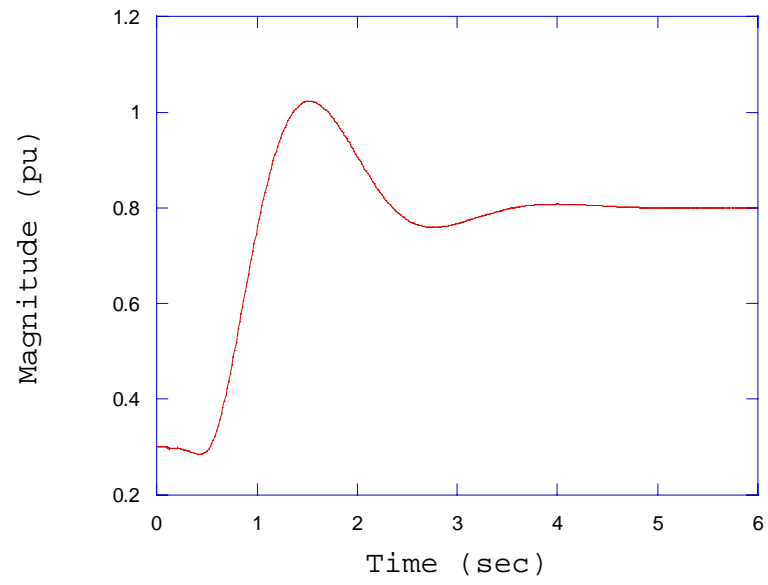

Fig. 5-28 The mechanical power of a gas turbine when a three-phase fault occurs at transmission line.

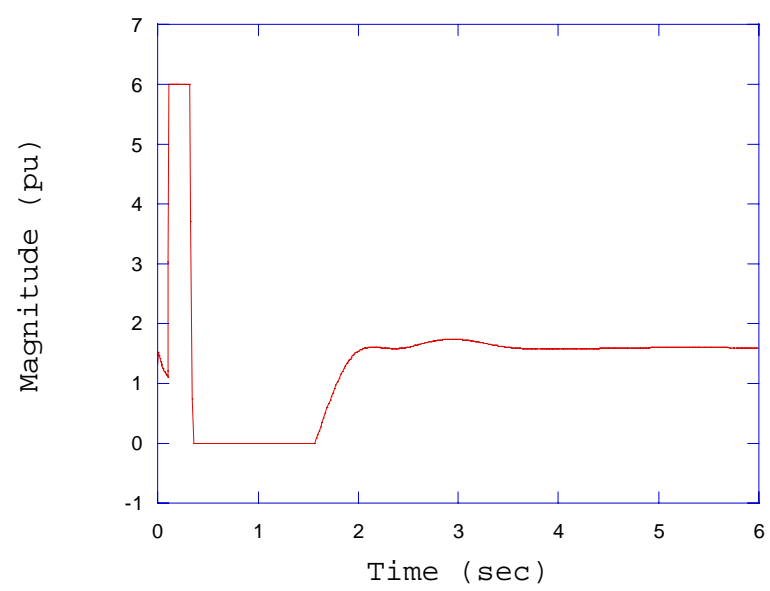

Fig. 5-29 The exciter voltage output

when a three-phase fault occurs at transmission line. 


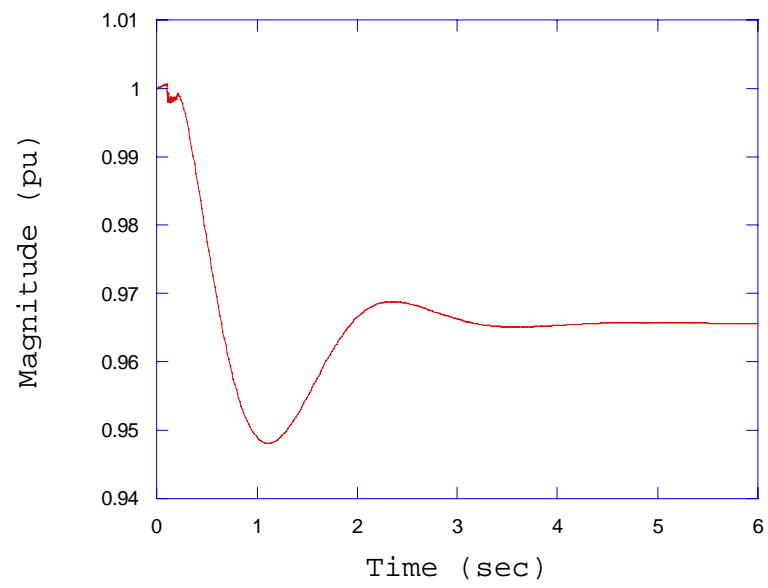

Fig. 5-30 The speed of synchronous machine when a three-phase fault occurs at transmission line.

\subsection{An Inverter Simulation}

For an inverter simulation, the balanced and unbalanced (5\% more and 5\% less) voltage sources are examined and the adjusted current references are applied on unbalanced voltage sources case. For the cases, the three-phase currents, the voltages of the sources, and the power delivered across the voltage sources are displayed.

In the section 5.3 the inverter simulation results are shown. For the voltage and current cases the voltage magnitudes are divided by 10 throughout the figures since the voltage magnitudes are a lot bigger than those of the currents. The balanced voltage magnitude cases are shown in Fig. 5-31 through Fig. 5-34. In Fig. 5-31, Fig. 5-32, and Fig. 5-33 the voltages and currents of phase A, phase B, and phase C are shown respectively. The power delivered to the voltage sources is shown in Fig. 5-34. For the unbalanced cases the voltages and currents of phase A, phase $\mathrm{B}$, and phase $\mathrm{C}$ are shown in Fig. 5-35, Fig. 5-36, and Fig. 5-37 respectively. In case of the voltage unbalanced case the power delivered to the voltage sources is shown in Fig. 5-38. When the voltage sources are unbalanced with adjusted reference currents, the simulation results are shown 
in Fig. 5-39 to Fig. 5-42. The voltages and currents of the phase A, phase B, and phase C are shown in Fig. 5-39, Fig. 5-40, and Fig. 5-41 respectively. The power delivered to the voltage sources is shown in Fig. 5-42 in case of the unbalanced voltage magnitude with the adjusted current reference.

The comparisons of the balanced and unbalanced voltage sources are shown in Fig. 5-43 for phase A, Fig. 5-44 for phase B, and Fig. 5-45 for phase C. The comparisons of the balanced and unbalanced voltage sources with adjusted current reference are shown in Fig. 5-46, Fig. 5-47, and Fig. 5-48 for each phase A, B, and C.

\section{4-1 Balanced Source Voltages}

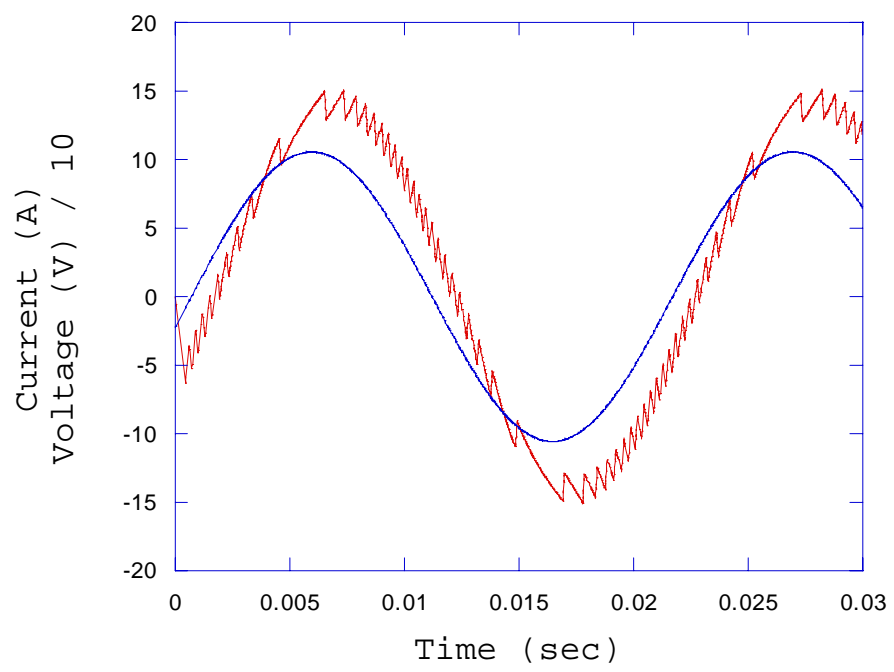

Fig. 5-31 The voltage and current of phase A on the system for balanced voltage magnitude. 


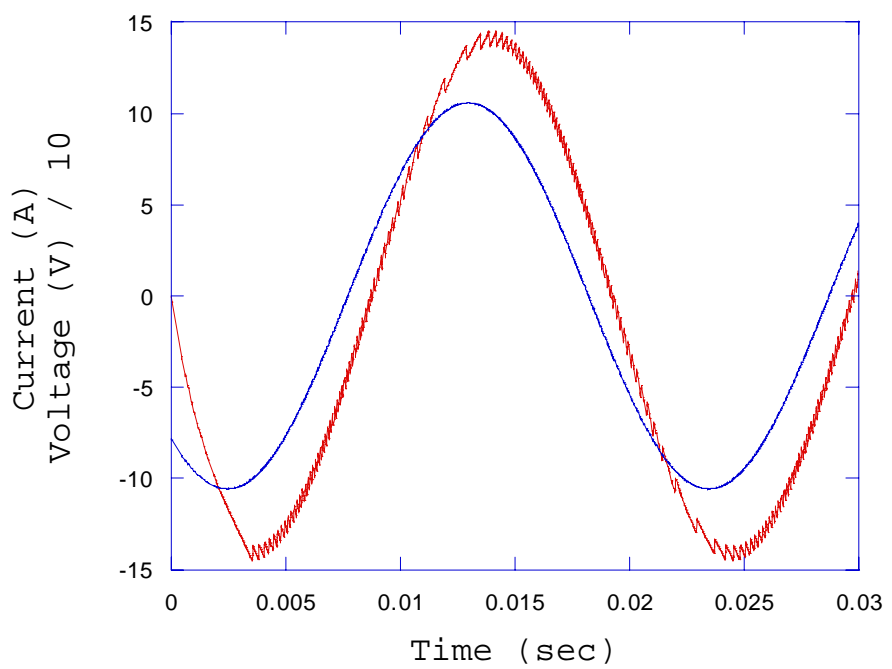

Fig. 5-32 The voltage and current of phase B on the system for balanced voltage magnitude case.

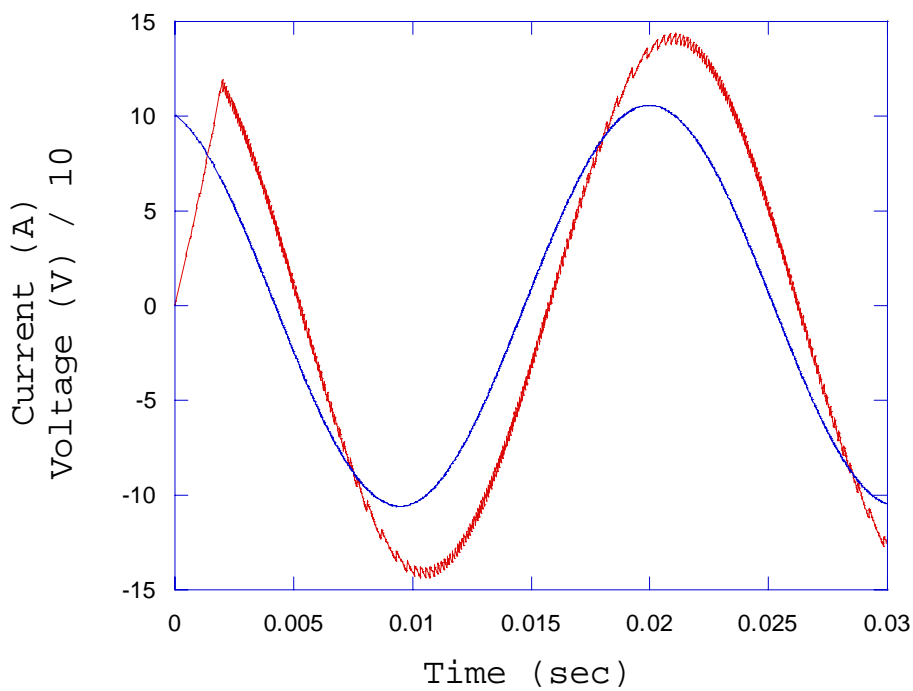

Fig. 5-33 The voltage and current of phase $\mathrm{C}$ on the system for balanced voltage magnitude case. 


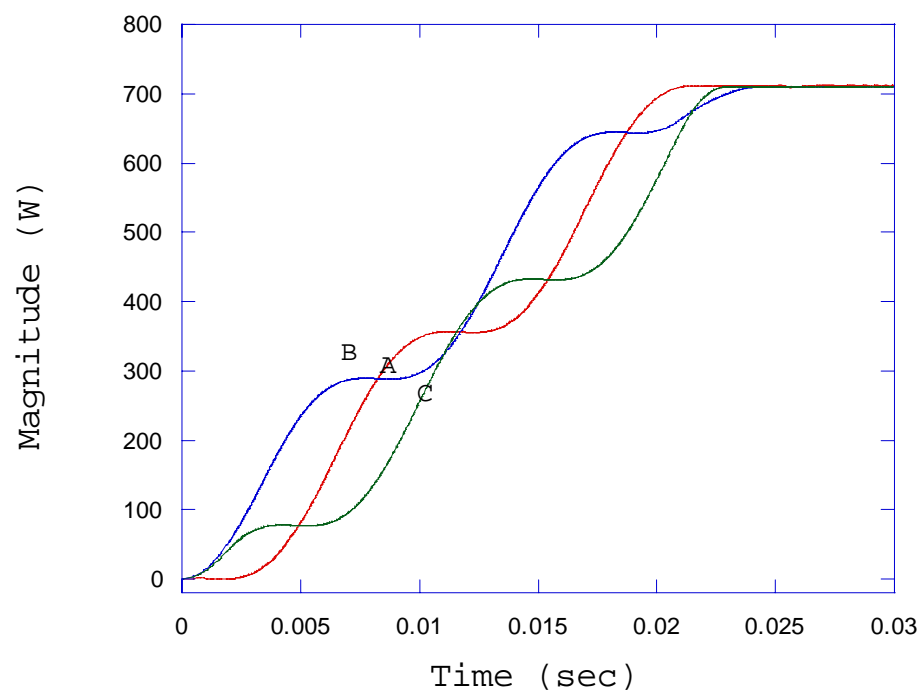

Fig. 5-34 The power of phase A, B, and C on the system for balanced voltage magnitude case.

\section{3-2 Unbalanced Source Voltages}

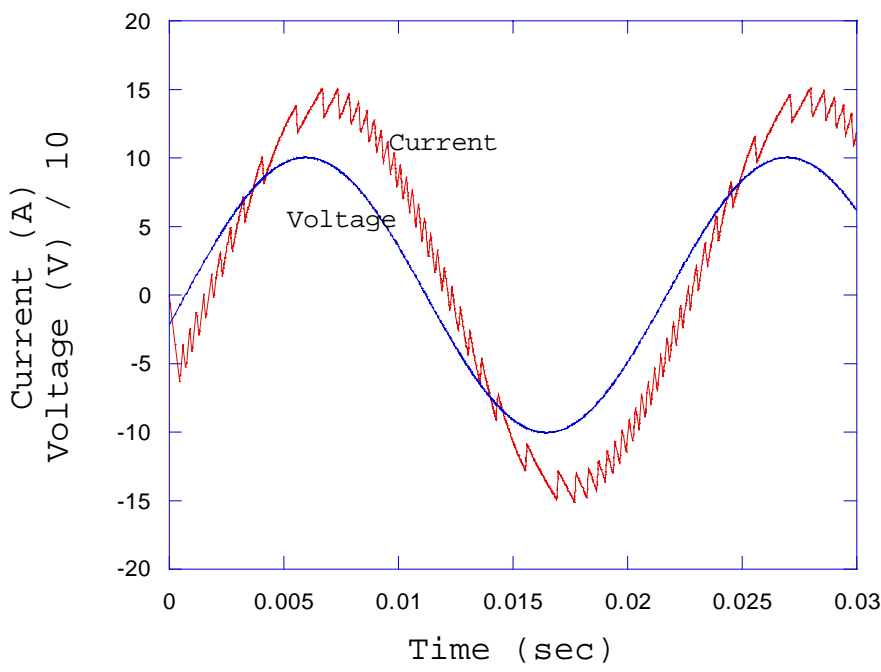

Fig. 5-35 The voltage and current of phase A on the system for unbalanced voltage magnitude case. 


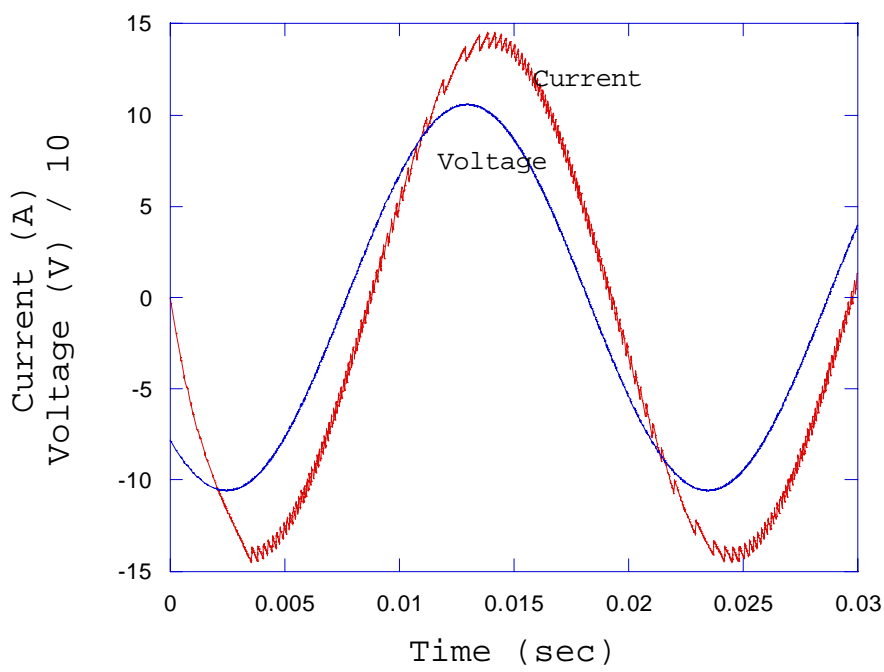

Fig. 5-36 The voltage and current of phase B on the system for unbalanced voltage magnitude case.

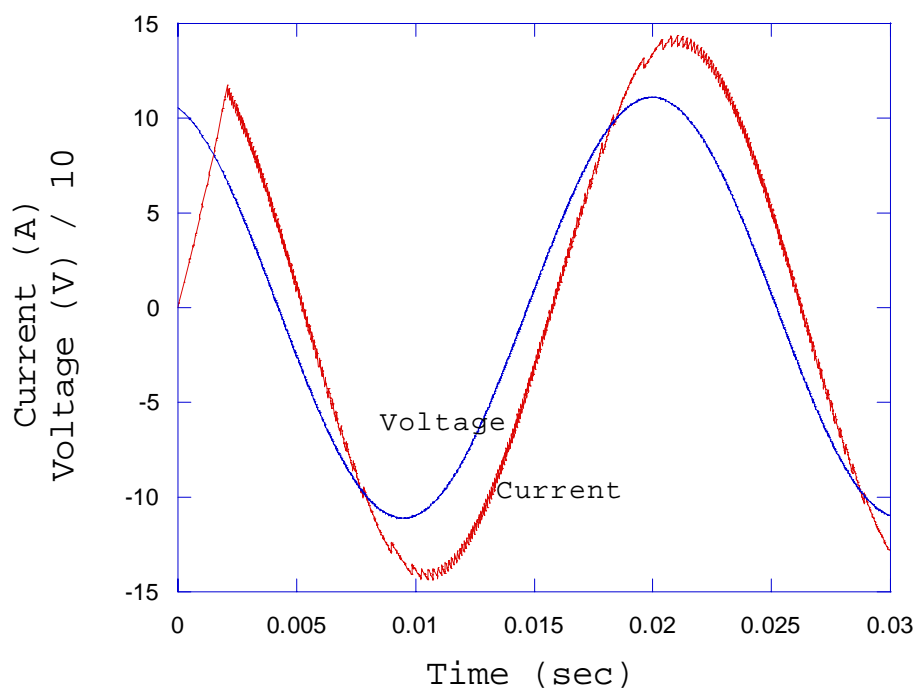

Fig. 5-37 The voltage and current of phase C on the system for unbalanced voltage magnitude case. 


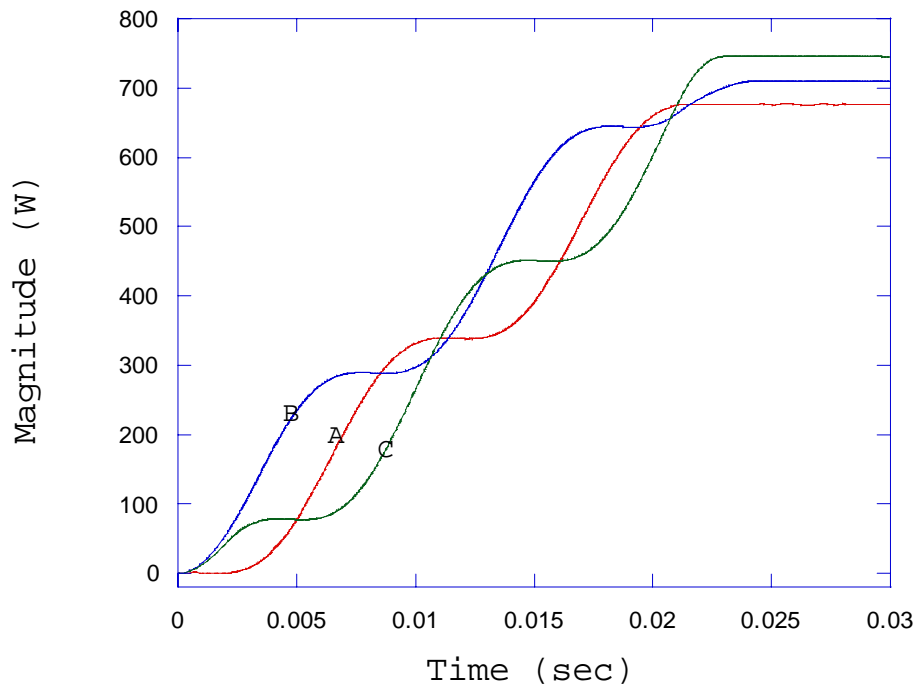

Fig. 5-38 The power of phase A, B, and C

delivered to the voltage sources for unbalanced voltage magnitude case.

\section{3-3 Unbalanced Voltage Sources with Adjusted Current Reference}

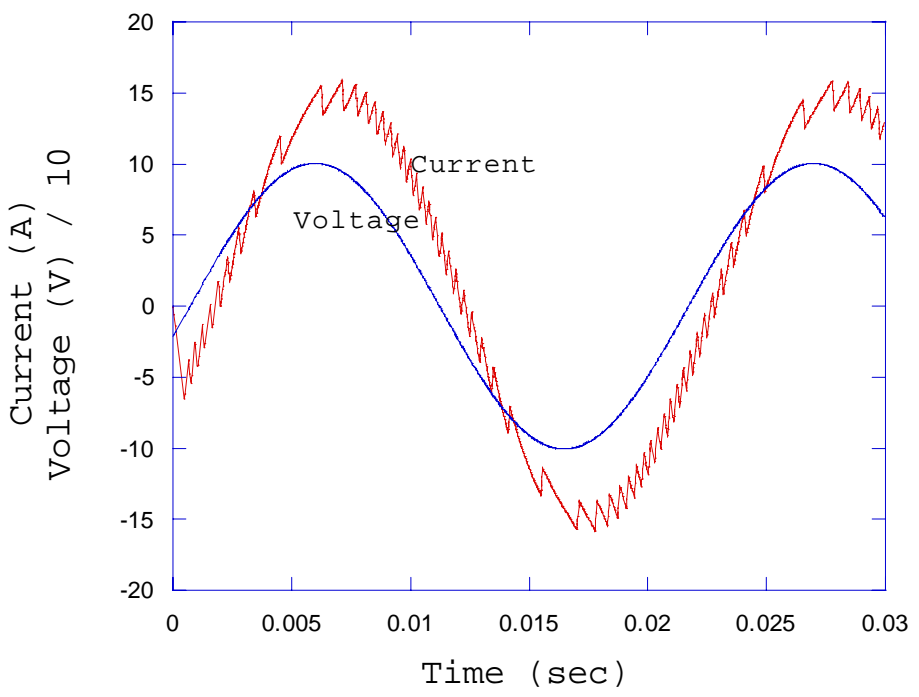

Fig. 5-39 The voltage and current of phase A on the system with adjusted reference current. 


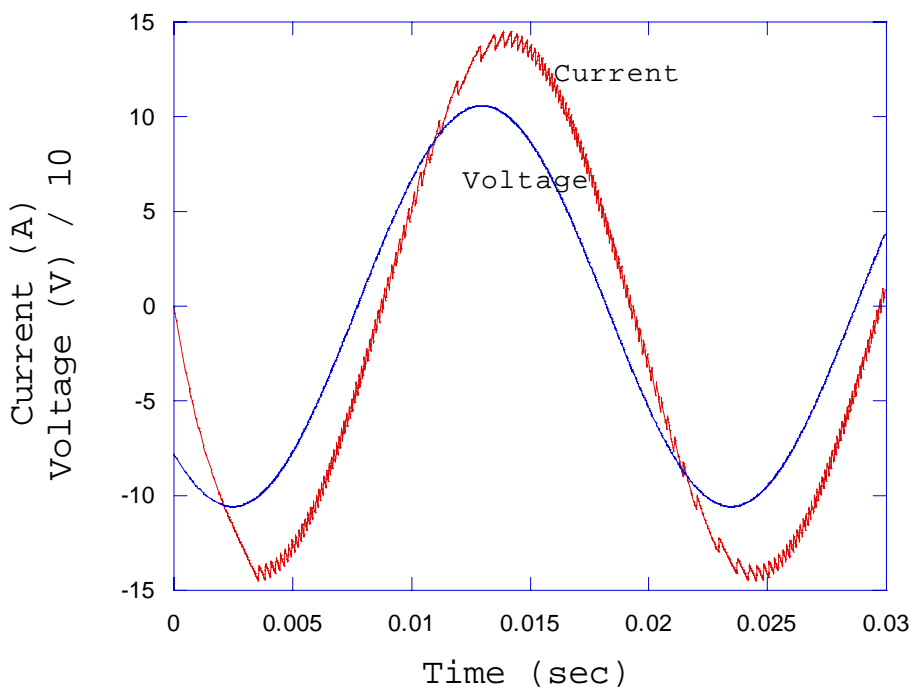

Fig. 5-40 The voltage and current of phase B on the system with adjusted reference current.

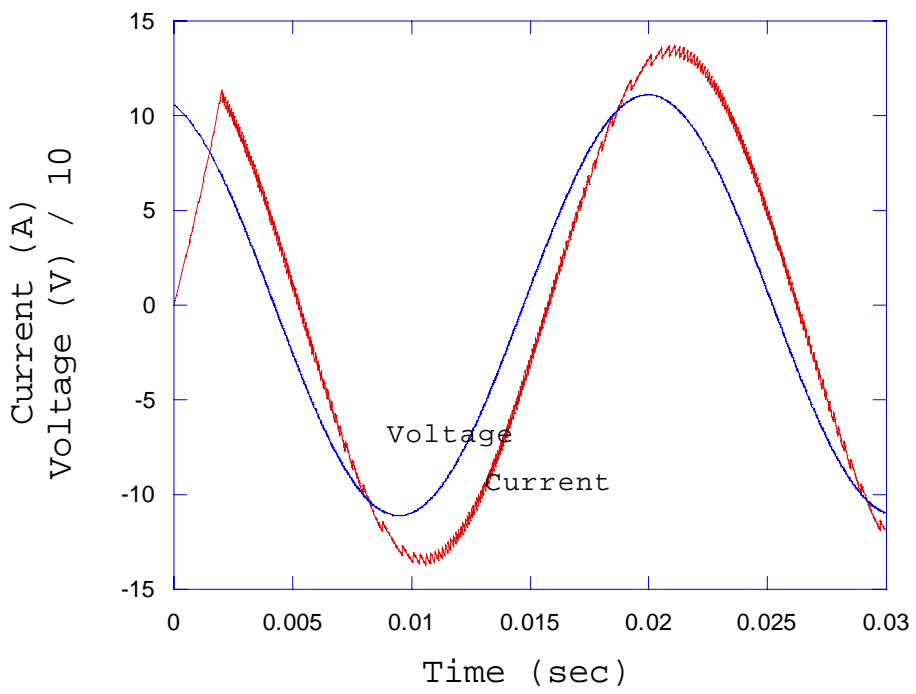

Fig. 5-41 The voltage and current of phase $\mathrm{C}$ on the system with adjusted reference current. 


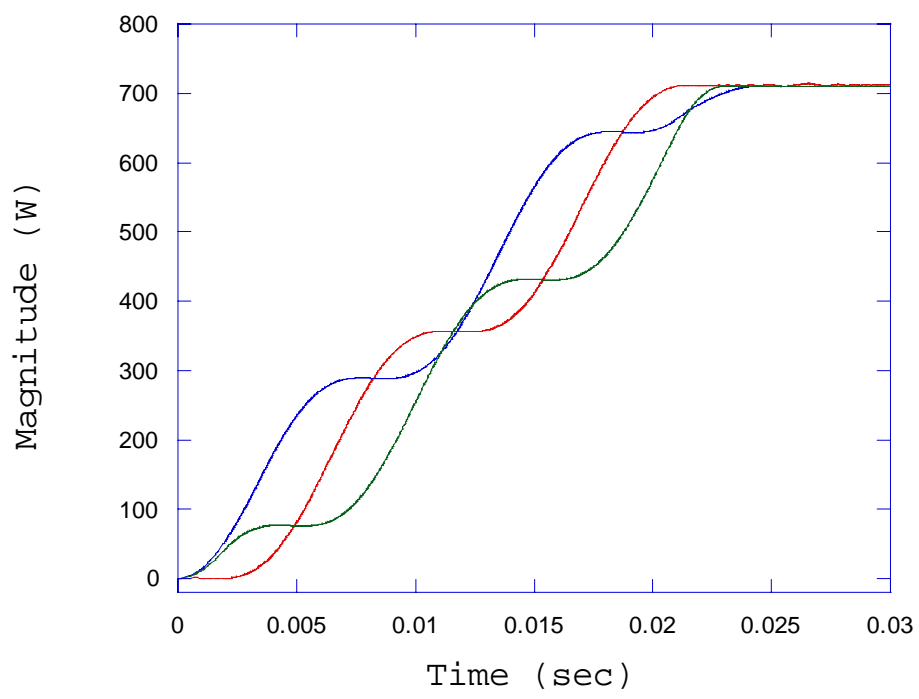

Fig. 5-42 The power of phase A, B, and C delivered to the voltage sources with adjusted reference current.

\section{3-4 Compare the Power Delivered on the Sources}

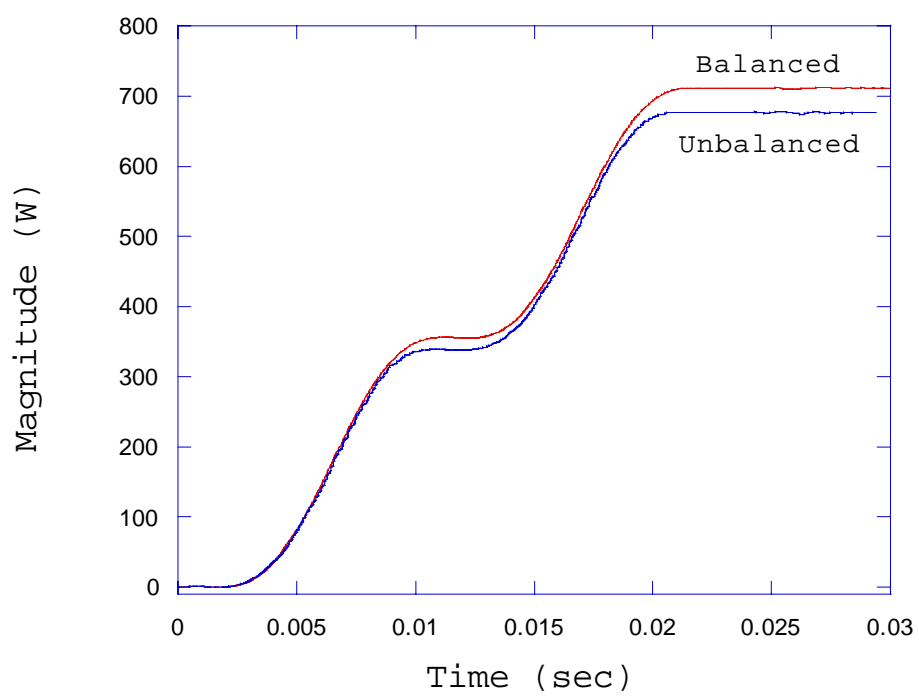

Fig. 5-43 The power of phase A delivered to voltage source for balanced and unbalanced voltage magnitudes. 


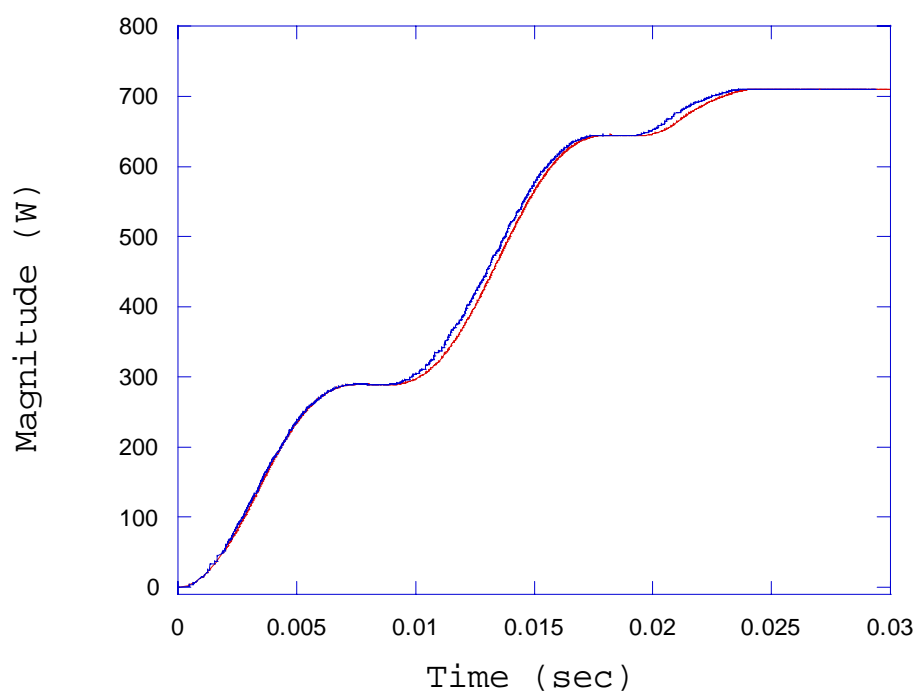

Fig. 5-44 The power of phase B delivered to voltage source for balanced and unbalanced voltage magnitude.

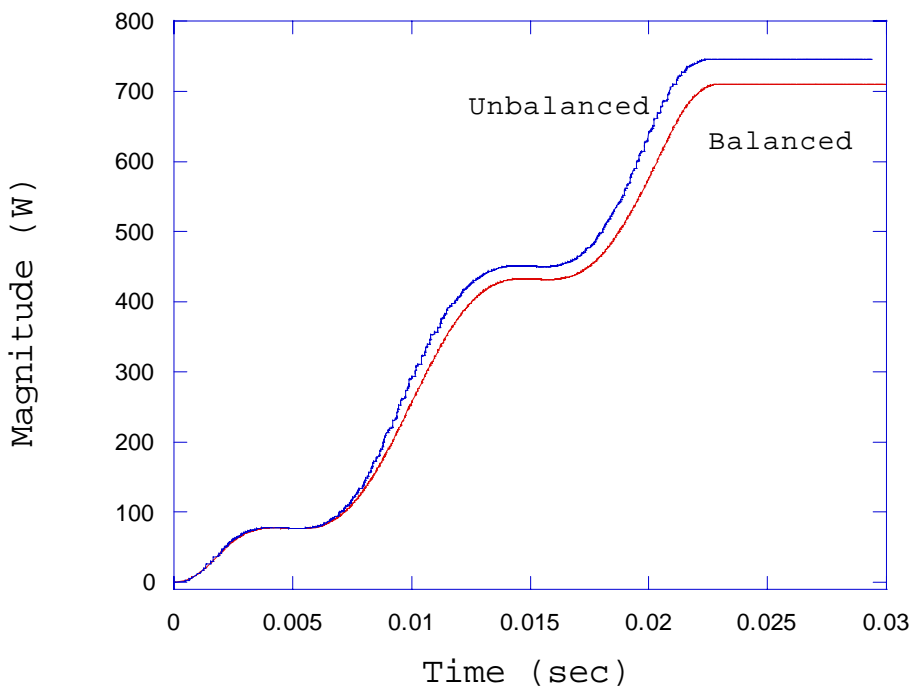

Fig. 5-45 The power of phase $\mathrm{C}$ delivered to voltage source for balanced and unbalanced voltage magnitude. 


\section{3-5 Adjusted Reference Currents to Deliver Nominal Power}

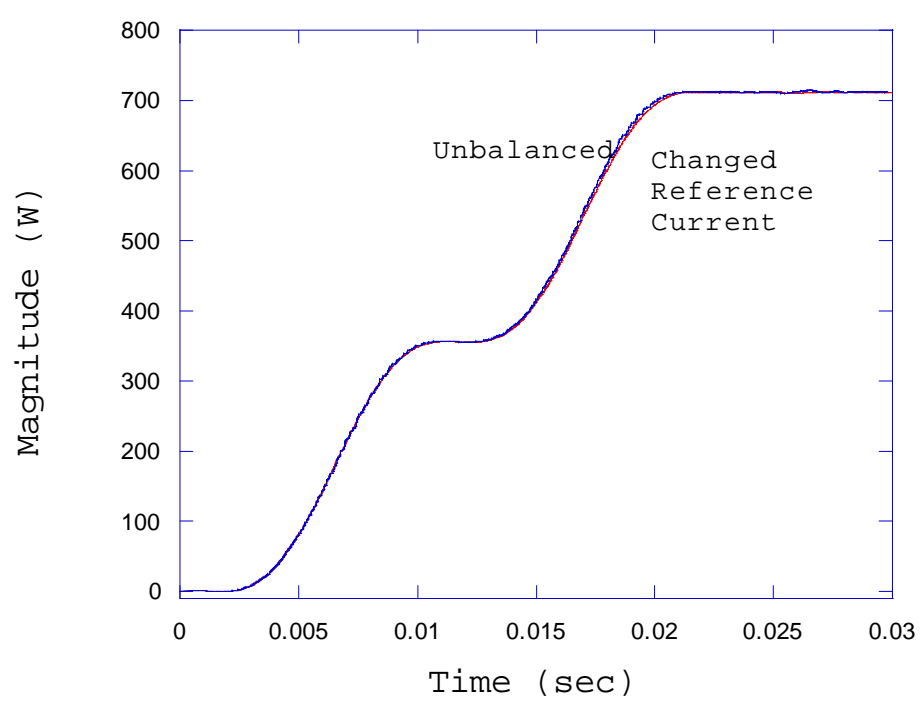

Fig. 5-46 The power of phase A delivered to voltage source for balanced and unbalanced voltage magnitude.

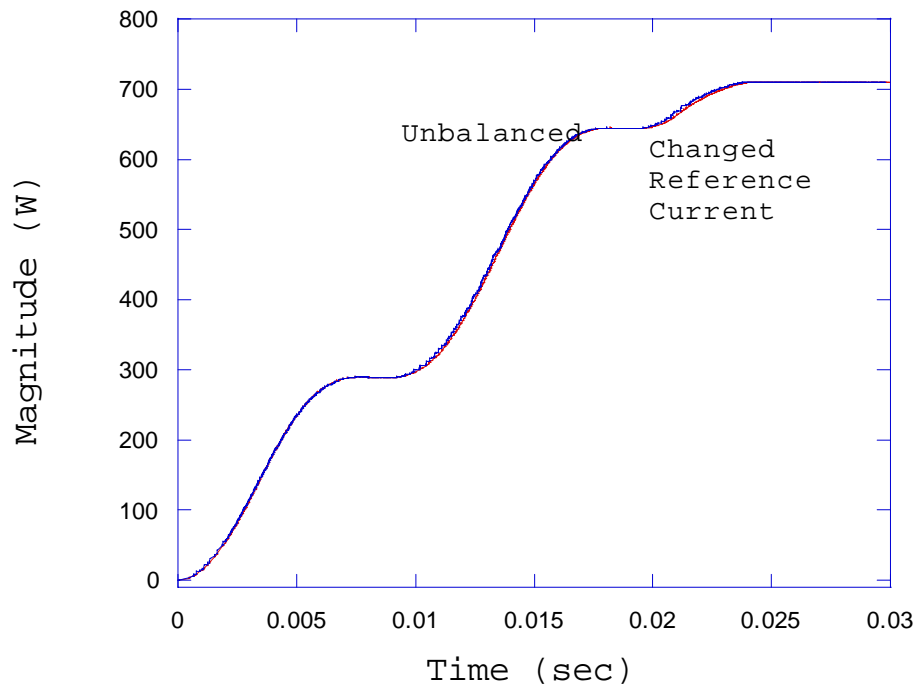

Fig. 5-47 The power of phase B delivered to voltage source for balanced and unbalanced voltage magnitude. 


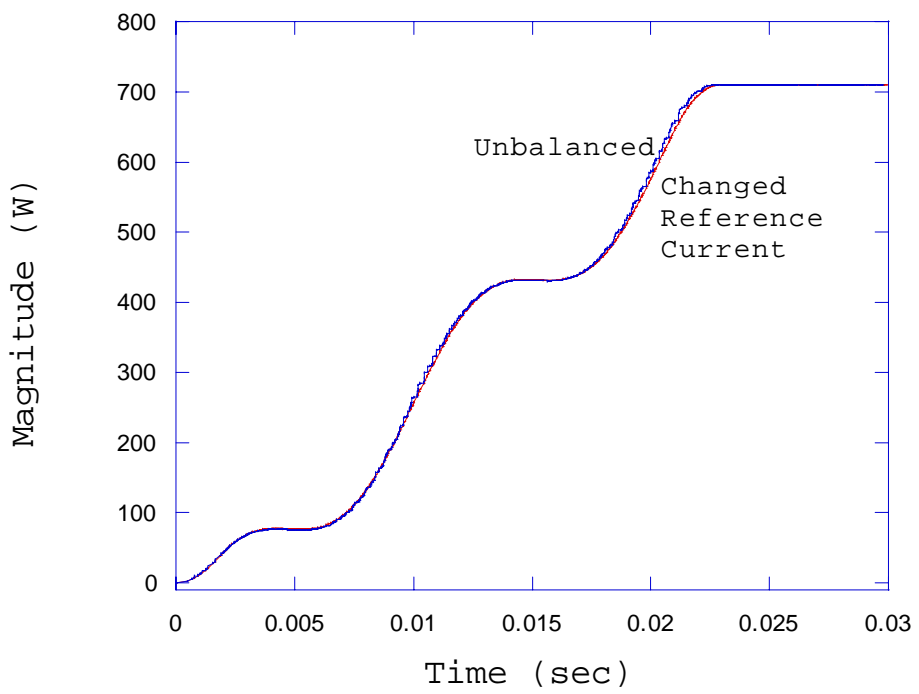

Fig. 5-48 The power of phase $\mathrm{C}$ delivered to voltage source for balanced and unbalanced voltage magnitude. 


\section{Chapter six}

\section{CONCLUSIONS}

\subsection{Dynamic Models}

A synchronous machine with an infinite bus system was simulated when mechanical power is supplied from small combustion turbines or diesel engines. The combustion turbine model included a speed governor, a temperature control, and a gas turbine dynamic, which were represented by the transfer functions and the time delays. The diesel engine model involved a speed governor and an actuator model, as well. These models didn't include the nonlinearity; however, the maximum and the minimum values have been included in the model because the power sources can't afford the extreme operation conditions.

The excitation system model was obtained from IEEE standards [11]. It included saturation effects, depending on the machine voltages and the regulator voltages. The maximum output is $6.0(\mathrm{pu})$ and the minimum value is $0(\mathrm{pu})$.

The synchronous machine model consisted of the detailed differential equations, but did not include the saturation effects. For all the models, particularly the steady state,

normal operating conditions were considered. All of the parameters for the models such as, a combustion turbine, a diesel engine, an excitation system, and a synchronous machine model were in per unit systems.

For the inverter model, the ideal diode models and the ideal switch models are used to represent the on-off states. The currents measured from the system are compared with the reference currents. The system consists of the resistance, the inductance, and the voltage sources to represent the three-phase AC machine. To avoid an algebraic loop, transfer functions with a small time constant $\left(10^{-6}\right)$ were placed between the inverter and the control systems. 


\subsection{Simulation Results}

The mechanical power, the speed of the synchronous machine, the voltage of the exciter, and the currents and voltages of the synchronous machine are presented for the synchronous machine simulation. When a $\pm 1 \%$ speed disturbance was applied to the speed reference of the diesel engine connected with the synchronous machine, the output power of diesel engine increased at the steady state value. The voltage of the exciter was not much changed in magnitude and had the large variation in the oscillation period. In the case of the combustion turbine, the output power increased or decreased about $33 \%$ and the voltage of the exciter changed when the disturbances were applied. In the $\pm 10 \%$ of the exciter reference disturbances, the powers and speeds of all cases remained almost constant. The voltages from the exciter and the synchronous machine, however, followed the reference voltages.

With a combustion turbine or a diesel engine, the speed of synchronous machine reached steady state no matter what the disturbances were applied. The magnitude of the exciter also reached steady state with some oscillations after applied disturbances. The voltage magnitude of exciter, however, is greater than that of exciter without disturbance. On the other hand, the exciter still generated the steady state values that are greater or less depending on the disturbances.

In an inverter simulation, the powers delivered to the voltage sources were examined. Each phase reached a steady state (constant value) calculated by $S=V I^{*}$. The powers with adjusted reference currents were the same as those measured from the balanced voltage magnitude. The simulations were performed with several leading and lagging current cases. In all of the cases the powers delivered to the voltage sources can be adjusted with current references. In this simulation, the powers can be delivered under normal conditions even though there are some unbalanced voltage magnitudes.

In the fault simulations with bulk and small generators, the power, speed and the magnitude of exciter were examined. For the diesel engine model, the speed was constant, and the power delivered increased to $0.8(\mathrm{pu})$ after the fault to meet the load demand. On the other hand, the exciter voltage became larger than that of normal 
condition. In the combustion turbine simulation, the exciter voltage also became larger and the power delivered increased to $0.8(\mathrm{pu})$. The magnitude of speed, however, became reduced about $5 \%$. From these simulations it is concluded that the distributed generation can supply emergency power or standby power with good power quality.

\subsection{Potential of the Distributed Generation}

Chemical and wood product industries use steam and electrical power. The cost of power interruption is very high for chemical industry. Wood industry has an onsite fuel in the form of wood waste. Distributed generation has potential application for wood and chemical industries for combined heat and power applications in West Virginia.

\subsection{Future Work}

In this research, the combustion turbine and diesel engine models were only considered. Since the other models such as a fuel cell, a micro-turbine, and a solar cell can be used in the distributed generation, these models must be considered to study power quality issues on the distributed generation. Once the models are obtained, these models can be used to other applications such as three-phase faults, voltages, and currents. There are several kinds of distribution feeders in the power distribution system. Another area of research will be modeling of distributed feeders with unbalanced load and distributed generation. 
REFERENCE

[1] Judith Cardell and Richard Tabors. Operation and Control in a Competitive Market:

Distributed Generation in a Restructured Industry, The Energy Journal.

[2] OMS fact sheet, Emission Control Potential for heavy-duty Diesel Engines June 1996, http://earth1.epa.gov/OMSWWW/noxfact2.htm.

[3] P.C. Krause, Simulation of a Single Machine Infinite Bus System.

[4] S.D. Sudhoff, K.A. Corzine, H.J. Hegner and D.E. Delisle Transient and Dynamic Average-Value Modeling of Synchronous Machine Fed Load-Commutated

Converters IEEE Trans. on Energy Conversion, Vol.11, No.3, Sep. 1996.

[5] W.W. Hung, Dynamic simulation of gas-turbine generating unit, IEE ProceedingsC, Vol. 138, No.4, July 1991.

[6] Working Group on Prime Mover and Energy Supply Models for System Dynamic Performance Studies, Dynamic Models for Combined Cycle Plants in Power System Studies, IEEE Trans. on Power Systems, Vol. 9, No. 3, August 1994.

[7] F.P. de Mello Boiler Models for System Dynamic Performance Studies, IEEE Trans. on Power Systems, Vol. 6, No. 1, Feb 1991.

[8] L. N. Hannett, George Jee, and B. Fardanesh, A Governor/Turbine Model for a Twin-Shaft Combustion Turbine, IEEE Trans. on Power Systems, Vol. 10, No. 1, Feb 1995.

[9] L. N. Hannett and Afzal Khan, Combustion Turbine Dynamic Model Validation from Tests, IEEE Trans. on Power Systems, Vol. 8, No. 1, Feb 1993. 
[10] W. I. Rowen, Simplified Mathematical Representations of heavy-duty Gas Turbines, Trans. of ASME, Vol. 105, October 1983.

[11] IEEE Power Engineering Society, IEEE Recommended Practice for Excitation System Models for Power System Stability Studies, IEEE Std 421.5-1992.

[12] Vladimir Gurau, Sadik Kakac, and Hongtan Liu, Mathematical Model for Proton Exchange Membrane Fuel Cells, AES-Vol. 38, Proceedings of the ASME Advanced Energy Systems Division ASME 1998.

[13] P. M. Anderson and M. Mirheydar, Analysis of a Diesel Engine Driven Generating Unit and The Possibility for Voltage Flicker, IEEE Trans. on Energy Conversion, Vol. 10, No. 1, March 1995.

[14] K. E. Yeager and J. R. Willis, Modeling of Emergency Diesel Generators in an 800 Megawatt Nuclear Power Plant, IEEE Trans. on Energy Conversion, Vol. 8, No. 3 , September 1993.

[15] A. G. Stefanopoulou and I. Kolmanovsky, Control of Variable Geometry Turbocharged Diesel Engines for Reduced Emissions, Proceedings of the American Control Conference Philadelphia, Pennsylvania, Jun 1998.

[16] S. Roy, O. P. Malik and G. S. Hope, An Adaptive Control Scheme for Speed Control of Diesel Driven Power Plants, IEEE Trans. on Energy Conversion, Vol. 6, No. 4, December 1991.

[17] V. F. Filreker and R. K. Shaltens, Wind Turbine Generator Interaction with Diesel Generators on an Isolated Power System, IEEE Trans. on Power Apparatus and Systems, Vol. PAS-103, No. 5, May 1984. 
[18] J. Perahia and C. V. Nayar, Model and Simulation of a Stand Alone Power System Comprising a Diesel Engine Driven Synchronous Generator and a Power Conditioner, Int. J. Elect. Enging. Educ. Vol. 35, pp. 245-270, Manchester U. P., 1998. Printed in Great Britain.

[19] Omar S. Mazzoni, Transient Performance Evaluation of Nuclear Generating Station Standby Diesel Generators, IEEE Systems Research International, Great Falls, VA.

[20] Yahay H. Zweiri, James F. Whidborne and Lakmal D. Senevirtne, A Mathematical Transient Model for the Dynamics of a Single-Cylinder Diesel Engine, Department of Mechanical Engineering, King's College London, UK.

[21] IEEE Committee Report, Dynamic Models Steam and Hydro Turbines in Power System Studies.

[22] D. G. Ramey and John W. Skooglund, Detailed Hydro-governor Representation for System Stability Studies, Trans. on Power Apparatus and Systems, Vol. PAS-80, No. 1, January 1970.

[23] Working Group on Prime Mover and Energy Supply Models for System Dynamic Performance Studies, Dynamic Models for Fossil Fueled Steam units in Power system Studies, IEEE Trans. on Power Systems, Vol. 6, No. 2, May 1991.

[24] E. Fuchs, Electromechanical Systems, University of Colorado at Boulder, Lecture notes for ECEN 3170.

[25] M. H. Rashid, Power Electronics Circuits, Devices, and Applications, Printice Hall, Inc. 1988. 
[26] P. C. Krause, Oleg Wasynczuk, and S. D. Sudhoff, Analysis of Electric Machinery, IEEE Press 1994 Editorial Board.

[27] Andrei Vladimirescu, The Spice Book, John Wiley \& Sons, Inc. 1994.

[28] MATLAB POWER SYSTEM BLOCKSET user's guide, The Mathworks Inc., 1997.

[29] MATLAB SIMULINK user's guide, The Mathworks Inc., 1997.

[30] The Design Center user's guide, MicroSim Corporation, 1993.

[31] The role of Distributed Generation in Competitive Energy Markets, Distributed Generation Forum, March 1999. Prepared by ONSITE SYCOM Energy Corporation (http://www.gri.org/pub/solutions/dg).

[32] Kemm Farney, and Ralph Russo, Electric Power Outlook: The Cost of New Capacity and the Price of Electric Power, PMA Online Magazine 07-1998.

[33] Charles D. Feinstein, Ren Orans, and Stephen W. Chapel, The Distributed Utility: A New Electric Utility Planning and Pricing Paradigm, Annu. Rev. Energy Environment. 1997 22:155-85.

[34] Small-scale Fuel Cell Commercialization Group, Inc. (http://www.oge.com/sfccg).

[35] PMA Online Magazine (www.retailenergy.com). 


\section{APPENDIX}

\section{A.1 Synchronous Machine Parameters}

$$
\begin{aligned}
& f=60 \mathrm{~Hz} \\
& \omega_{b}=2 \pi f \\
& R_{s}=0.005(p u) \\
& R_{k q 1}=R_{k q 2}=0.02(p u) \\
& R_{k d d}=0.02(p u) \\
& R_{f d}=0.0005(p u) \\
& X_{l s}=0.1(p u) \\
& X_{l k q 1}=X_{l k q 2}=0.1(p u) \\
& X_{l k d}=0.1(p u) \\
& X_{l f d}=0.1(p u) \\
& X_{m d}=1.0(p u) \\
& X_{m q}=0.8(p u) \\
& R_{e}=0.02(p u) \quad X_{e}=0.2(p u)
\end{aligned}
$$




\section{A.2The Diagram of a Synchronous Machine connected an Infinite Bus with Combustion or a Diesel Engine A Synchronous Machine Simulation Diagram}

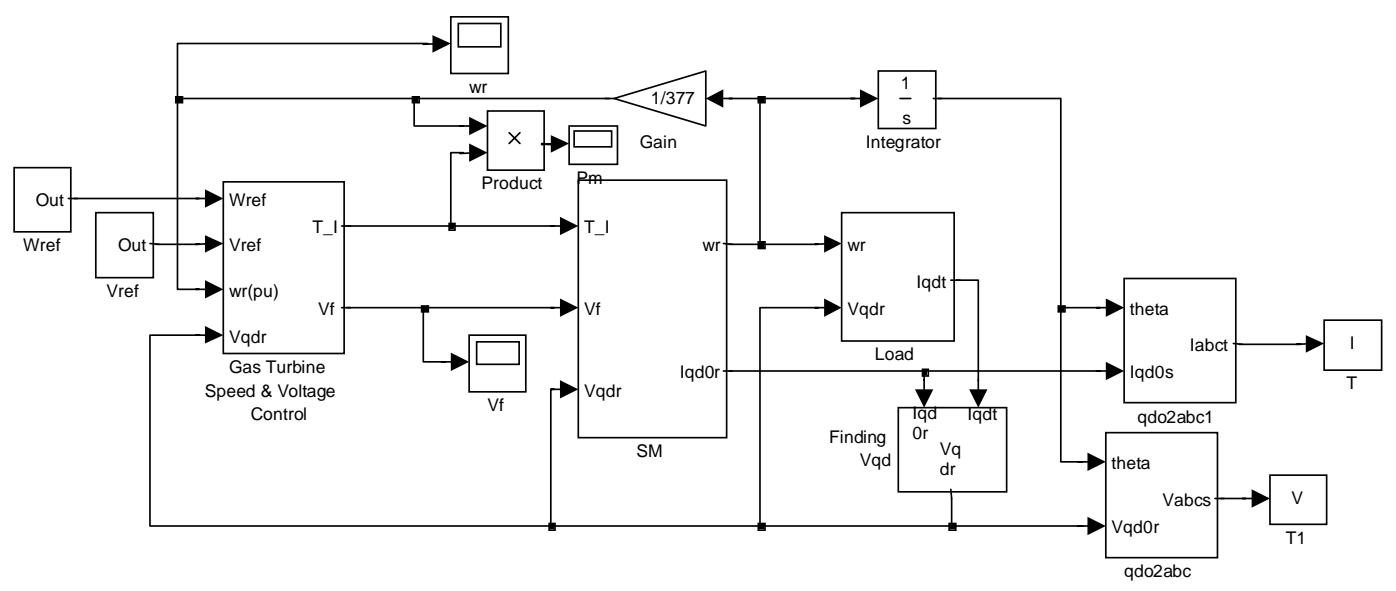

Fig. A-1 the overall diagram implemented by MATLAB SIMULINK.

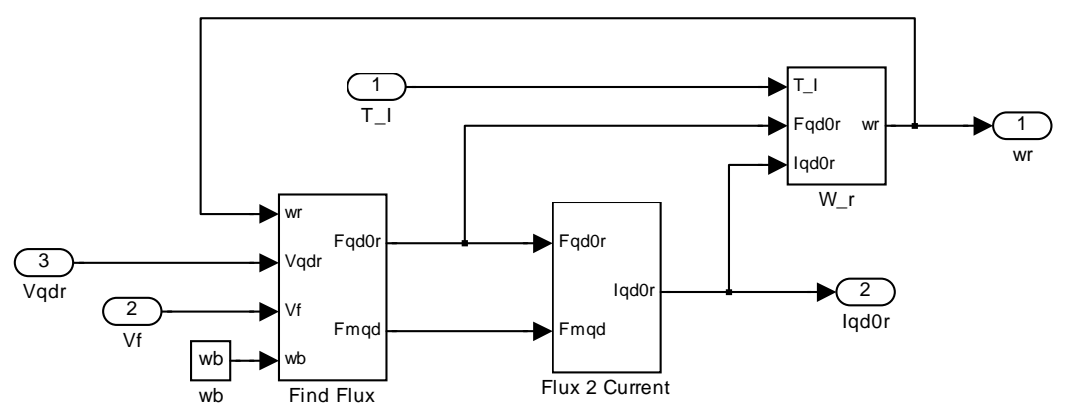

Fig. A-2 The block diagram inside a synchronous machine block. 


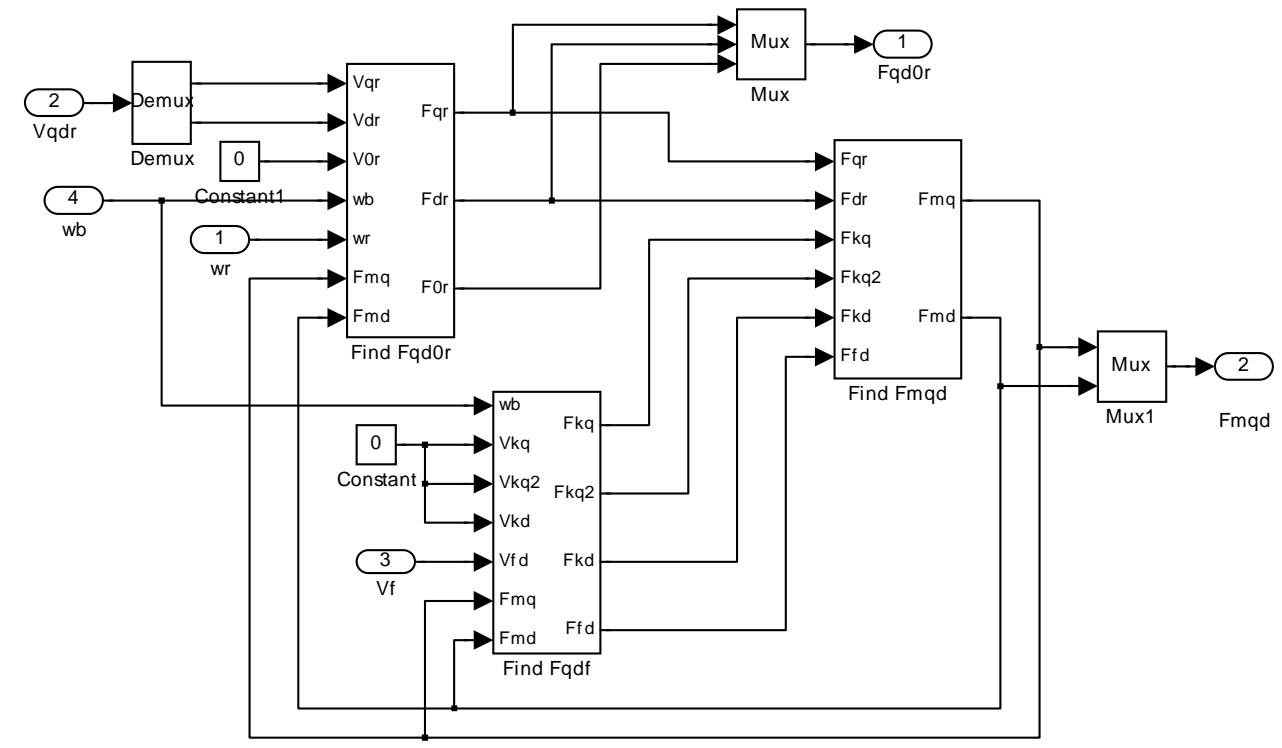

Fig. A-3 The block diagram "Find Flux" implemented by MATLAB SIMULINK.

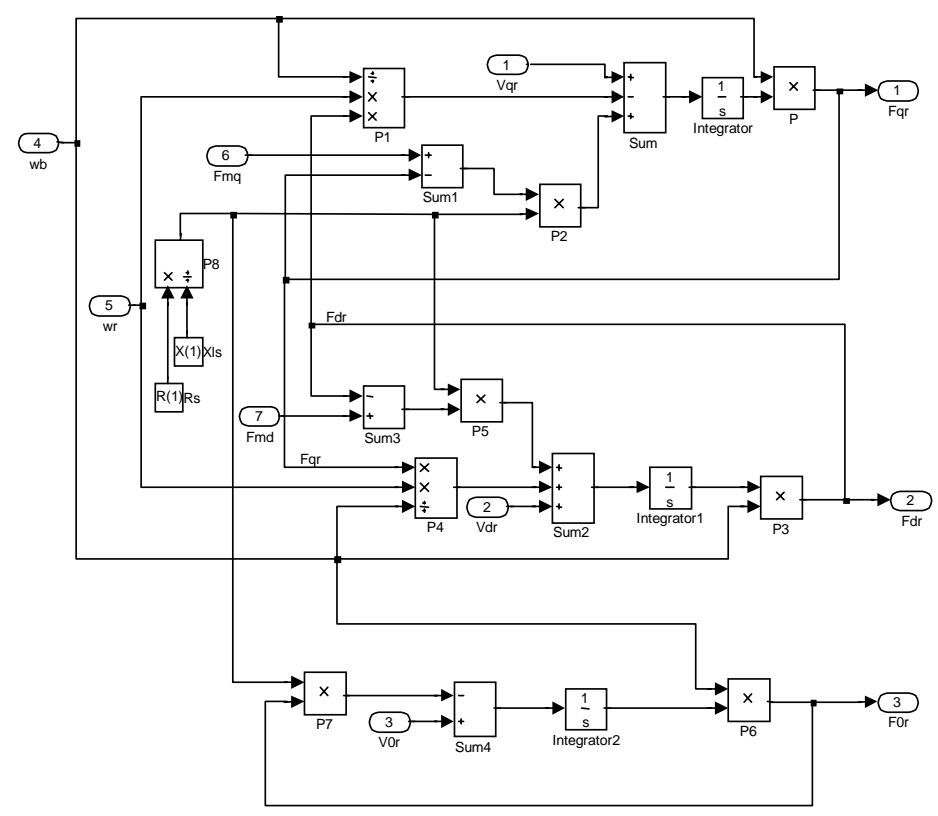

Fig. A-4 The block diagram "Find Fqd0r" implemented by MATLAB MIMULINK. 


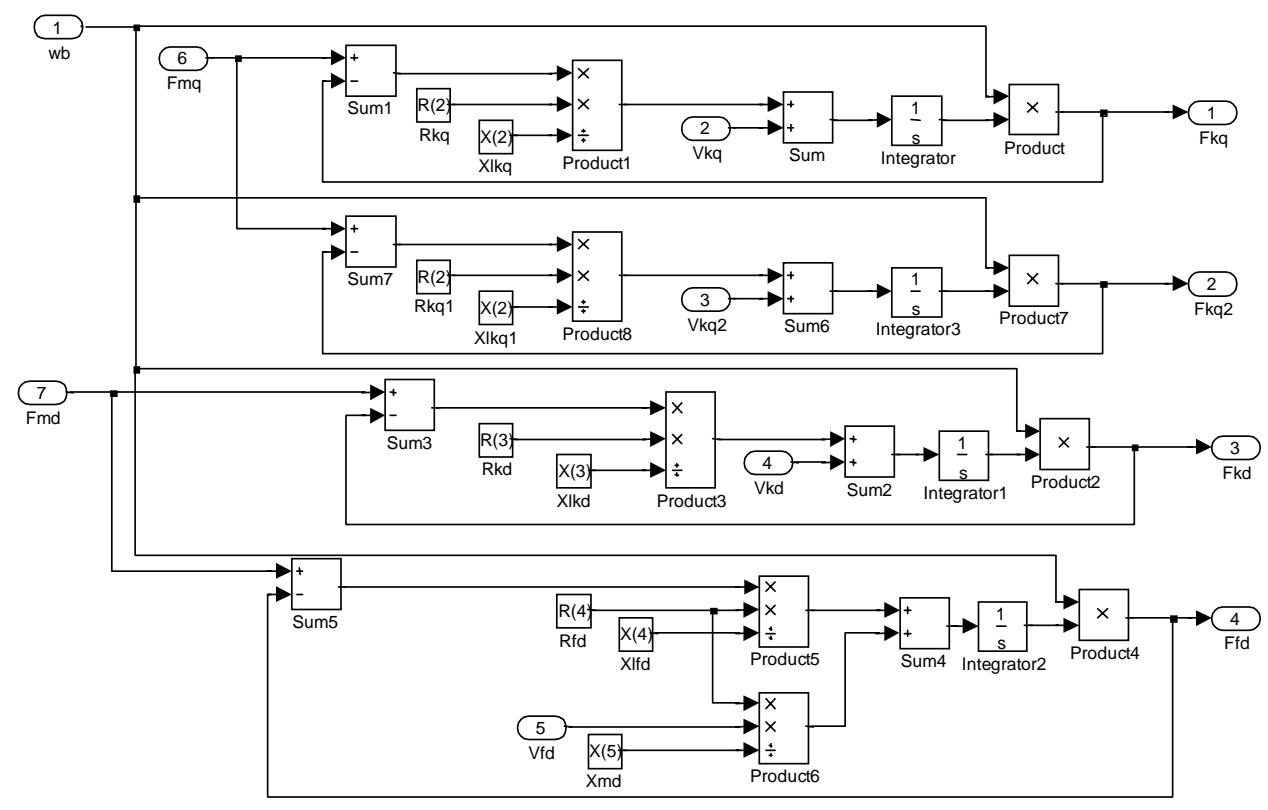

Fig. A-5 The block diagram "Find Fqdr" implemented by MATLAB SIMULINK.

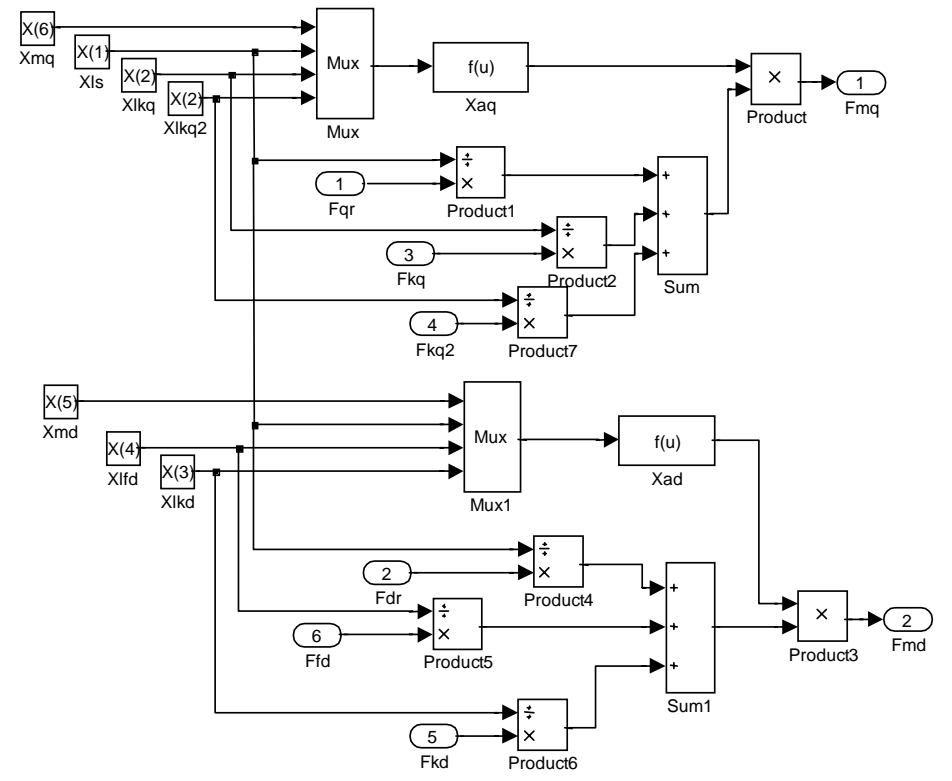

Fig. A-6 the block diagram "Find Fmqd" implemented by MATLAB SIMULINK. 


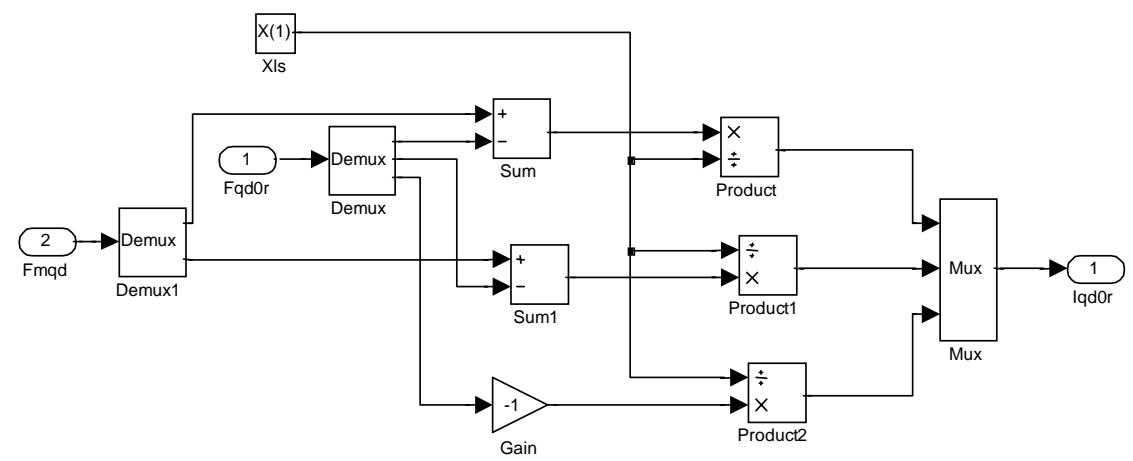

Fig. A-7 The block diagram "Find Current" implemented by MATLAB SIMULINK.

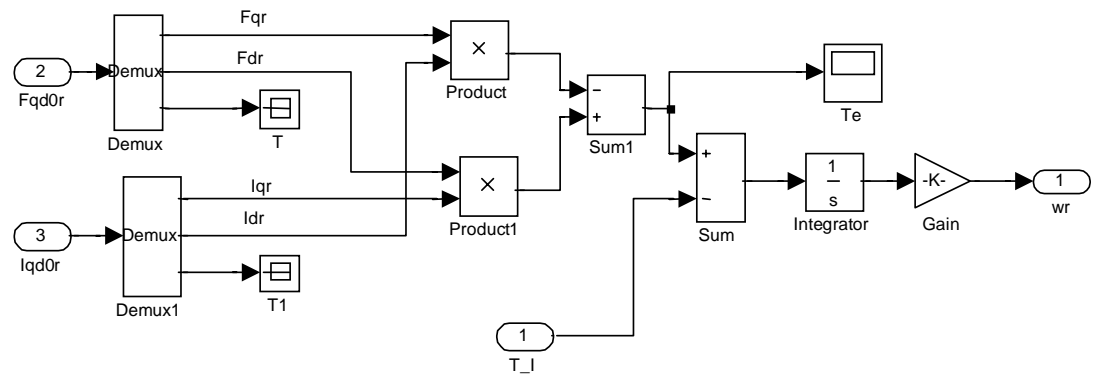

Fig. A-8 the block diagram "w_r” implemented by MATLAB SIMULINK.

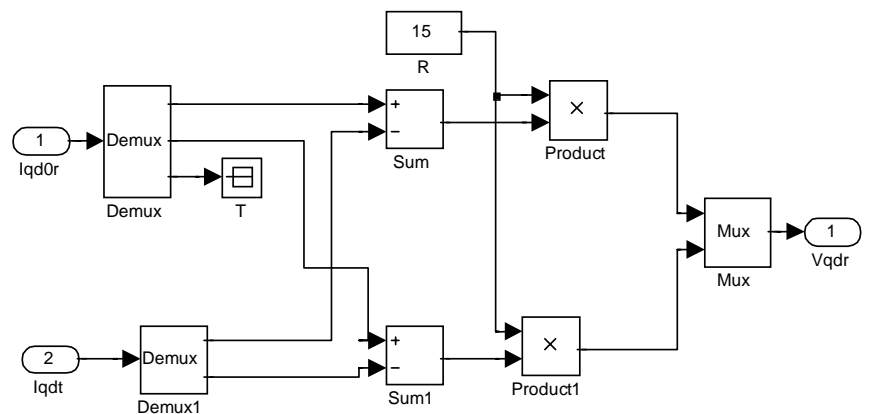

Fig. A-9 the block diagram "Finding Vqd" implemented by MATLAB SIMULINK. 


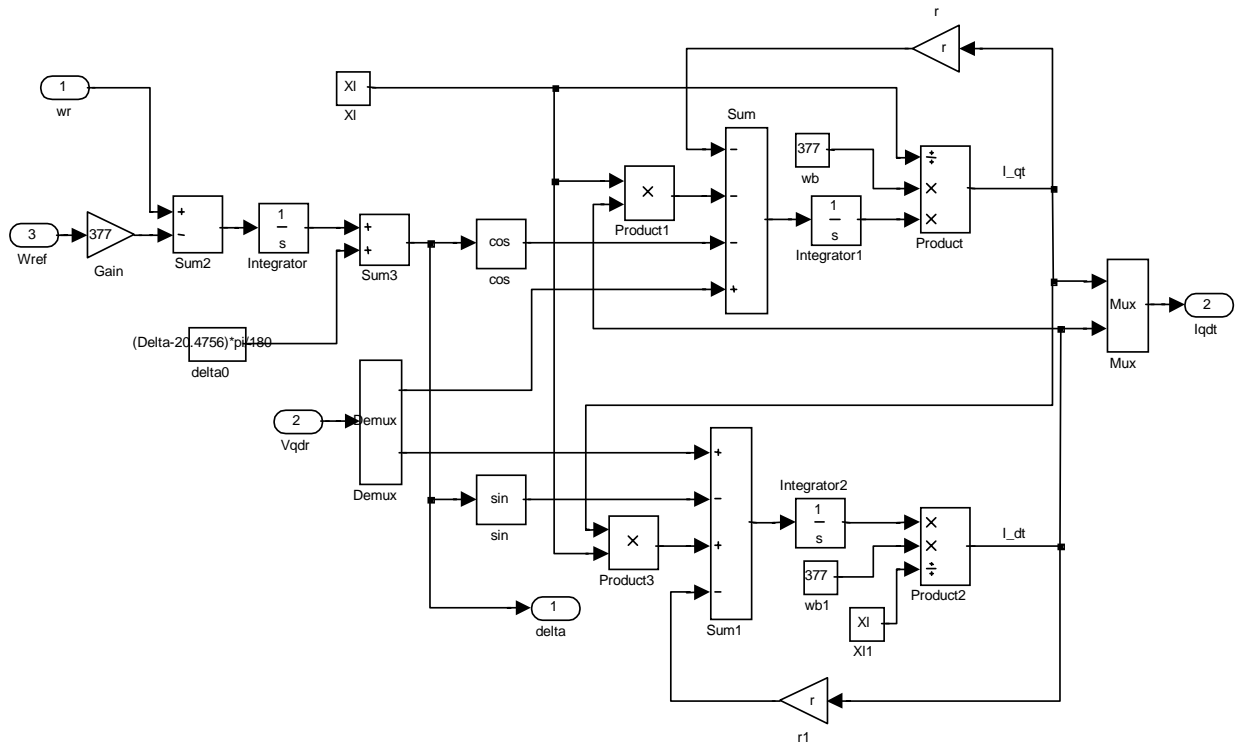

Fig. A-10 The block diagram "Load” implemented by MATLAB SIMULINK.

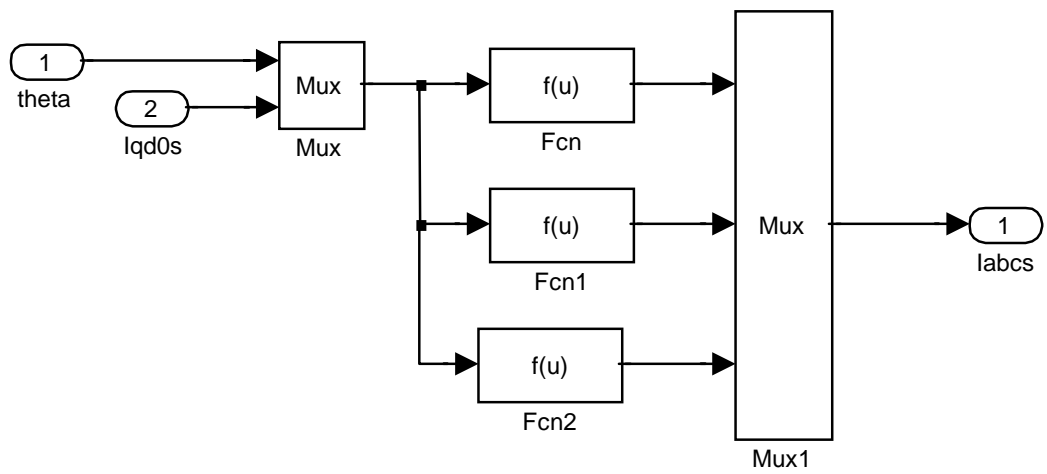

Fig. A-11 The block diagram "qd02abc" implemented by MATLAB SIMULINK. 


\section{A-3 An Three-Phase Inverter}

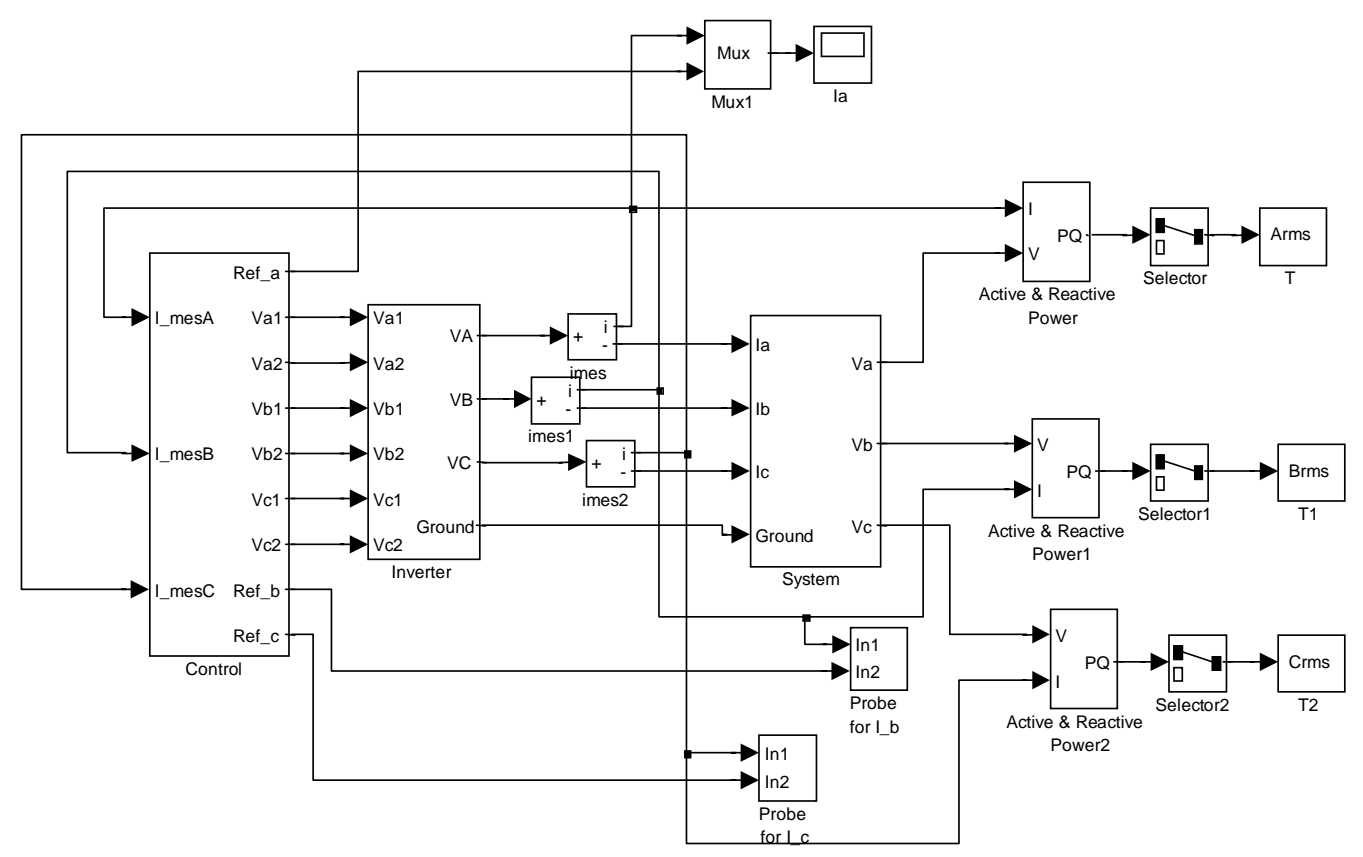

Fig. A-12 The block diagram of inverter.
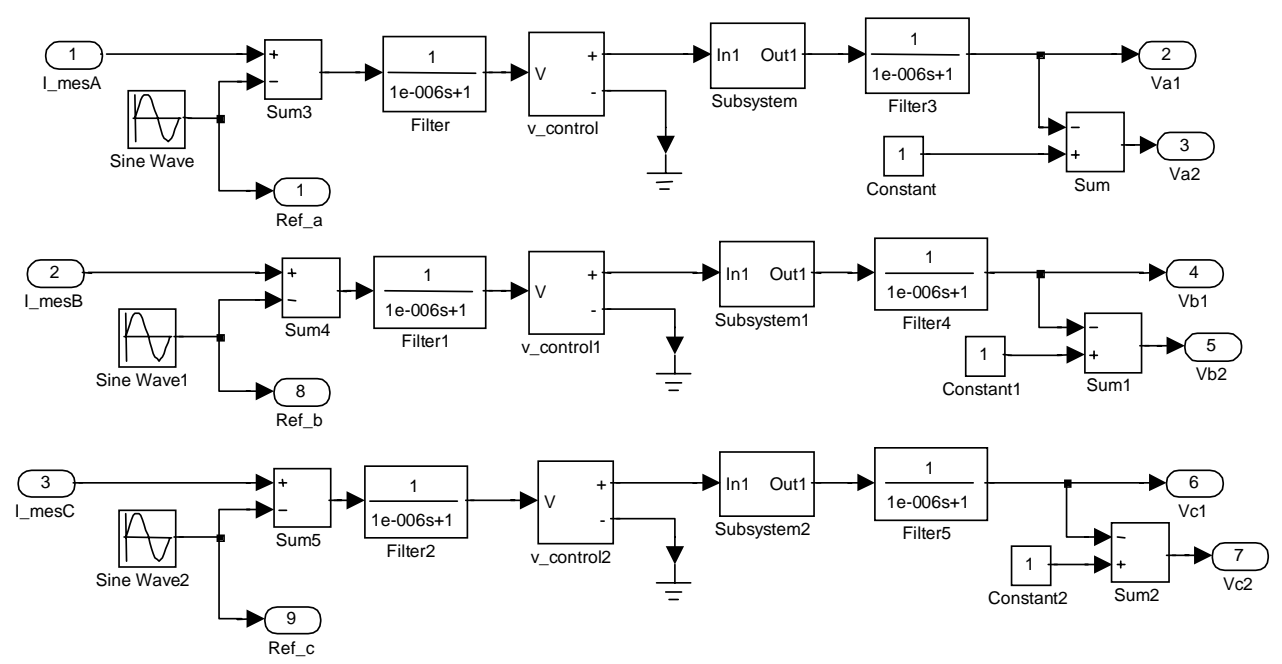

Fig. A-13 The block diagram "Control". 


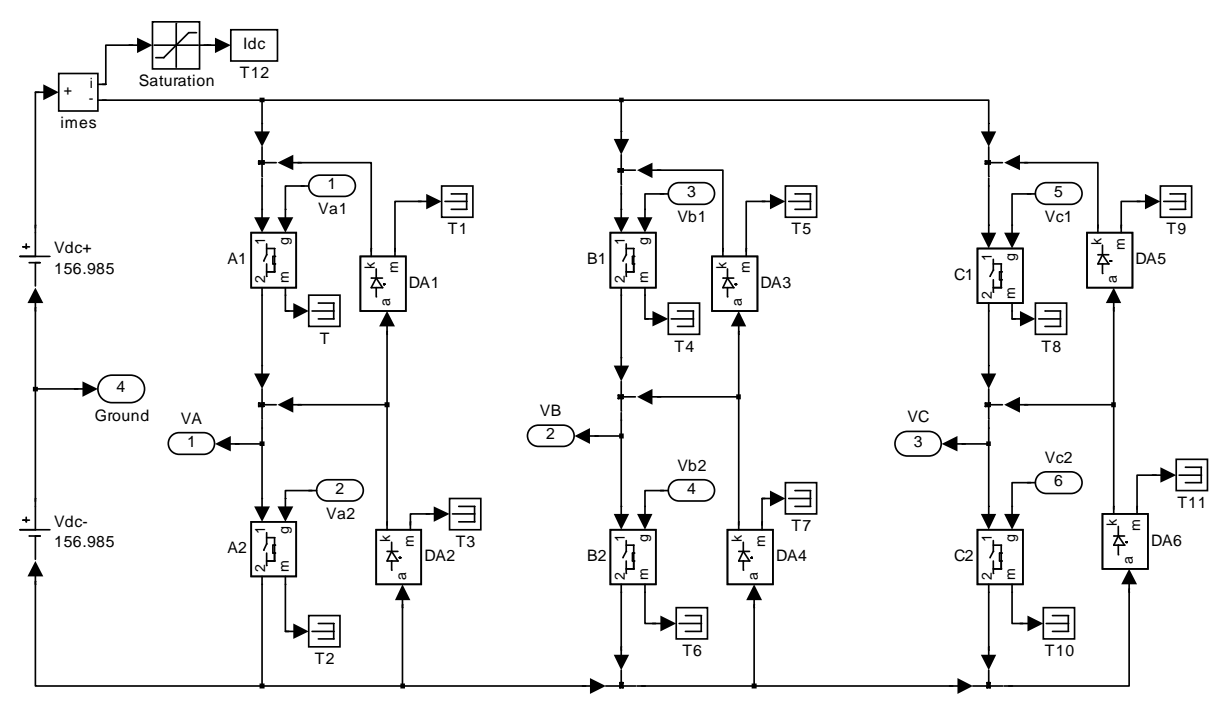

Fig. A-14 The block diagram "inverter".

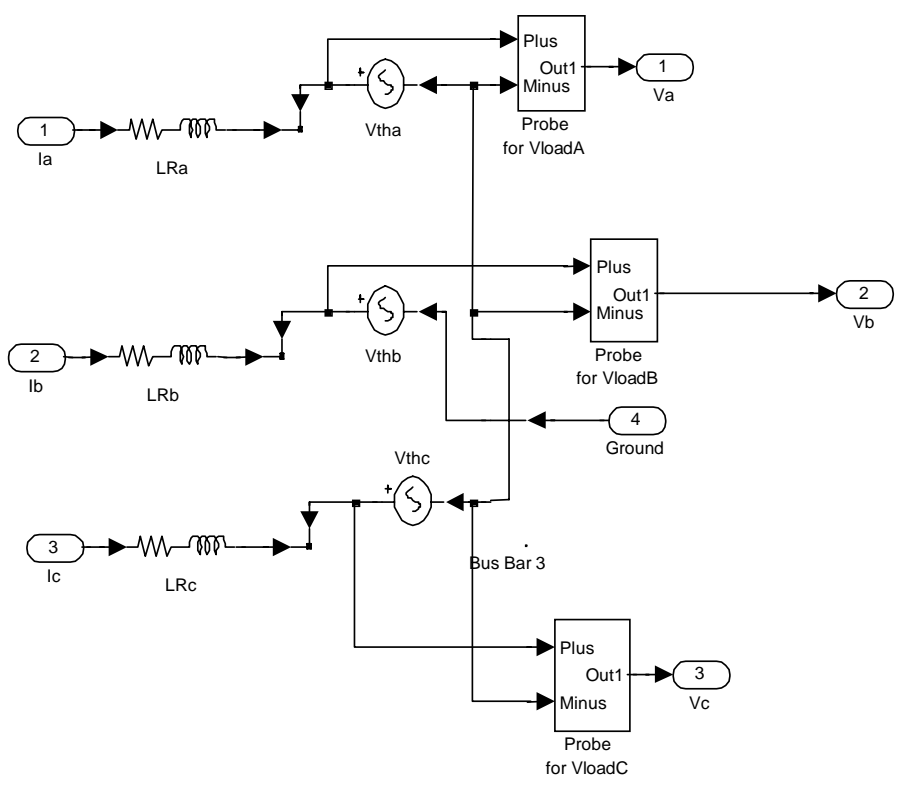

Fig. A-15 The block diagram "system".

Notes: In an inverter model, the MATLAB POWER SYSTEM BLOCKSET and SIMULINK are used to implement each of the block. 